\title{
Applications of density functional theory (DFT) to investigate the structural, spectroscopic and magnetic properties of lanthanide(III) complexes
}

\author{
Carlos Platas-Iglesias*, Adrián Roca-Sabio, Martín Regueiro-Figueroa, David Esteban-Gómez, \\ Andrés de Blas, Teresa Rodríguez-Blas
}

Departamento de Química Fundamental, Universidade da Coruña, Campus da Zapateira, Rúa da Fraga 10, 15008

A Coruña, Spain

The published manuscript is available at EurekaSelect via

http://www.eurekaselect.com/openurl/content.php?genre=article \&doi=10.2174/1877944111101010091.

Current Inorganic Chemistry, volume 1, issue 1, pages 91-116, 2011

Received 30 November 2010, revised 26 January 2011, accepted 27 January 2011

\section{How to cite:}

Carlos Platas-Iglesias, Adrian Roca-Sabio, Martin Regueiro-Figueroa, David Esteban-Gomez, Andres de Blas and Teresa Rodriguez-Blas, "Applications of Density Functional Theory (DFT) to Investigate the Structural, Spectroscopic and Magnetic Properties of Lanthanide(III) Complexes", Current Inorganic Chemistry (Discontinued) (2011) 1: 91. https://doi.org/10.2174/1877944111101010091.

\begin{abstract}
Density functional theory (DFT) has become a general tool to investigate the structure and properties of complicated inorganic molecules, such as lanthanide(III) coordination compounds, due to the high accuracy that can be achieved at relatively low computational cost. Herein, we present an overview of different successful applications of DFT to investigate the structure, dynamics, vibrational spectra, NMR chemical shifts, hyperfine interactions, excited states, and magnetic properties of lanthanide(III) complexes. We devote particular attention to our own work on the conformational analysis of LnIII-polyaminocarboxylate complexes. Besides, a short discussion on the different approaches used to investigate lanthanide(III) complexes, i. e. all-electron relativistic calculations and the use of relativistic effective core potentials (RECPs), is also presented. The issue of whether the $4 \mathrm{f}$ electrons of the lanthanides are involved in chemical bonding or not is also shortly discussed.
\end{abstract}

Keywords: density functional theory; computational chemistry; lanthanide complexes; ab initio calculations; relativistic effects; rare-earths; RECPs; magnetic anisotropy; Sparkle/PM3 models; Hohenberg-Kohn theorem

\section{Introduction and scope}

The lanthanides constitute a unique series of elements that occupy the first period of the f-block from lanthanum $(Z=57)$ to lutetium $(Z=71)$. They are characterized by the common + III oxidation state with electronic $[\mathrm{Xe}] 4 \mathrm{f}^{\mathrm{n}}$ configurations $(\mathrm{n}=1-14)$ that confer to their compounds fascinating electronic,

*carlos.platas.iglesias@udc.es 
spectroscopic and magnetic properties. The successful biomedical application of lanthanide chelates both in diagnostics [1-5] and therapy [6-9] has promoted a fast development of lanthanide coordination chemistry during the last two decades [10]. Indeed, $\mathrm{Gd}^{\mathrm{III}}$ complexes are currently used in vivo as magnetic resonance imaging (MRI) contrast agents, which enhance the image contrast by preferentially influencing the relaxation efficiency of the water proton nuclei in the target tissue. Furthermore, luminescent lanthanide complexes offer exceptional photophysical properties that find applications in different fields such as biomedical analyses and imaging [11], while many research groups working in the field of molecular magnetism have investigated $\mathrm{Ln}^{\mathrm{III}}$ complexes due to their large magnetic moment and magnetic anisotropy [12-14]. An understanding of the coordination chemistry of lanthanides is also important in nuclear fuel reprocessing, where the separation of nuclear wastes containing both trivalent lanthanides and trivalent minor actinides is complicated by the similar chemical properties of these species $[15,16]$.

The description of the electronic structure of $\mathrm{Ln}^{\mathrm{III}}$ complexes is essential to an understanding of their chemical and physical properties, and therefore to aid developing applications in many technological fields. The experimental work performed in $\mathrm{Ln}^{\mathrm{III}}$ coordination compounds provides a plethora of information about the solid-state and solution structure of the complexes, as well as on their physicochemical properties. However, theoretical investigations performed on this kind of systems are very much behind the experimental knowledge, which can be partially adscribed to the difficulties that are faced in the quantum chemical treatment of $\mathrm{Ln}^{\mathrm{III}}$ complexes. Among these difficulties are: i) The presence of open shell $4 \mathrm{f}$ electrons; ii) the treatment of relativistic effects, and iii) the preference of $\mathrm{Ln}^{\mathrm{III}}$ ions for high coordination numbers (typically 8-9) [17], which may lead to structural artefacts if the ligands are oversimplified [18]. The difficulties associated to the treatment of the open shell $4 \mathrm{f}$ electrons have been ocassionally overtaken either by using yttrium as a model for lanthanides [19-21], or by limiting the calculations to the closed-shell members of the series $\mathrm{La}^{\mathrm{III}}$ or $\mathrm{Lu}^{\mathrm{III}}[22,23]$. In spite of these problems, in the last decade much progress has been made on the computational treatment of lanthanide compounds, and many succesful computational studies have been published.

Due to the difficulties in modeling lanthanide complexes some authors have turned their attention to molecular mechanics (MM) methods, which were used succesfully to predict the structures of certain lanthanide complexes [24-26]. However, the use of MM methods to investigate lanthanide complexes is often problematic due to the lack of parametrization of lanthanide high-coordination compounds in commonly available force-fields. Alternatively, semiempirical calculations based on the Sparkle/AM1 or Sparkle/PM3 models were shown to provide molecular structures of lanthanide(III) complexes comparable to those obtained with more sophisticated ab initio methods but with a much smaller expense of computational power [27-32]. These models were subsequently succesfully applied for the prediction of different spectroscopic properties such as absorption spectra and the position of the ligand-centred singlet and triplet state positions [33]. However, these semiempirical approaches have been tested so far in a limited number of systems, and therefore require very careful evaluation and testing by comparison with high level calculations.

Density functional theory (DFT) has become a general tool to investigate the properties of complicated inorganic molecules due to the high accuracy that can be achieved at relatively low computational cost [34]. DFT methods are based on the Hohenberg-Kohn theorem, which states that all molecular electronic properties can be calculated if the electron density of the system is known. Although the exact form of all the components of the functional (a function of a function) that gives the energy from the electron density is not known, the currently available functionals provide in most cases a very accurate description of many chemical properties. Most current density functionals have been developed by adjusting only a few parameters to reference sets of molecules, but it turned out that these functionals also work quite well for metal-containing compounds that are hardly tractable by sophisticated ab initio methods. Thus, the DFT approach has revealed to be a powerful alternative for investigating metal complexes to the classical Hartree- 
Fock (HF) or post-HF methods. Although high-level correlated wavefunction based ab initio computational methods have been occasionally applied to investigate small lanthanide complexes $[35,36]$, the scaling behavior of these methods with system size prevent their application to larger systems with the currently available computational resources. DFT calculations provide two major advantages in the context of metalcontaining systems: i) they scale relatively well with the size of the system to be investigated, so that relatively large complexes can be calculated, and ii) the computed orbitals are suitable for molecular orbital analysis and interpretation of the bonding and properties of the system. However, it must be also pointed out that DFT calculations show some serious limitations for the treatment of some particular systems [37]. For instance, hydrogen bonding and proton transfer reactions are often not treated properly by DFT methods [38], while DFT calculations on metal complexes are also known to favor low coordination numbers [39].

The present article is intended to provide an overview of different successful applications of DFT calculations to investigate the structure and properties of different lanthanide(III) coordination compounds. The theoretical background of DFT has been reviewed recently [34, 40], and will not be covered in this review, which is focused on more practical aspects that may be interesting for experimentalists that wish to employ DFT in parallel to their experimental work, rather than to hard-core theoretical chemists. This paper is organized as follows: In the first part we present a quick overview of the different methods available for the treatment of lanthanide compounds within the DFT framework [41], followed by a short discussion on the nature of chemical bonding in $\mathrm{Ln}^{\mathrm{III}}$ complexes and whether the $4 \mathrm{f}$ electrons play an important role in bonding or not. These sections are intended to facilitate the reading of the remaining part of the article to those who are not specialists in the field, and again the reader will be referred to appropriate references for more detailed descriptions. In the second part of the article we cover the use of DFT calculations to investigate the structure and dynamics, conformational energies, spectroscopic, photophysical and magnetic properties of lanthanide(III) coordination compounds.

\section{An overview of the computational methods for treatment of $\mathrm{Ln}^{\mathrm{III}}$ complexes with DFT calculations}

An important issue in the computational treatment of $\mathrm{Ln}^{\mathrm{III}}$ complexes and other systems containing heavy elements is the adequate treatment of relativistic effects [42]. Indeed, high nuclear charges have a strong influence on the shape and energy of the valence orbitals in heavy element systems. The following qualitative explanation is often given to introduce the reader to the effects of relativity in heavy elements [43]: The ground state energy of a 1 s electron bound to a nucleus of charge $+Z$ amounts to $-Z 2 / 2$ atomic units. Thus, the kinetic energy is calculated to be $+Z 2 / 2=1 / 2 m v 2$, where $m$ is the electron mass and $v$ the speed of the electron. Since the electron mass equals one atomic unit, at the nonrelativistic limit the average electron velocity would be $v=Z$ atomic units. In these units the speed of light has a rather small numerical value $(c=137.036)$, and therefore for heavy nuclei the electron velocities may approach a substantial fraction of the speed of light. The main effects of relativity on the atomic orbitals of heavy elements are the radial contraction and energetic stabilization of the $\mathrm{s}$ and $\mathrm{p}$ shells, the spin-orbit splitting, and the radial expansion and energetic destabilization of the outer $\mathrm{d}$ and $\mathrm{f}$ shells.

In general, there are two different approaches to handle relativistic effects in systems containing heavy elements: i) The use of all-electron relativistic approaches; ii) The use of relativistic effective core potentials (RECP), which may be either pure scalar or include spin-orbital effects. The most widely used approximation to deal with the problems of quantum chemical treatment of lanthanides is the RECP approach, in which only the chemically relevant valence electrons are treated explicitly and relativistic effects are only implicitly accounted for by a proper adjustment of free parameters in the valence model Hamiltonian [44]. The RECP approach also serves to decrease the computational requirements, so that calculations on relatively large lanthanide(III) complexes become feasible. There are mainly three classes of RECPs and associated basis sets available for computational treatment of lanthanides: i) The averaged 
relativistic RECPs with a [Xe] core and spin-orbit operators of Ross et al. [45]; ii) the shape-consistent RECPs of Stevens et al. [46], and iii) the energy-consistent quasirelativistic RECPs and associated basis sets of Dolg and co. [47-51]. Two different core definitions have been developed for the latter RECPs: "largecore", in which the $4 \mathrm{f}$ electrons are included in the core, and "small-core", which treats the four, five and six shell electrons explicitly. The use of large core RECPs has been justified by the fact that $4 \mathrm{f}$ orbitals do not significantly contribute to bonding due to their limited radial extension as compared to the $5 \mathrm{~d}$ and $6 \mathrm{~s}$ shells. Two different basis sets were derived for relativistic energy-consistent small-core lanthanide pseudopotentials: a Gaussian $(14 \mathrm{~s} 13 \mathrm{p} 10 \mathrm{~d} 8 \mathrm{f} 6 \mathrm{~g}) /[10 \mathrm{~s} 8 \mathrm{p} 5 \mathrm{~d} 4 \mathrm{f} 3 \mathrm{~g}]$ valence basis set using a segmented contraction scheme [52] and a $(14 \mathrm{~s} 13 \mathrm{p} 10 \mathrm{~d} 8 \mathrm{f} 6 \mathrm{~g}) /[6 \mathrm{~s} 6 \mathrm{p} 5 \mathrm{~d} 4 \mathrm{f} 3 \mathrm{~g}]$ atomic natural orbital (ANO) Gaussian valence basis set [53]. Diffuse functions for the latter basis set have been suggested for a better description of the polarization properties of lanthanide atoms [54].

The importance of relativistic effects in lanthanide complexes was examined by comparing the Ln-N bond distances in $[\operatorname{Ln}(\text { tpy })]^{3+}$ complexes calculated at the HF level with the large-core nonrelativistic [55] and quasirelativistic [47] pseudopotentials of Dolg et al. The use of quasirelativistic pseudopotentials induced an increasing bond length contraction from $\mathrm{La}$ to $\mathrm{Lu}$ along the lanthanide series, as Lu exhibits larger relativistic effects than La [56].

The use of large-core RECPs requires a separate potential for each oxidation state or $4 \mathrm{f}$ subconfiguration, and in practice eliminates most of the magnetic and electronic subtleties of the lanthanides, thereby precluding the modeling of $\mathrm{f}-\mathrm{f}$ centered processes and the treatment of spin-orbit coupling. However, this approach avoids many difficulties associated to the computational treatment of open-shell systems, and despite their approximate nature are an efficient computational tool that has proven to give good results in studies that focus on the structural features or the estimates of relative energies for $\mathrm{Ln}^{\mathrm{III}}$ complexes at both the HF and DFT level [57-67]. Several successful applications of the 4f-in-core method will be presented in the next sections.

In spite of their wide and successful use for many chemical problems, it has been also shown that the use of RECPs has some important limitations for the treatment of some specific situations, such as the calculation of hyperfine coupling constants [68]. Currently, the highest level of relativistic treatment in quantum chemistry is the four-component methods based on the Dirac equation [69], but reasonable accuracy may also be obtained by a number of more approximate methods. Among the all-electron relativistic approaches the family of Douglas-Kroll-Hess (DKH) transformation based methods [70-72] and zero order regular approximation (ZORA) [73-75] are the methods most widely tested and used. A detailed description of the theoretical background of relativistic DFT theory is beyond the scope of this paper, and the reader is referred to Refs. [76,77] for further details. Several investigations have shown that ZORA and DKH approaches provide often very similar results. For instance, a comparison of scalar-relativistic ZORA and DKH density functional schemes applied to monohydrides, monoxides and monofluorides of La and Lu shows that both schemes yield results for bond lengths, vibrational constants, binding energies and valence orbital energies of essentially the same quality [78]. Although computationally more expensive, these methods constitute an alternative to RECP approaches that can be successfully applied to relatively large lanthanide-containing systems when properties of the inner shells are investigated. A DFT investigation of lanthanide(III) complexes with tridentate ligands containing nitrogen donor atoms revealed that the small-core RECP and ZORA approaches provide very similar results, which was attributed to the ionicity of the metal-ligand interactions [79]. However, in some particular cases relativistic allelectron calculations provide much better results than RECP calculations, at it has been recently shown in the case of lanthanide mercaptobenzothiazolyl complexes, for which pseudopotential calculations led to a strong overestimation of the Ln-S bond lengths compared to all-electron relativistic calculations (up to $0.5 \AA$ ) [80].

Among the different basis sets available to be used with scalar relativistic Hamiltonians are the Slater type scalar relativistic all-electron basis sets for ZORA calculations of the Amsterdam density functional code 
[81], the atomic natural orbital (ANO-RCC) basis set of Roos et al. [82] for use with the DKH2 Hamiltonian, the DKH3 basis set of Hirao [83,84], and the segmented contracted correlating basis set of Koga and coworkers [85]. These basis sets provide high quality results for small systems, but they are hardly applicable to larger lanthanide complexes. Recently, Neese and Pantazis reported segmented all-electron relativistically contracted basis sets for the lanthanides, which are intended for use in combination with the DKH2 or ZORA approaches for day-to-day DFT calculations [86].

Several research groups have investigated the accuracy of different DFT methods for metal complexes. However, most of these studies have been focused on transition-metal complexes [87,88], while the investigation of the performance of different DFT functionals for lanthanide complexes has been limited to a relatively small number of functionals applied to small model systems and the $\mathrm{Ln}^{\mathrm{III}}$ aqua ions [89]. The different functionals available for application to molecular systems can be divided into four classes: i) Functionals based on the local density approximation (LDA), which depend on the value of the electron density at any given point in space; ii) Functionals based on the generalized gradient approximation (GGA), which depend not only on the value of the electron density, but also on its gradient; iii) Meta-GGA functionals, which depend on the electron density, its gradient, and the kinetic energy density; iv) Hybrid functionals, which can be divided into hybrid GGA and hybrid meta-GGA functionals, and include a mixture of Hartree-Fock exchange with DFT exchange-correlation. It has been shown that the LDA approximation including spin-orbit corrections provides ionization potentials close to the experimental values for lanthanide atoms [90]. However, the electronic description becomes less accurate in molecular calculations, which often predict too short Ln-ligand bonds and too high binding energies [89,91]. Different GGA functionals such as BLYP [92,93], or BP86 [92,94] have been successfully used for describing lanthanide coordination compounds, yet hybrid functionals such as B3LYP [92,95] are often the functionals of choice within computational lanthanide chemistry [96-100]. An evaluation of different GGA and hybrid functionals on the $\mathrm{LnF}(\mathrm{Ln}=\mathrm{Nd}, \mathrm{Eu}, \mathrm{Gd}, \mathrm{Yb})$ and $\mathrm{YbH}$ systems showed that B3LYP and BP86 functionals give very similar geometries, with BLYP calculations deviating slightly more from the experimental results [101]. B3LYP was also shown to provide bond strengths in closer agreement to the experimental values than BLYP and BP86 [101].

All members of the $4 \mathrm{f}$ period except $\mathrm{La}^{\mathrm{III}}$ and $\mathrm{Lu}^{\mathrm{III}}$ have unpaired f-electrons, and therefore can potentially display multiconfigurational character in their wave functions. The importance of the multiconfigurational wave function for systems containing these metal ions is however unclear, and no systematic studies have been performed to date. Some multiconfigurational character was observed in the $\left[\mathrm{Ln}\left(\mathrm{H}_{2} \mathrm{O}\right)_{8}\right]^{3+}$ and $\left[\mathrm{Ln}\left(\mathrm{H}_{2} \mathrm{O}\right)_{9}\right]^{3+}$ systems that contain between 2 and 5 unpaired electrons $(\mathrm{Ln}=\mathrm{Pr}, \mathrm{Nd}, \mathrm{Pm}, \mathrm{Sm}, \mathrm{Dy}, \mathrm{Ho}, \mathrm{Er}$, $\mathrm{Tm}$ ). In these cases the correlation energy, calculated as the energy difference between CASSCF (Complete Active Space Self-Consistent Field) and ROHF energies, was quite consistent across the period and was independent of the coordination number. This allows for error cancellation in DFT energetics using $4 \mathrm{f}$-in core RECPs when considering reaction energetics of the octa-aqua and nona-aqua species [102].

Due to their specific applications, the modeling of lanthanide complexes often requires the investigation of their behavior in solution. In principle there are two different approaches to take into account solvent effects in quantum chemical calculations of lanthanide(III) complexes: cluster calculations and the continuum models of solvation. Cluster calculations are performed in model clusters that explicitly include a second hydration shell [103]. These calculations have the advantage that minima and transition states can be optimized and characterized in order to study reactions (i. e. water exchange reactions) $[39,103]$. Moreover, cluster calculations may also provide useful direct information about the second sphere solvation shell [104], which has been shown to play an important role in certain properties of $\mathrm{Ln}^{\mathrm{III}}$ chelates such as on their relaxivity $[105,106]$ The major disadvantage of cluster calculations is that adding extra solvent molecules to the first solvation sphere increases the computational cost. Moreover, the more atoms are included in the system, the larger the number of degrees of freedom and the higher the number of minimum energy 
structures. An alternative to the use of cluster calculations is to introduce solvent effects with the aid of a continuum model. Two main types of continuum solvation models are available, the polarizable continuum model (PCM) of Tomasi et al. [107] and the conductor-like screening model (COSMO) of Klamt at al. $[108,109]$. In both models the molecule (solute) is surrounded by apparent charges that polarize it as it would do a surrounding solvent. In the PCM approach the magnitude of these apparent charges is calculated by considering that the molecule is surrounded by a polarizable continuum of the appropriate dielectric constant. In the COSMO approximation the dielectric constant of the medium is changed from the specific finite value characteristic of each solvent to $\varepsilon=\infty$, which corresponds to that of a conductor. One of the major problems for the application of continuum models of solvation is that they cannot account for specific solvent-solute interactions, which may be particularly important for charged solutes. Furthermore, it is not often obvious to find an appropriate definition of the solute cavity, which in the framework of PCM is often built as an envelope of spheres of appropriate radii centered on atoms or atomic groups. Indeed, Dixon et al. [110] tested different cavity models for the water addition reaction of the tetra-aqua uranyl cation using PCM approaches, showing that the definition of the solute cavity has an important impact in the computed values for the free energy of the exchange reaction. A similar conclusion was reached by A. Clark and co. [111] investigating the thermodynamic properties of aqueous $\mathrm{Ce}^{\mathrm{III}}$. After testing UA0, UFF, UAHF/UAKS, and Pauling polarized continuum model cavities, the UA0 and UAKS cavities were found to best reproduce experimental free energies of hydration when using a single hydration shell. In contrast, when a second hydration shell was employed the UFF and Pauling cavities were recommended. The use of the selfconsistent isodensity polarizable continuum model (SCIPCM) approach avoids using atomic radii to define the solute cavity, which is given by a isocontour level of the electronic density. An additional problem of PCM calculations is that geometry optimizations with continuum models often suffer convergence problems such as slow convergence, no convergence, or convergence to higher energetic conformations [112].

\section{The nature of chemical bonding in $\mathrm{Ln}^{\mathrm{III}}$ complexes}

$\mathrm{Ln}^{\mathrm{III}}$ ions are classified as hard Lewis acids in the Pearson HSAB classification [113], and thus metal-ligand interactions are expected to be mainly electrostatic, which results in a large variety of coordination numbers and the absence of predetermined chemical bonds directionality [17]. Furthermore, the $4 \mathrm{f}$ electrons are efficiently shielded from external perturbations by the $5 \mathrm{~d}$ and $6 \mathrm{~s}$ shells, and therefore they are not expected to be significantly involved in chemical bonding. However, this assumption is in fact a rough approximation, different spectroscopic properties of $\mathrm{Ln}^{\mathrm{III}}$ complexes pointing to a certain influence of the chemical environment on the $4 \mathrm{f}$ electrons. These properties include the sensitivity of the ${ }^{5} \mathrm{D}_{0}{ }^{7} \mathrm{~F}_{0}$ transition observed in emission spectra of Eu ${ }^{\text {III }}$ complexes to the nature of the surrounding ligands, which has been related to the

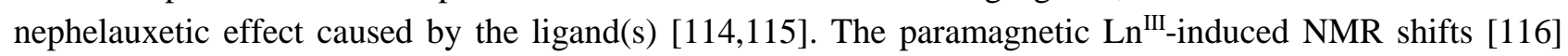
depend also strongly on the chemical environment around the metal ion. Indeed, Parker and co. demonstrated that the nature of the axial ligand coordinated to $\mathrm{Ln}^{\mathrm{III}}$ DOTA-like complexes affects importantly not only the relative intensity of the emission bands, but also the anisotropy of the magnetic susceptibility tensor that governs the paramagnetic pseudocontact shift contribution [117,118]. More recently Maury and co. investigated the nonlinear optics (NLO) activity of different lanthanide complexes. These studies evidenced a direct contribution of the $4 \mathrm{f}$ shell filling to the quadratic hyperpolarizability, which indicated that the $\mathrm{f}$ electrons are sensitive to the external laser electric field, and therefore they are polarizable [119].

The extent to which the $4 \mathrm{f}$ electrons of lanthanides are involved in bonding was first analyzed by Adamo and Maldivi [120], who performed DFT calculations on the $\mathrm{LnX}_{3}$ systems ( $\mathrm{Ln}=\mathrm{La}, \mathrm{Gd}$ or $\mathrm{Lu} ; \mathrm{X}=\mathrm{F}$ to I) with the aid of the hybrid B3LYP functional and the RECP of Stevens et al. [46]. Subsequent Natural Bond Orbital Analyses (NBO) [121] revealed a negligible role of $4 \mathrm{f}$ electrons in bonding, the residual covalent bonding interaction in these complexes involving sd hybrids of the metal ion and p orbitals of the halide. 
Few years later Maron and Eisestein performed a comparison of the structural parameters obtained from a detailed DFT investigation of $\mathrm{Ln}\left(\mathrm{NR}_{2}\right)_{3}$ complexes $\left(\mathrm{R}=\mathrm{H}, \mathrm{SiH}_{3}\right)$ using smalland large-core RECPs $[122,123]$. The geometries calculated with large core calculations suggested the nonparticipation of the $f$ electrons to the Ln-N bonding. The same group performed DFT calculations on $\mathrm{MX}_{3}$ complexes $(\mathrm{M}=\mathrm{Ln}$, $\mathrm{Sc}, \mathrm{Y}, \mathrm{Ti}^{+}, \mathrm{Zr}^{+}, \mathrm{Hf}^{+} ; \mathrm{X}=\mathrm{H}, \mathrm{Me}, \mathrm{Hal}, \mathrm{NH}_{2}$ ), and concluded that the $\mathrm{M}-\mathrm{X}$ bond has a considerably stronger ionic component in lanthanide complexes than in isoelectronic complexes of groups 3 and 4 [124]. State averaged CASSCF calculations performed on $\mathrm{Ln}\left(\mathrm{C}_{6} \mathrm{H}_{6}\right)_{2}$ complexes led to a similar conclusion concerning the ionic nature of the bonding [125], while a DFT investigation by using the ZORA formalism suggested purely ionic bonding for lanthanide complexes with different $N$-heterocyclic ligands [126]. A recent theoretical investigation on $\mathrm{DyBr}_{3}$ showed that the $4 \mathrm{f}$ electrons do not participate in bonding, but their inclusion in the valence shell, together with the whole $n=5$ shell, was essential to get reliable structural parameters from computation [127]. Different computational studies compared the covalent contribution to bonding of analogous lanthanide and actinide complexes [128-134]. These works revealed that the $5 \mathrm{f}$ orbitals in actinide complexes play a significant role in bonding, while the participation of $4 \mathrm{f}$ orbitals of lanthanides in bonding appears to be minimal or even negligible [135]. For instance, it was shown that the frontier MOs with important $4 \mathrm{f}$ metallic character in $\mathrm{Nd}^{\mathrm{III}}$ tris(dithiolene) complexes possess zero contribution from the ligands, while in the U(III) system these orbitals are delocalized over the metal and the ligands and contain a substantial 5 f contribution [136]. As a result, large-core RECPs, which often provide good results for $\mathrm{Ln}^{\mathrm{III}}$ complexes, are of more limited application in the case of their actinide counterparts [137]. A recent study on the octahedral calcogenolate lanthanide complexes $\left[(\mathrm{THF})_{3} \operatorname{Er}\left(\mathrm{SeC}_{6} \mathrm{~F}_{5}\right)_{3}\right]$ and $\left[(\mathrm{THF})_{3} \mathrm{Yb}\left(\mathrm{SC}_{6} \mathrm{~F}_{5}\right)_{3}\right]$ suggested that covalent bonding can have a measurable impact on the structures of Ln coordination compounds [138]. However, this was attributed to a covalent bonding between ligand based $\mathrm{p}$ orbitals and the Ln $5 \mathrm{~d}$ orbitals rather than to a participation of $\mathrm{Ln} 4 \mathrm{f}$ orbitals in chemical bonding.

In spite of the plethora of calculations that suggested a negligible participation of $4 \mathrm{f}$ electrons in bonding, this topic is still a matter of current debate within the literature. For instance, Clavaguéra et al. presented a DFT study on the $\mathrm{LuF}_{3}$ molecule that showed a pronounced $4 \mathrm{f}$ hybridization indicative of bonding interactions [139]. This is however a quite unexpected result considering the examples presented in the previous paragraph, and the fact that these authors found this behavior at the end of the series where the contraction of the $4 \mathrm{f}$ orbitals is largest. Furthermore, a similar claim concerning the participation of $4 \mathrm{f}$ orbitals in bonding between Gd and F in GdF [140] was shown to be wrong by Dolg et al. [141], who attributed the mixing of $4 \mathrm{f}$ orbitals of the lanthanide and the $2 \mathrm{p}$ orbitals of $\mathrm{F}$ to accidentally similar orbital energies. A recent analysis of the chemical bond in $\mathrm{LuF}_{3}$ did not confirm the unexpected results obtained by Clavaguéra et al. [82]. Finally, Chermette et al. [142] suggested on the basis of a DFT investigation on $\left[\mathrm{Ln}\left(\mathrm{C}_{3} \mathrm{H}_{5}\right) \mathrm{Cp}(\mathrm{OMe})\right]$ complexes that, contrary to the general opinion, the $4 \mathrm{f}$ orbitals are indeed involved in bonding. However, they attributed this to a somewhat indirect effect: the quasidegeneracy of the $4 \mathrm{f}$ and $5 \mathrm{~d}$ orbitals in the complexes.

In light of the different theoretical investigations performed on $\mathrm{Ln}^{\mathrm{III}}$ complexes we hold the view that the $4 \mathrm{f}$ electrons play a minor role (if any) in chemical bonding for most systems, particularly for coordination compounds. In spite of this, the $4 \mathrm{f}$ electron density appears to be polarized to a certain extent as a consequence of the metal-ligand interaction. Indeed, in a recent work Maury and co. [143] demonstrated that the $4 \mathrm{f}$ electron density in $\mathrm{Ln}^{\mathrm{III}}$ complexes is very sensitive to the coordination environment, as the metalligand interaction induces the polarization of the $4 \mathrm{f}$ density, resulting in the creation of maxima located in trans position to the metal-ligand bonds. This polarization effect is probably a general feature that explains certain experimental evidences such as the dependency of quadratic hyperpolarizability to the number of $f$ electrons in lanthanide picolinates [119]. Experimental evidence for the polarizable nature of the $4 \mathrm{f}$ electrons was obtained by Chatterjee from X-ray diffraction studies on the $\left[\mathrm{Ln}\left(\mathrm{H}_{2} \mathrm{O}\right)_{9}\right]\left(\mathrm{CF}_{3} \mathrm{SO}_{3}\right)_{3}$ complexes [144]. 


\section{DFT investigations on $\mathrm{Ln}^{\mathrm{III}}$ aqua-ions}

The complexes formed between the $\mathrm{Ln}^{\mathrm{III}}$ ions and one of the simplest ligands possible, water, have been the subject of extensive experimental and theoretical investigations. Nowadays it is generally accepted that the number of innersphere water molecules in the first coordination sphere of the $\mathrm{Ln}^{\mathrm{III}}$ aqua-ions decreases from 9 to 8 with the decrease of the ionic radius of the $\mathrm{Ln}^{\mathrm{III}}$ ion across the series. Experimental evidence for this change in coordination number was obtained from neutron diffraction [145,146], ${ }^{17} \mathrm{O}$ NMR [147] and EXAFS [148] measurements, while theoretical support for these findings was provided by classical molecular dynamics simulations [149-152]. Different computational studies based on classical [153] and ab initio [154] molecular dynamics simulations, HF [155,156], and DFT [157-159] calculations have shown that the $\left[\mathrm{Ln}\left(\mathrm{H}_{2} \mathrm{O}\right)_{9}\right]^{3+}$ ions possess a tricapped trigonal prismatic coordination with (often somewhat distorted) $D_{3}$ symmetry, while for the $\left[\mathrm{Ln}\left(\mathrm{H}_{2} \mathrm{O}\right)_{8}\right]^{3+}$ complexes these calculations provide a square antiprismatic coordination with $S_{8}$ symmetry around the lanthanide ion (Fig. 1).
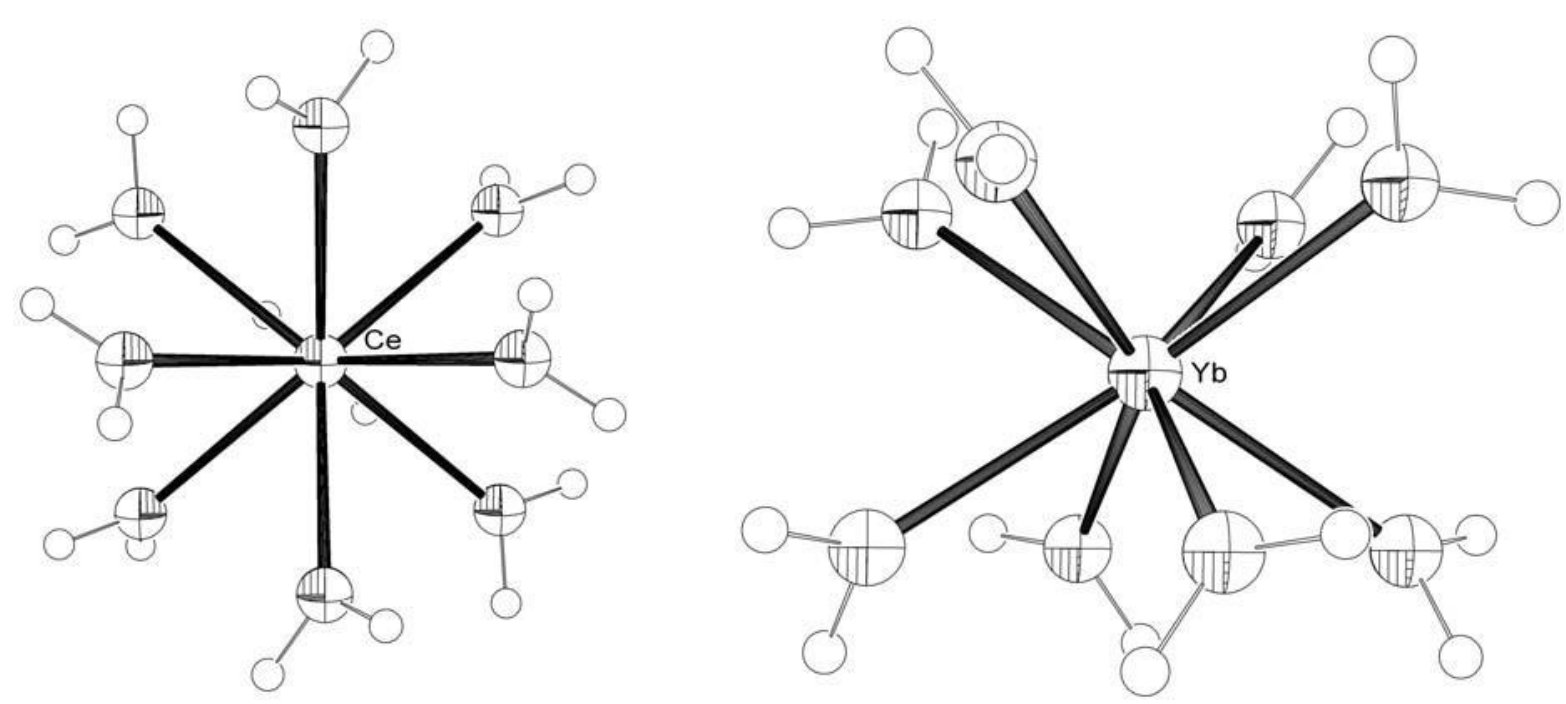

Fig. 1. Geometries of the $\left[\mathrm{Ce}\left(\mathrm{H}_{2} \mathrm{O}\right)_{9}\right]^{3+}(\mathrm{left})$ and $\left[\mathrm{Yb}\left(\mathrm{H}_{2} \mathrm{O}\right)_{8}\right]^{3+}$ (right) complexes optimized at the B3LYP level by using a "small-core" RECPs and the aug-cc-pVDZ basis set for O and H (redrawn from Reference [102]).

A DFT investigation on the $\left[\mathrm{Ln}\left(\mathrm{H}_{2} \mathrm{O}\right)_{9}\right]^{3+}$ and $\left[\mathrm{Ln}\left(\mathrm{H}_{2} \mathrm{O}\right)_{8}\right]^{3+}$ systems by using a "large core" RECP and the B3LYP model showed that the inclusion of solvent effects is crucial to obtain molecular structures in better agreement with the experimental ones [147]. Indeed, geometry optimizations performed in the gas phase provide Ln-O distances considerably longer (ca. $0.05 \AA$ ) than those obtained in aqueous solution (PCM model), in agreement with previous calculations performed at the HF level [155]. The mean Ln-O distances calculated in aqueous solution for the $\left[\mathrm{Nd}\left(\mathrm{H}_{2} \mathrm{O}\right)_{9}\right]^{3+}$, $\left[\mathrm{Dy}\left(\mathrm{H}_{2} \mathrm{O}\right)_{8}\right]^{3+}$ and $\left[\mathrm{Yb}\left(\mathrm{H}_{2} \mathrm{O}\right)_{8}\right]^{3+}$ systems $(2.54,2.41$ and $2.36 \AA$, respectively) [147] were only slightly longer than those obtained experimentally from neutron diffractions studies in solution $(2.50,2.38$ and $2.32 \AA$, respectively) [145,146]. Lanthanide hydration was studied by Dolg et al. [160] by utilizing DFT and MP2 calculations combined with a scalarrelativistic smallcore RECP of the Stuttgart family. Calculations performed on the $\left[\mathrm{Ln}\left(\mathrm{H}_{2} \mathrm{O}\right)_{n}\right]^{3+}(\mathrm{n}=7,8,9)$ and $\left[\mathrm{Ln}\left(\mathrm{H}_{2} \mathrm{O}\right)_{n-}\right.$ $\left.{ }_{1} \cdot \mathrm{H}_{2} \mathrm{O}\right]^{3+}$ systems in combination with the COSMO solvation model were used to obtain molecular structures, binding energies, entropies and energies of hydration as well as Gibbs free energies of hydration. These calculations showed that DFT methods performed in the gas phase overestimate the calculated Ln-O distances with respect to experimental values, which was mainly ascribed to the neglect of bulk solvation. At the GGA level of density-functional theory (BP86) a preferred hydration number of 8 was found for LaII_$\mathrm{Tm}^{\mathrm{III}}$ and 7 for $\mathrm{Yb}^{\mathrm{III}}-\mathrm{Lu}^{\mathrm{III}}$, whereas hybrid density-functional theory (B3LYP) predicted a hydration number 
8 for all $\mathrm{Ln}^{\mathrm{III}}$ ions. At the MP2 level of theory the preferred hydration number is found to be 9 for La $a^{\mathrm{III}}-\mathrm{Sm}^{\mathrm{III}}$ and 8 for $\mathrm{Eu}^{\mathrm{III}}-\mathrm{Lu} \mathrm{u}^{\mathrm{III}}$, in good agreement with experimental evidence.

In a series of recent works A. E. Clark performed a detailed investigation of the structural and thermodynamic features of $\mathrm{Ln}^{\mathrm{III}}$ aqua-ions. A comparison of the calculated structures for the $\left[\mathrm{Ln}\left(\mathrm{H}_{2} \mathrm{O}\right)_{8}\right]^{3+}$ $(\mathrm{Ln}=\mathrm{La}$ or $\mathrm{Lu})$ systems by using small-core and large-core RECPs of the Stuttgart family revealed that the latter predicts longer Ln-O bond lengths relative to small-core calculations [161]. This is in line with previous calculations performed on the $\mathrm{Ln}\left(\mathrm{NR}_{2}\right)_{3}\left(\mathrm{R}=\mathrm{H}, \mathrm{SiH}_{3}\right)$ complexes [122] and lanthanide(III) complexes with tridentate ligands with nitrogen donor atoms [79]. Concerning the performance of different density functionals, the structural parameters calculated for $\left[\mathrm{Ln}\left(\mathrm{H}_{2} \mathrm{O}\right)_{8}\right]^{3+}(\mathrm{Ln}=\mathrm{La}$ or $\mathrm{Lu})$ indicated overbinding when using LDA functionals. The meta-GGA TPSS functional provided the closest structural agreement with experimental results, while the performance of the hybrid B3LYP functional was also reasonable [89]. Analogous calculations performed on the $\left[\mathrm{Ce}\left(\mathrm{H}_{2} \mathrm{O}\right)_{9}\right]^{3+}$ and $\left[\mathrm{Ce}\left(\mathrm{H}_{2} \mathrm{O}\right)_{8}\right]^{3+}$ species led to a similar conclusion [111]. The investigation of the structural trends across the $4 \mathrm{f}$ period shows that the average $\mathrm{Ln}-\mathrm{OH}_{2}$ bond distances decrease quadratically for both the $\left[\mathrm{Ln}\left(\mathrm{H}_{2} \mathrm{O}\right)_{9}\right]^{3+}$ and $\left[\mathrm{Ln}\left(\mathrm{H}_{2} \mathrm{O}\right)_{8}\right]^{3+}$ species (Fig. 2) [102,147], as it should be expected according to the lanthanide contraction and recent experimental studies of isostructural lanthanide(III) complexes [162].

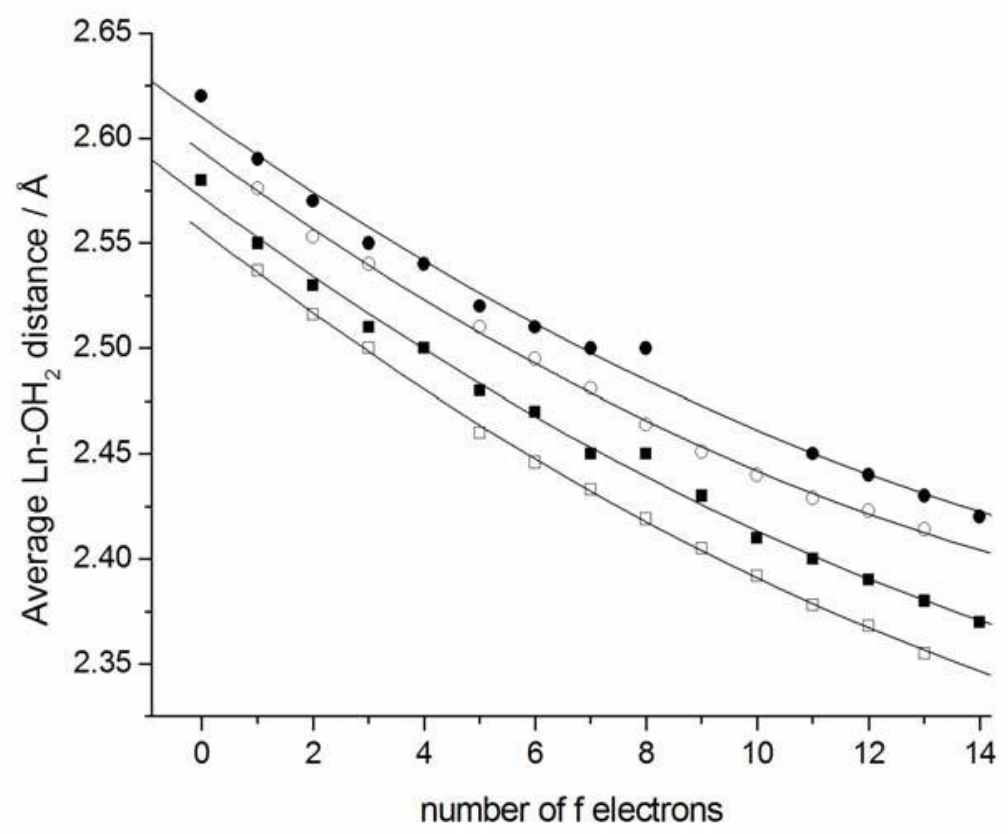

Fig. 2. The average $\mathrm{Ln}-\mathrm{OH}_{2}$ distances against the number of $\mathrm{f}$ electrons for $\left[\mathrm{Ln}\left(\mathrm{H}_{2} \mathrm{O}\right)_{9}\right]^{3+}(\operatorname{circles})$ and $\left[\mathrm{Ln}\left(\mathrm{H}_{2} \mathrm{O}\right)_{8}\right]^{3+}$ (squares) complexes obtained from DFT calculations (B3LYP). The solid symbols represent data obtained from gasphase calculations with "small-core" RECPs and the aug-cc-pVDZ basis set for O and H [102], while the open symbols refer to data obtained in aqueous solution (C-PCM) with "largecore" ECPs and the 6-31+G(d) basis set for O and H [147]. The lines represent the quadratic fit of the data with $\mathrm{R}^{2}=0.9983(\mathrm{o}), 0.9993(\square), 0.9904(\bullet)$ and $0.9947(\mathbf{\square})$.

The thermodynamics of solvation of aqueous $\mathrm{Ce}^{\mathrm{III}}$ has been investigated in detail by performing DFT calculations on the $\left[\mathrm{Ce}\left(\mathrm{H}_{2} \mathrm{O}\right)_{8}\right]^{3+}$ and $\left[\mathrm{Ce}\left(\mathrm{H}_{2} \mathrm{O}\right)_{9}\right]^{3+}$ systems in combination to different implementations of the PCM model [111]. After testing different polarized continuum model cavities, the UA0 and UAKS models, which are based on the United Atom Topological Model of Barone and co. [163], were found to best reproduce experimental free energies of solvation. The size of the relativistic RECP was found to dramatically influence calculated free energies of hydration, with the large core results performing poorly. A subsequent extension of these studies across the whole lanthanide series showed that the calculated free 
energies of hydration of the lanthanide aqua-ions fall within the $\sim 11 \mathrm{kcal} \cdot \mathrm{mol}^{-1}$ error bar of the experimental data [102]. Finally, a DFT based Car-Parrinello molecular dynamics (CPMD) [164] investigation on the Gd $^{\text {III }}$ ion provided bond distances in good agreement with the experiment. These calculations also reproduced the square antiprismatic coordination environment around the metal ion in $\left[\mathrm{Gd}\left(\mathrm{H}_{2} \mathrm{O}\right)_{8}\right]^{3+}$ [165]. However, the limited time duration of these simulations (4 ps) prevented the observation of any exchange event of the inner-sphere water molecules [166].

\section{Structure and dynamics of $\mathrm{Ln}^{\mathrm{III}}$ complexes}

The stereoisomerism associated with lanthanide complexes is relatively well understood and has been documented in a number of reviews $[1,10,167]$. For instance, it is well known that in $\mathrm{Ln}^{\text {III }}$ DOTA-like complexes the four ethylenediamine groups adopt gauche conformations giving rise to two macrocyclic ring conformations: $(\delta \delta \delta \delta)$ and $(\lambda \lambda \lambda \lambda)$. Furthermore, there are two possible orientations of the four pendant arms (absolute configuration $\Delta$ or $\Lambda$ ), resulting in four possible stereoisomers, existing as two enantiomeric pairs $[168,169]$. These stereoisomers differ by the layout of the four acetate arms, adopting either a squareantiprismatic (SAP) or a twisted square-antiprismatic (TSAP) geometry (Fig. 3) [170-172]. The two structures display a different orientation of the two square planes formed by the four cyclen nitrogen atoms and the four binding oxygen atoms, making an angle of $c a .40^{\circ}$ in SAP-type structures, whereas this situation is reversed and reduced to $c a .-30^{\circ}$ in TSAP-type derivatives [10]. The SAP and TSAP isomers may interconvert in solution by either ring inversion, which leads to a $(\delta \delta \delta \delta) \leftrightarrow(\lambda \lambda \lambda \lambda)$ conformational change, or arm rotation, which results in a $\Delta \leftrightarrow \Lambda$ configurational change. Either process alone interconverts SAP and TSAP geometries, while the combination of the two processes exchanges enantiomeric pairs (Fig. 3) $[173,174]$. The isomer ratio affects dramatically certain physicochemical properties of the chelate, such as the water exchange rate of the inner-sphere water molecule, an important parameter related to the efficiency of MRI contrast agents. The water exchange on the inner-sphere water molecule has been studied on both isomers for several $\mathrm{Ln}^{\mathrm{III}}$ complexes with DOTA-like derivatives. It is found that the water exchange on the TSAP isomer is about two orders of magnitude faster than on the SAP one [175-178]. Thus, understanding the factors that govern the isomeric composition of DOTA-like complexes in solution is of crucial importance for the design of chelates with predetermined properties.

Theoretical investigations performed on DOTA-like complexes based on molecular mechanics [179-183], Hartree-Fock [184,185], density-functional theory [186,187], or classical molecular dynamics [188,189], have been reported in the literature. These investigations contributed to increase the understanding of the structure and dynamics of this important family of complexes. In a seminar paper, Cosentino et al. [190] reported a conformational characterization of lanthanide(III)-DOTA complexes by using ab initio calculations. They demonstrated that geometry optimizations performed at the HF level and a large-core RECP provide calculated structures in good agreement with the experimental ones obtained from X-ray diffraction studies. However, single point energy calculations at the density functional theory (DFT) level (B3LYP model) had to be used to obtain relative energies between the SAP and TSAP isomers in better agreement with the experimental ones. A similar methodology was applied to investigate the conformational behavior of $\mathrm{Eu}^{\mathrm{III}}$ DTPA-bisamide complexes (DTPA = diethylenetriaminepentaacetate) [191]. More recently, the same group also investigated a $\mathrm{Gd}^{\mathrm{III}}$ DOTA-like complex containing a $\beta$-galactopyranose residue by using a combination of HF and classical molecular dynamics simulations [192].

In a series of recent papers we investigated the conformational properties of lanthanide complexes with ligands DOTA, DO3AP, DO2A2P, DOA3P, DOTP and $N$-benzyl-DO3A by using DFT calculations (Scheme 1) [193,194]. In these studies the large-core RECPs of the Stuttgart family were used for the lanthanides [47], while the ligand atoms were described by using the standard 6-31G(d) basis set [195]. Geometry optimizations performed on the $\left[\mathrm{Ln}(\mathrm{L})\left(\mathrm{H}_{2} \mathrm{O}\right)_{q}\right]^{\mathrm{n}-}$ systems $[\mathrm{L}=$ DOTA, $q=0,1, \mathrm{n}=1$; L $=$ DO3AP, 
$q=1, \mathrm{n}=2 ; \mathrm{L}=$ DO2A2P, $q=0, \mathrm{n}=3 ; \mathrm{L}=$ DOA3P, $q=0, \mathrm{n}=4 ; \mathrm{L}=$ DOTP, $q=0, \mathrm{n}=5 ; \mathrm{L}=N$-benzylDO3A, $q=1, \mathrm{n}=0$ ] provided the expected SAP and TSAP isomers as minimum energy conformations. The average Ln-O distances obtained from DFT calculations are in excellent agreement with the experimental values. The main discrepancy between the experimental and calculated geometries arises from the Ln- $\mathrm{N}$ distances. Indeed, the optimized geometries present substantially longer Ln-N bond distances than the solid state structures. This can be partially ascribed to the fact that the large-core RECPs usually provide bond distances ca. 0.02-0.07 $\AA$ longer than the experimental ones [79,111,122]. To test the effect of the solvent in the geometries of these complexes we performed geometry optimizations in aqueous solution by using a polarizable continuum model (PCM). However, it is well known that geometry optimizations in solution based on the PCM model suffer from convergence problems such as slow convergence, no convergence, or convergence to higher energetic conformations [112]. Thus the calculated geometries should be considered as stable conformations for the chosen minimization algorithm rather than energy minima. The results obtained for the $\left[\mathrm{Nd}(\mathrm{HDO} 3 \mathrm{AP})\left(\mathrm{H}_{2} \mathrm{O}\right)\right]^{-}$and $[\mathrm{Er}(\mathrm{HDO} 3 \mathrm{AP})]^{-}$systems show that the inclusion of solvent effects results in a relatively important shortening of the Ln-N bond distances (ca. 0.07-0.08 $⿱$ ), while the Ln-O bonds are only slightly increased (ca. $0.03 \AA$ ). An important shortening of the metal-N bond distances upon solvent inclusion was also observed for the $\left[\mathrm{Ln}(\mathrm{DOTA})\left(\mathrm{H}_{2} \mathrm{O}\right)\right]^{-}$complexes [190], and for $\mathrm{In}^{\mathrm{III}}$ and $\mathrm{Ga}^{\mathrm{III}}$ complexes with functionalized triazamacrocycles [196].

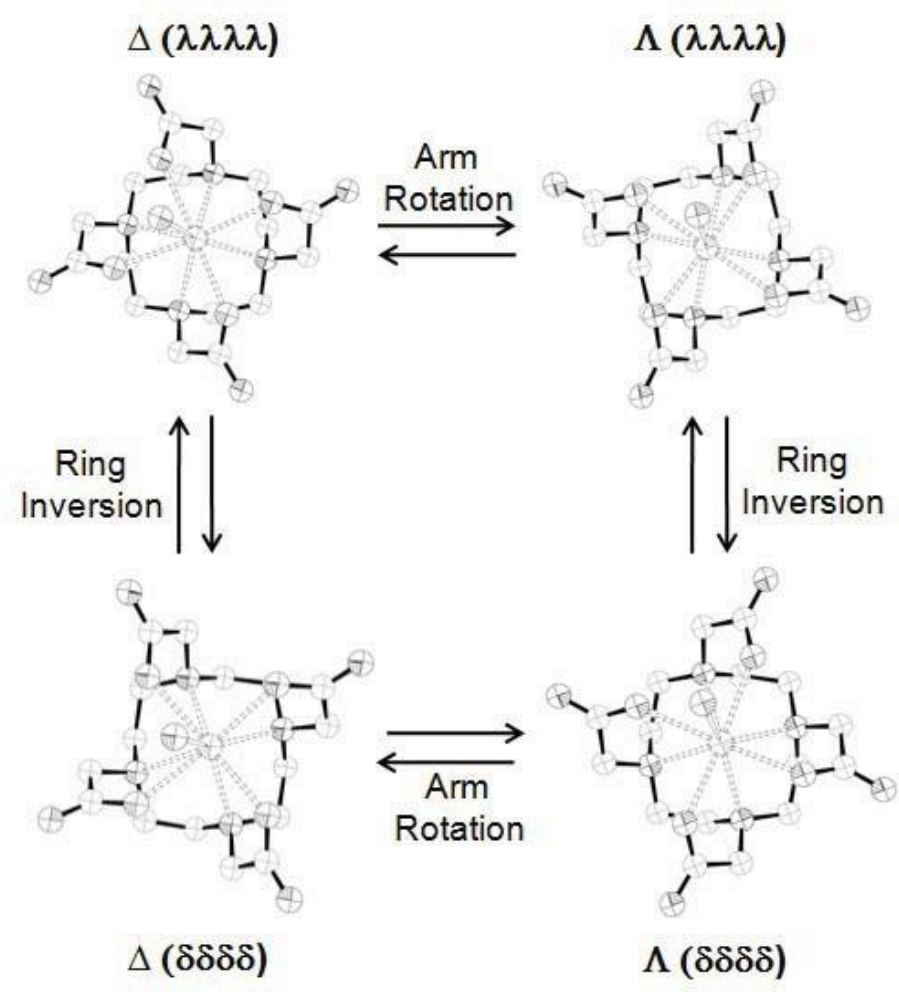

Fig. 3. The two enantiomeric pairs observed in aqueous solutions of $\left[\mathrm{Ln}(\mathrm{DOTA})\left(\mathrm{H}_{2} \mathrm{O}\right)\right]$ complexes. Symbols $\Delta$ and $\Lambda$ refer to the helicity of the pendant arms, $\delta$ and $\lambda$ to that of the macrocycle $[168,169]$.

$\mathrm{Ab}$ initio Car-Parrinello molecular dynamics simulations based on the PBE functional were used to investigate the [Gd(HP-DO3A)] system in explicit aqueous solution [197]. These calculations predicted a SAP conformation of the complex in solution, the calculated structural parameters being in good agreement with experimental values. 


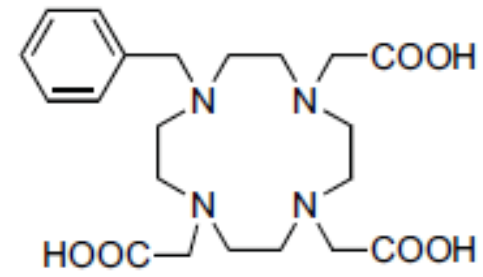

$\mathrm{H}_{3}$-N-benzyl-DO3A<smiles>O=C(O)CN1CCN(CC(=O)O)CCN(CC(=O)O)CCN(CC(=O)O)CC1</smiles>

$\mathrm{H}_{5}$ DO3AP<smiles>O=C(O)CN1CCN(CP(=O)(O)O)CCN(CP(=O)(O)O)CCN(CP(=O)(O)O)CC1</smiles>

$\mathrm{H}_{7}$ DOA3P<smiles>O=C(O)CN1CCN(CC(=O)O)CCN(CC(=O)O)CCN(CC(=O)O)CC1</smiles>

$\mathrm{H}_{4}$ DOTA<smiles>O=C(O)CN1CCN(CC(=O)O)CCN(CP(=O)(O)O)CCN(CC(=O)O)CC1</smiles>

$\mathrm{H}_{6}$ DO2A2P<smiles>O=P(O)(O)CN1CCN(CP(=O)(O)O)CCN(C[PH](=O)(=O)O)CCN(CP(=O)(O)O)CC1</smiles>

$\mathrm{H}_{8}$ DOTP<smiles>c1ccc(CN2CCN(Cc3ccccn3)CCN(Cc3ccccn3)CCN(Cc3ccccn3)CC2)nc1</smiles>

Scheme 1.

The relative population of the TSAP and SAP conformations of lanthanide complexes of DOTA [170] and DO3AP [198] were studied in detail by using NMR spectroscopy. The relative energy of these isomers in $[\mathrm{Eu}(\mathrm{DO} 2 \mathrm{~A} 2 \mathrm{P})]^{3-}$ was also investigated [199]. The experimental evidence indicates that the TSAP geometry is progressively stabilized upon replacing the acetate arms of DOTA by methylenephosphonate groups. In the case of the $\left[\mathrm{Eu}(\mathrm{DOTA})\left(\mathrm{H}_{2} \mathrm{O}\right)\right]^{-}$complex the SAP conformation is the most abundant one in solution (ca. $80 \%)$, while for the $[\mathrm{Eu}(\mathrm{DO} 2 \mathrm{~A} 2 \mathrm{P})]^{3-}$ complex the SAP abundance amounts only to ca. $7 \%$. $\mathrm{Ln}(\mathrm{DOTP})$ complexes are known to exist as the TSAP isomer both in the solid state and in solution [200].

The relative energies of the SAP and TSAP isomers obtained from DFT calculations for the $\left[\mathrm{Eu}(\mathrm{L})\left(\mathrm{H}_{2} \mathrm{O}\right)_{q}\right]^{\mathrm{n}-}$ systems $[\mathrm{L}=\mathrm{DOTA}, q=1, \mathrm{n}=1 ; \mathrm{L}=\mathrm{DO} 3 \mathrm{AP}, q=1, \mathrm{n}=2 ; \mathrm{L}=\mathrm{DO} 2 \mathrm{~A} 2 \mathrm{P}, q=0, \mathrm{n}=3 ; \mathrm{L}=\mathrm{DOA} 3 \mathrm{P}, q=0$, $\mathrm{n}=4$; $\mathrm{L}=$ DOTP, $q=0, \mathrm{n}=5$ ] indeed predict a progressive stabilization of the TSAP isomer upon increasing the number of methylenephosphonate pendant arms (Fig. 4). The calculated values were shown to deviate 
from the experimental ones by less than $1.1 \mathrm{kcal} \cdot \mathrm{mol}^{-1}$. The binding energies of the ligand to the metal ion indicated that the SAP conformation of the ligand provides a stronger binding to the lanthanide ion for all complexes investigated. However, the relative strain energies of the ligand, calculated as the difference between the ligand energies for the two isomers with the ligands at the conformation found within the corresponding complex, indicated a higher degree of steric strain in the SAP form with respect to the TSAP one. The replacement of acetate groups of DOTA by bulkier methylenephosphonate pendant arms further increases the steric strain in the SAP form with respect to the TSAP one. This increased steric strain is not fully compensated by the increased binding energy obtained upon introduction of methylenephosphonate pendants in the SAP form. Indeed, the sum of relative SEs and relative BEs ( $\triangle \mathrm{E}$, Fig. 4) shows a trend that nearly matches that observed for the calculated relative free energies. Thus, the introduction of methylenephosphonate pendant arms in DOTA-like systems stabilizes the TSAP isomer as a result of the high steric demand of the phosphonate groups, and the higher strain of the ligand in the SAP isomer.

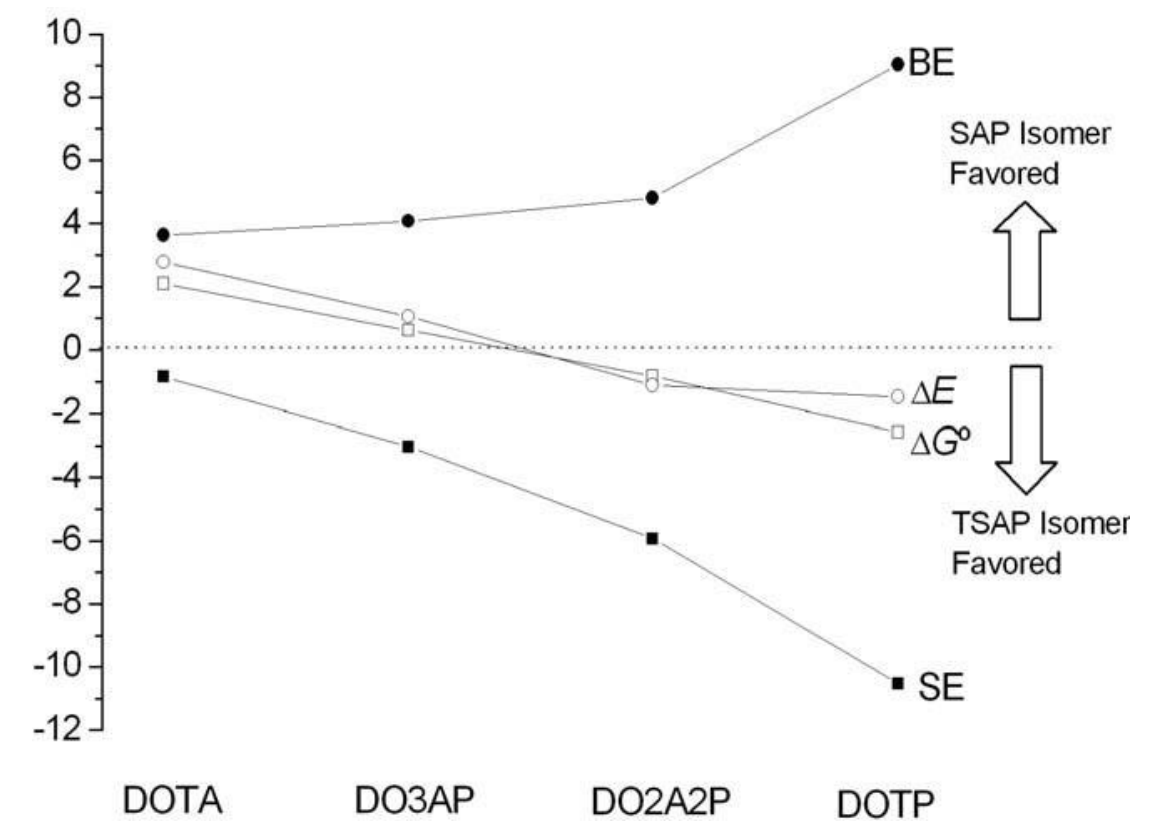

Fig. 4. Relative free energies $\left(\Delta G^{\circ}\right.$ ), relative strain energies (SE), relative binding energies (BE) and $\Delta E=\mathrm{BE}+\mathrm{SE}$ obtained from DFT calculations for different $\mathrm{Ln}^{\mathrm{III}}$ DOTA-like complexes [193]. Values are given in $\mathrm{kcal} \cdot \mathrm{mol}^{-1}$.

The calculated relative free energies of the SAP and TSAP isomers of the $\left[\mathrm{Ln}(\mathrm{DO} 3 \mathrm{AP})\left(\mathrm{H}_{2} \mathrm{O}\right)\right]^{2-}$ complexes pre dict a progressive stabilization of the SAP isomer upon in creasing the atomic number of the lanthanide ion (Fig. 5) [193]. The TSAP isomer is predicted to be the most stable one for the large lanthanides, while for the heaviest lantha nides the SAP form becomes the most stable one, in nice agreement with the experimental results [198]. The relative SEs show little variation along the lanthanide series (ca. 1.7 $\mathrm{kcal} \cdot \mathrm{mol}^{-1}$ from $\mathrm{La}$ to $\mathrm{Lu}$ ), while the relative binding energies experience important changes. The SAP form provides the stronger interaction between the ligand and the lanthanide ion along the whole lanthanide series. This effect is magni fied as the ionic radius of the lanthanide ion decreases, the relative BEs changing from ca. 2.5 to $6.8 \mathrm{kcal} \cdot \mathrm{mol}^{-1}$ from La to Lu. Thus, the SAP isomer appears to be endowed with the highest BE, which also increases with respect to that of the TSAP isomer across the lanthanide series as the charge den sity of the metal ion increases. 


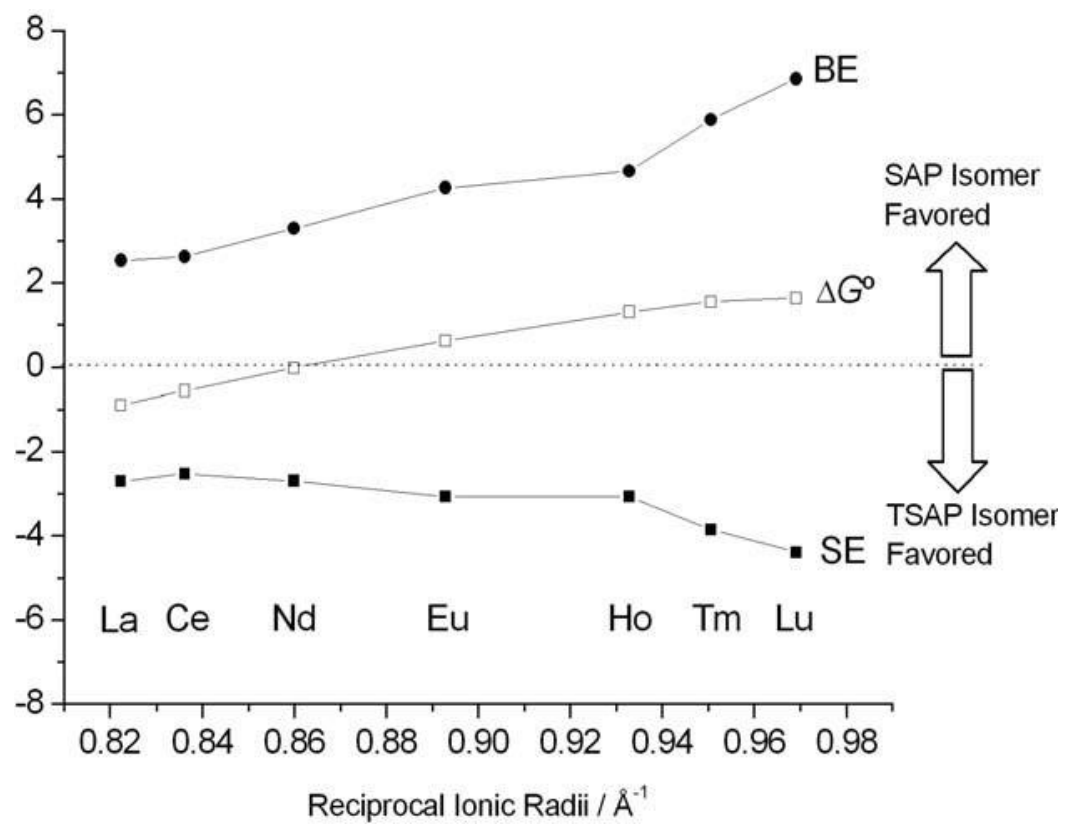

Fig. 5. Relative free energies $\left(\Delta G^{\mathrm{o}}\right)$, relative strain energies (SE) and relative binding energies (BE) obtained from DFT calculations for $\left[\mathrm{Ln}(\mathrm{DO} 3 \mathrm{AP})\left(\mathrm{H}_{2} \mathrm{O}\right)\right]^{2-}$ complexes [193]. Values are given in $\mathrm{kcal} \cdot \mathrm{mol}^{-1}$.

The DFT investigations performed on $\mathrm{Ln}^{\mathrm{III}}$ DOTA-like complexes allows concluding that an increased steric hindrance around the lanthanide ion favors the TSAP isomer with respect to the SAP one. In those cases where steric hindrance is not important the SAP isomer is favored because it is endowed with the highest binding energy of the ligand to the metal ion, an effect that is magnified as the charge density of the metal ion increases along the lanthanide series. In line with these conclusions, DFT calculations performed on the [Ln $(N$-benzyl-DO3A $\left.)\left(\mathrm{H}_{2} \mathrm{O}\right)\right](\mathrm{Ln}=\mathrm{Gd}$ or $\mathrm{Lu})$ complexes predicted the SAP isomer to be the most stable one, as the absence a the fourth pendant arm in the ligand structure decreases the steric hindrance for the coordination of the ligand to the metal ion. Furthermore, a stabilization of the SAP isomer is observed as the ionic radius of the metal ion decreases from $\mathrm{Gd}^{\mathrm{III}}$ to $\mathrm{Lu}^{\mathrm{III}}$ [194].

The interconversion between the SAP and TSAP isomers in [ $\mathrm{Lu}(\mathrm{N}$-benzyl-DO3A $\left.)\left(\mathrm{H}_{2} \mathrm{O}\right)\right],[\mathrm{Lu}(\mathrm{DOTA})]^{-}$and $[\mathrm{Lu}(\mathrm{DO} 2 \mathrm{~A} 2 \mathrm{P})]^{3-}$ was investigated by using DFT calculations (B3LYP model) and the large-core RECPs of the Stuttgart family for the lanthanides [193,194]. As illustrated in Fig. 3, the interconversion between the TSAP and SAP isomers of these family of complexes may proceed either through the inversion of the macrocyclic cyclen unit, or following the rotation of the pendant arms of the ligand. According to the results obtained on B3LYP/6-31G(d) optimized geometries the inversion of the cyclen moiety in these complexes is a four step process (Fig. 6). In each of these steps one of the five-membered chelate rings changes its configuration from $\delta$ to $\lambda$, passing through a transition state (TS) in which the chelate ring adopts a nearly planar conformation with the NCCN moiety in eclipsed disposition (Fig. 7). Previous investigations performed at the HF level pointed to the same mechanism [190], with the energy of the transition state responsible of a concerted pathway involving the simultaneous rotation of the four ethylenediamine units being too high for such a path to be of practical significance [201]. A recent DFT investigation of the ring inversion process in $\left[\mathrm{Y}\left(\mathrm{L}^{\mathrm{PY}}\right)\right]^{3+}$ (Scheme 1) predicted a similar stepwise mechanism with the presence of several metastable intermediates [202].

The energy profiles calculated for the ring inversion process in [ $\mathrm{Lu}(\mathrm{N}$-benzyl-DO3A $\left.)\left(\mathrm{H}_{2} \mathrm{O}\right)\right]$, [Lu(DOTA) ${ }^{-}$ and $[\mathrm{Lu}(\mathrm{DO} 2 \mathrm{~A} 2 \mathrm{P})]^{3-}$ complexes point to very similar activation barriers for these systems (Fig. 6). Assuming the rate determining step for the ring inversion process in $\left[\mathrm{Lu}(N \text {-benzyl-DO3A })\left(\mathrm{H}_{2} \mathrm{O}\right)\right]^{-}$and $[\mathrm{Lu}(\mathrm{DO} 2 \mathrm{~A} 2 \mathrm{P})]^{3-}$ to be the passage between $\mathrm{I}_{3}$ and the TSAP isomer, the barrier for this path is the one associated to $\mathrm{TS}_{4}$, 
which amounts to 13.5 and $14.4 \mathrm{kcal} \cdot \mathrm{mol}^{-1}$ for the DO2A2P and $N$-benzyl-DO3A complexes, respectively. The value obtained for the DO2A2P analogue is in excellent agreement with the experimental value obtained from the analysis of the NMR spectra $\left(15.4 \mathrm{kcal} \cdot \mathrm{mol}^{-1}\right)$. In the case of the [Lu(DOTA) $]^{-}$complex the calculated free energy barrier for the ring inversion process, assumed to be the one associated to $\mathrm{TS}_{2}$, amounts to $15.4 \mathrm{kcal} \cdot \mathrm{mol}^{-1}$, in nice agreement with those obtained experimentally for the [Yb(DOTA) $]^{-}(14.6$ $\left.\mathrm{kcal} \cdot \mathrm{mol}^{-1}\right)$ and $[\mathrm{Lu}(\mathrm{DOTA})]^{-}\left(15.8 \mathrm{kcal} \cdot \mathrm{mol}^{-1}\right)$ complexes $[173,174]$. Similar calculations performed on the $[\mathrm{La}(\mathrm{DO} 2 \mathrm{~A} 2 \mathrm{P})]^{3-}$ system provide very similar activation free energies, indicating that the size of the $\mathrm{La}^{\mathrm{III}}$ ion does not have an important effect on the ring inversion process [193].

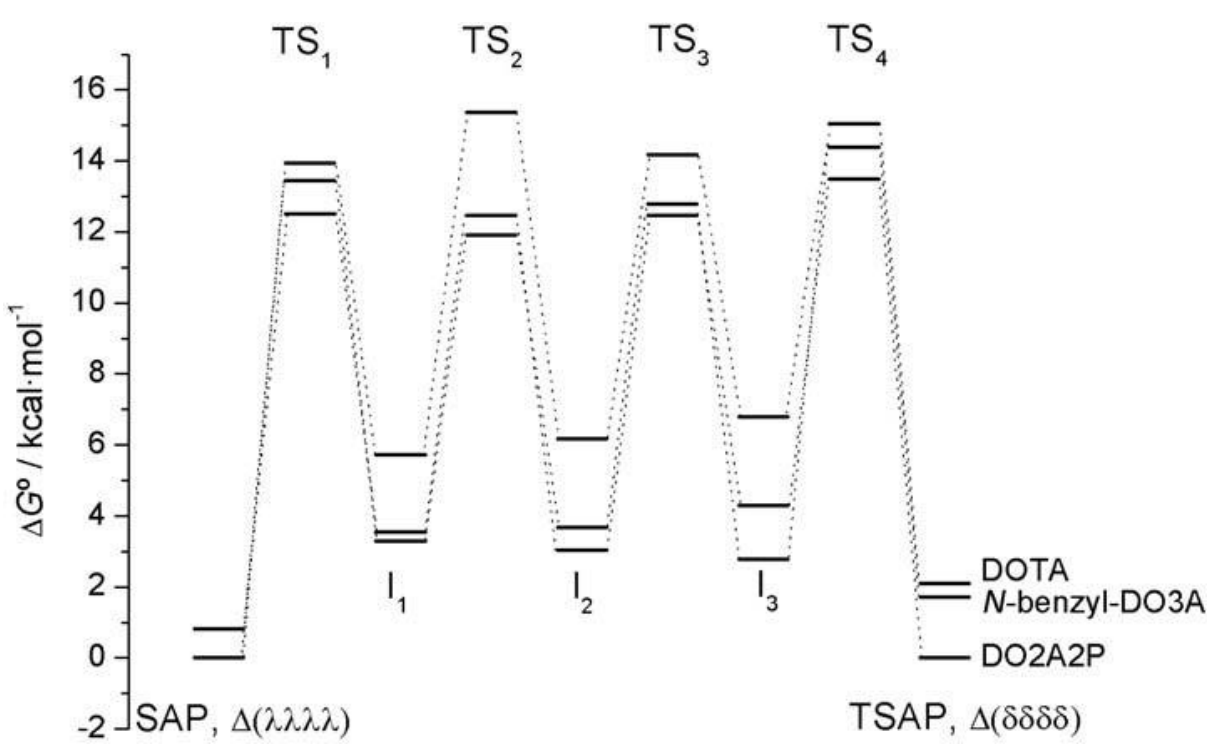

Fig. 6. In vacuo relative free energies of energy minima, intermediates (I) and transition states (TS) involved in the ring

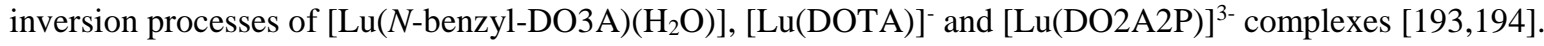
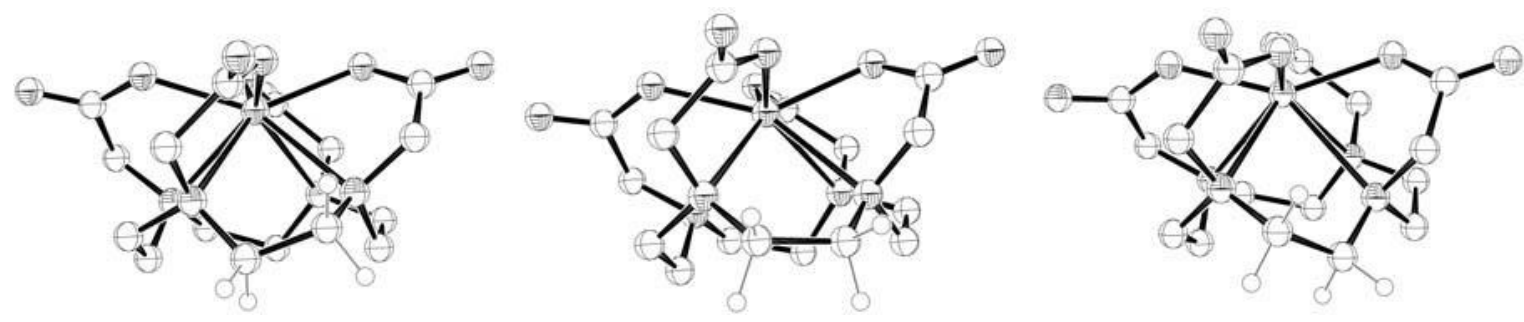

Fig. 7. Energy minimum, transition state and intermediate involved in the first step of the ring inversion process of [Lu(DOTA)] [193]. A nearly planar conformation with the NCCN moiety in eclipsed disposition is denoted as X. Hydrogen atoms, except those of the NCCN moiety involved in the configurational change, are omitted for clarity.

The arm rotation process responsible for the SAP - TSAP interconversion process in [ $\mathrm{Lu}(N$-benzyl-DO3A) $\left.\left(\mathrm{H}_{2} \mathrm{O}\right)\right],[\mathrm{Lu}(\mathrm{DOTA})]^{-}$and $[\mathrm{Lu}(\mathrm{DO} 2 \mathrm{~A} 2 \mathrm{P})]^{3-}$ complexes was also studied by using hybrid DFT calculations (B3LYP model) [193,194]. According to these calculations the arm rotation process in [Lu(DOTA)]- follows a concerted mechanism involving the simultaneous rotation of the four pendant arms, which is in agreement with calculations performed at the HF level $[190,201]$. On the contrary, the arm rotation process in $[\mathrm{Lu}(N$ benzyl-DO3A $\left.\left(\mathrm{H}_{2} \mathrm{O}\right)\right]$ and $[\mathrm{Lu}(\mathrm{DO} 2 \mathrm{~A} 2 \mathrm{P})]^{3-}$ proceeds following a stepwise rotation of each of the pendant arms of the ligand (Fig. 8). In the case of the DOTA analogue the planar nature of the acetate groups appears 
to hinder a stepwise mechanism due to steric crowding, while the tetrahedral arrangement of the phosphonate groups in DO2A2P favours a stepwise mechanism. For the DO3A derivatives the absence of a fourth pendant arm decreases the steric hindrance for the arm rotation process, which favours a step-by-step mechanism, and results in very low energy barriers for the arm rotation path. Indeed, the free energy barriers

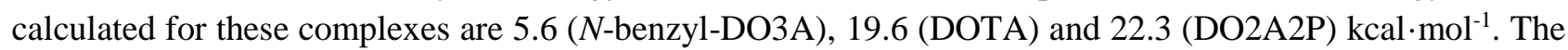
values calculated for the DOTA and DO2A2P derivatives are in reasonably good agreement with the experimental data obtained from NMR spectroscopy (15.6 and $15.8 \mathrm{kcal} \cdot \mathrm{mol}^{-1}$ for $[\mathrm{Yb}(\mathrm{DOTA})]^{-}$and $[\mathrm{Lu}(\mathrm{DO} 2 \mathrm{~A} 2 \mathrm{P})]^{3-}$, respectively) $[173,174]$. Thus, the detailed analysis of the arm rotation and ring inversion paths in this family of DOTA-like complexes suggests that energy barriers for the ring inversion process are relatively little affected by the nature of the pendant arms of the ligand. The situation is however very different for the arm rotation path, which is endowed with activation barriers that are very sensitive to the steric crowding caused by the coordination of the pendant arms.

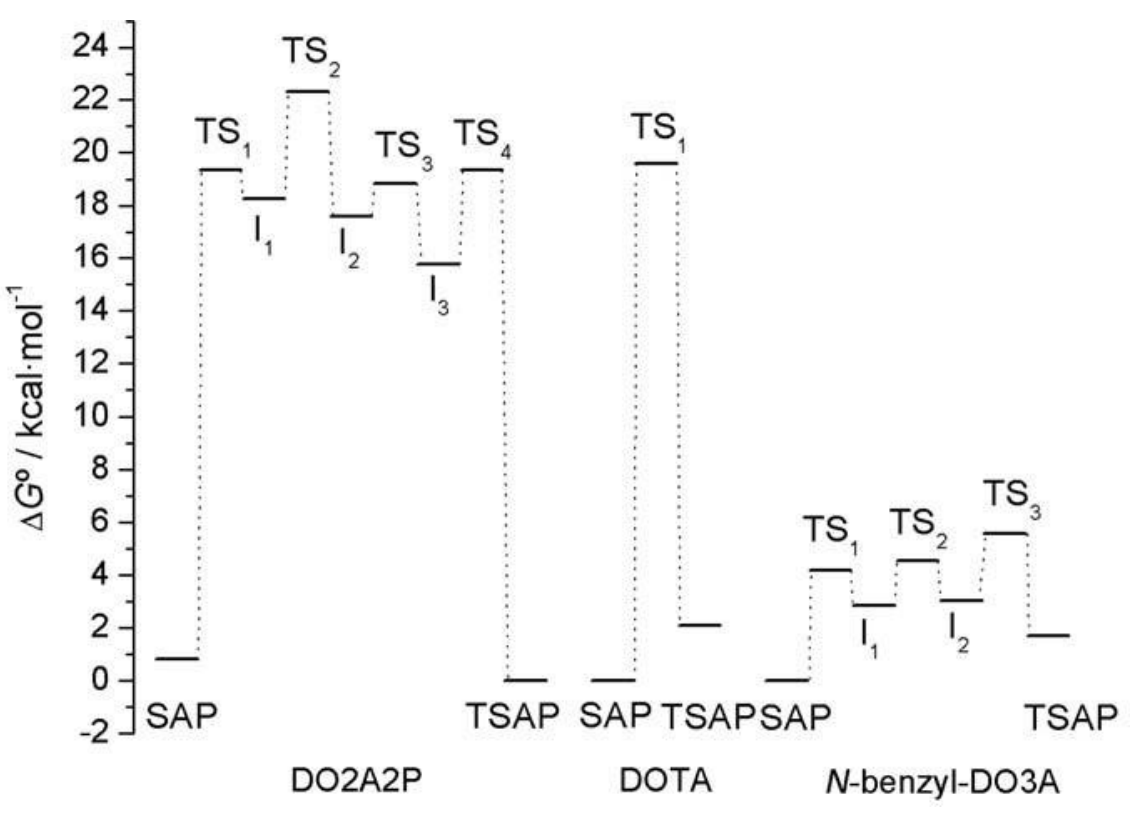

Fig. 8. In vacuo relative free energies of energy minima, intermediates (I) and transition states (TS) involved in the arm rotation processes of $\left[\mathrm{Lu}(N\right.$-benzyl-DO3A $\left.)\left(\mathrm{H}_{2} \mathrm{O}\right)\right]$, [Lu(DOTA) $]^{-}$and [Lu(DO2A2P) $]^{3-}$ complexes $[193,194]$.

The conformational properties of the lanthanide complexes with the macrocyclic ligands bp12c4 [203,204], bp15c5 [205] and bp18c6 [206] (Scheme 2) were investigated by using the same computational approach described above for DOTA-like complexes. The experimental NMR data show that these complexes adopt rigid $C_{2}$ symmetry in solution. A detailed analysis of the conformational properties of the complexes reveals that for $[\operatorname{Ln}(\mathrm{bp} 12 \mathrm{c} 4)]^{+}$complexes there are four possible enantiomeric pairs of diastereoisomers compatible with a $C_{2}$ symmetry: $\Lambda(\lambda \lambda \lambda \lambda), \Delta(\lambda \lambda \lambda \lambda), \Lambda(\delta \lambda \delta \lambda), \Lambda(\lambda \delta \lambda \delta)$ and the corresponding enantiomeric forms $\Delta(\delta \delta \delta \delta), \Lambda(\delta \delta \delta \delta), \Delta(\lambda \delta \lambda \delta)$ and $\Delta(\delta \lambda \delta \lambda)$. Geometry optimizations performed on the [Ln(bp12c4) $\left.\left(\mathrm{H}_{2} \mathrm{O}\right)_{\mathrm{n}}\right]^{+}$ systems ( $\mathrm{n}=1$ or 2 ) in the gas-phase were followed by single point energy calculations in aqueous solution (PCM model). These calculations reveal a structural change occurring close to the centre of the lanthanide series: the complexes of the heaviest $\mathrm{Ln}^{\mathrm{III}}$ ions possess one inner-sphere water molecule and adopt a $\Lambda(\delta \lambda \delta \lambda)$ conformation, while for the largest lanthanides the complexes are ten-coordinated with two inner-sphere water molecules and a $\Delta(\lambda \lambda \lambda \lambda)$ geometry. In the case of the $\left[\mathrm{Yb}(\mathrm{bp} 12 \mathrm{c} 4)\left(\mathrm{H}_{2} \mathrm{O}\right)\right]^{+}$system the conformational analysis performed with DFT calculations was validated by analyzing the $\mathrm{Yb}^{\mathrm{III}}$-induced paramagnetic ${ }^{1} \mathrm{H}$ NMR shifts. Indeed, the binding of a ligand to a paramagnetic $\mathrm{Ln}^{\mathrm{III}}$ ion generally results in large NMR 
frequency shifts at the ligand nuclei, with magnitudes and signs depending on both the nature of the lanthanide ion and the location of the nucleus relative to the metal centre [116]. Thus, the analysis of the NMR spectra of paramagnetic $\mathrm{Ln}^{\mathrm{III}}$ complexes can be used for the validation of the conformational analysis performed with DFT calculations. The hyperfine ${ }^{1} \mathrm{H}$ NMR shifts in $\mathrm{Yb}^{\mathrm{III}}$ complexes are considered to be largely pseudocontact in origin [116], and therefore they can be approximated by using the dipolar model. The dipolar shifts depend on the position of the observed nucleus with respect to $\mathrm{Ln}^{\mathrm{III}}$ at the origin and on the axial $\left[\chi_{z z}-1 / 3\left(\chi_{x x}+\chi_{y y}+\chi_{z z}\right)\right]$ and rhombic $\left(\chi_{x x}-\chi_{y y}\right)$ anisotropies of the magnetic susceptibility tensor $(\chi)$. For the $\left[\mathrm{Yb}(\mathrm{bp} 12 \mathrm{c} 4)\left(\mathrm{H}_{2} \mathrm{O}\right)\right]^{+}$system the excellent agreement between the experimental paramagnetic shifts and those calculated by using the dipolar model and the minimum-energy DFT optimized geometry unambiguously confirms that the complex adopts a $\Lambda(\delta \lambda \delta \lambda)$ conformation in solution [203].

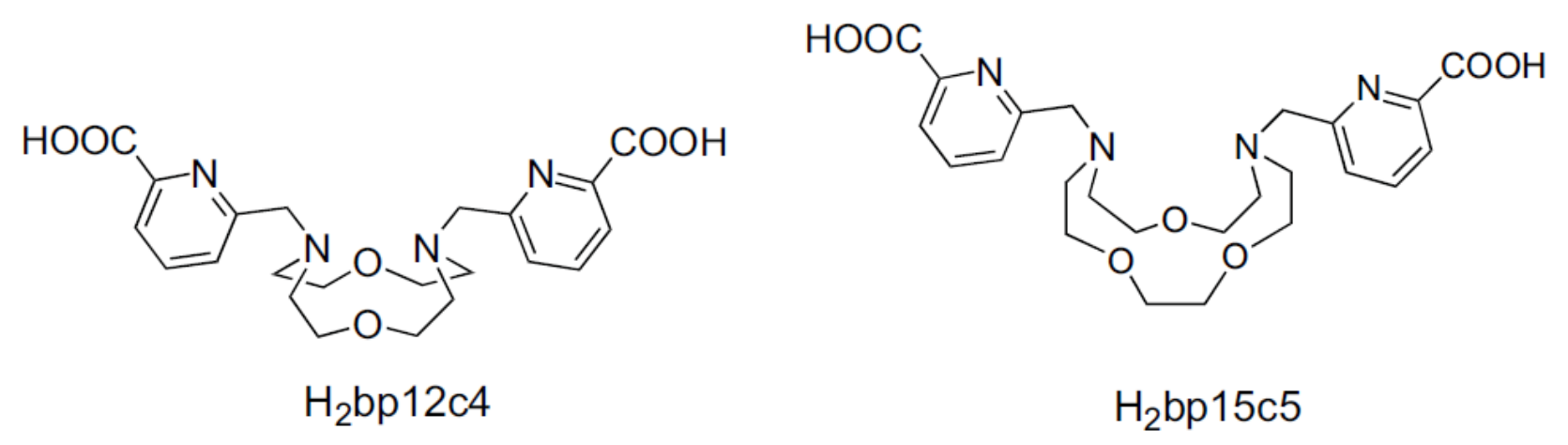<smiles>O=C(O)c1cccc(CN2CCOCCOCCOCCN(Cc3cccc(C(=O)O)n3)COCC2)n1</smiles>

$\mathrm{H}_{2} \mathrm{bp} 18 \mathrm{c} 6$

Scheme 2.

In the case of the [Ln(bp18c6) $]^{+}$complexes the larger number of five-membered chelate rings formed upon coordination of the macrocyclic fragment results in eight possible enantiomeric pairs of diastereoisomers within the $C_{2}$ point group [206]. The subsequent conformational analysis performed by using DFT calculations (PCM calculations on geometries optimized in the gas-phase) pointed again to a structural change along the lanthanide series, the complexes of the largest $\operatorname{Ln}^{\mathrm{III}}$ ions adopting a $\Delta(\delta \lambda \delta)(\delta \lambda \delta)$ conformation, and the complexes of the smallest analogues a $\Delta(\lambda \delta \lambda)(\lambda \delta \lambda)$ one. The analysis of the paramagnetic NMR shifts again confirmed the predictions made by the DFT calculations. Furthermore, the DFT optimized structures for the $[\operatorname{Ln}(\mathrm{bp} 18 \mathrm{c} 6)]^{+}$complexes allowed to rationalize the unprecedented selectivity that bp18c6 shows for the largest lanthanide ions. In both $\Delta(\delta \lambda \delta)(\delta \lambda \delta)$ and $\Delta(\lambda \delta \lambda)(\lambda \delta \lambda)$ conformations, most of the distances between the $\mathrm{Ln}^{\mathrm{III}}$ ions and the donor atoms of the ligand decrease along the lanthanide series, as usually observed for $\mathrm{Ln}^{\mathrm{III}}$ complexes as a consequence of the lanthanide contraction. However, the distances between the $\mathrm{Ln}^{\mathrm{III}}$ ion and the pivotal nitrogen atoms remain nearly unchanged. A similar situation also occurs with the distance between the $\mathrm{Ln}^{\mathrm{III}}$ ion and two of the oxygen atoms of the crown moiety for the $\Delta(\delta \lambda \delta)(\delta \lambda \delta)$ conformation (Fig. 9). Thus, the interaction between the $\mathrm{Ln}^{\mathrm{III}}$ ion and 
several of the donor atoms of bp18c6 is weakened as the ionic radius of the metal ion decreases. This indicates a better match between the binding sites offered by the ligand structure and the binding sites required by large $\mathrm{Ln}^{\mathrm{III}}$ ions, which results in a dramatic drop of the complex stability as the ionic radius of the metal ion decreases. A similar situation was predicted by DFT calculations for the bp $15 \mathrm{c} 5$ complexes, in line with a decreasing stability of the complexes in solution as the ionic radius of the $\mathrm{Ln}^{\mathrm{III}}$ ion decreases [205].

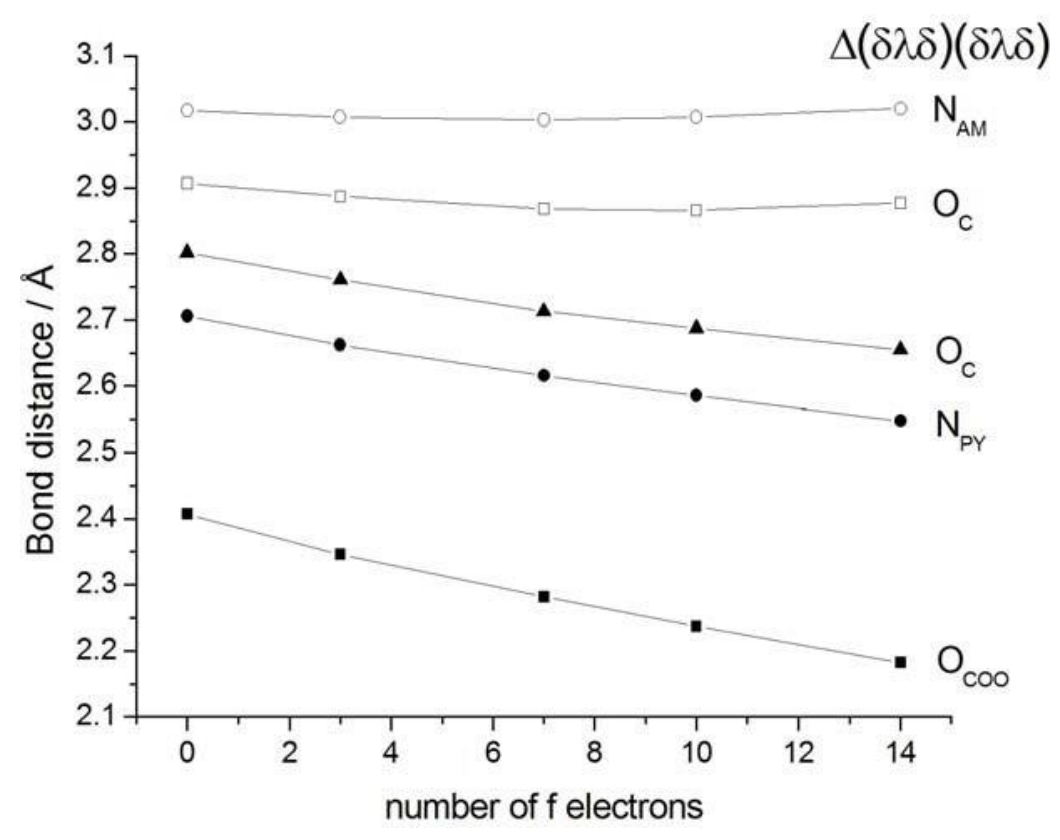

Fig. 9. Variation of the calculated bond distances of the metal coordination environments for $[\operatorname{Ln}(\mathrm{bp} 18 \mathrm{c} 6)]^{+}$complexes $\left(\Delta(\delta \lambda \delta)(\delta \lambda \delta)\right.$ conformation) at the B3LYP/6-31G(d) level (large-core RECP). $\mathrm{N}_{\mathrm{AM}}=$ amine nitrogen atoms; $\mathrm{N}_{\mathrm{PY}}=$ pyridyl nitrogen atoms; $\mathrm{O}_{\mathrm{COO}}=$ carboxylate oxygen atoms; $\mathrm{O}_{\mathrm{C}}=$ crown oxygen atoms. Data taken from Ref. [206].

Large-core RECP investigations at the B3LYP level performed on the lanthanide complexes of EDTMP and $\mathrm{L}^{\mathrm{PY} 6}$ (Scheme 3) provide further examples of successful conformational analysis [207,208]. The $\mathrm{L}^{\text {PY6 }}$ ligand forms two five-membered chelate rings upon coordination of the ethylenediamine moieties that can adopt $\delta$ or $\lambda$ conformations. The $\mathrm{X}$-ray structures showed that in the solid state the $\mathrm{La}^{\mathrm{III}}$ and $\mathrm{Ce}^{\mathrm{III}}$ complexes adopt a $(\delta \lambda)$ conformation, while the complexes of heavier lanthanides ( $\mathrm{Pr}, \mathrm{Gd}, \mathrm{Tb}, \mathrm{Er}$ and $\mathrm{Tm}$ ) show a $(\delta \delta)$ conformation. DFT calculations indeed provided two minimum energy conformations corresponding to the $(\delta \lambda)$ and $(\delta \delta)$ diastereoisomers, and predicted a stabilization of the latter form upon decreasing the ionic radius of the metal ion. The analysis of the $\mathrm{Ln}^{\mathrm{III}}$-induced paramagnetic shifts unambiguously proved that the complexes adopt a $(\delta \delta)$ conformation in solution from $\mathrm{Ce}^{\mathrm{III}}$ to $\mathrm{Yb}^{\mathrm{III}}$. The substitution of the pyridyl pendant arms of the ligand by acetohydrazide pendants provokes an important stabilization of the $(\delta \delta)$ conformation, which is more stable than the $(\delta \lambda)$ one along the whole lanthanide series. These predictions made on the basis of DFT calculations are in line with the solid state structure of the $\mathrm{La}^{\mathrm{III}}$ complex [209]. In the case of the complexes of EDTMP the emission spectrum of the $\mathrm{Eu}^{\mathrm{III}}$ derivative shows two components for the electric dipole transition ${ }^{5} \mathrm{D}_{0} \rightarrow{ }^{7} \mathrm{~F}_{0}$, which suggests the presence of two diastereoisomers in solution [210]. The subsequent conformational analysis performed with B3LYP calculations revealed that these two isomers correspond to the two possible orientations of the five-membered chelate ring formed upon coordination of the ethylenediamine moiety [208]. 
<smiles></smiles>

LPY6

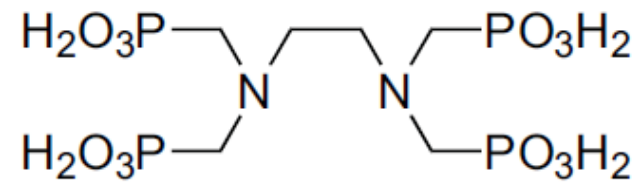

EDTMP

Scheme 3.

\section{Vibrational spectra}

The prediction of harmonical vibrational frequencies with DFT is rather straightforward, and involves the calculation of second derivatives with respect to the nuclear coordinates [40]. Second derivatives are normally used to characterize the stationary points (no imaginary frequencies) or transition states (one imaginary frequency) found in the potential energy surface. However, only a few investigations used calculated frequencies to aid the assignment of the experimental IR spectra and to validate the calculated structures of $\mathrm{Ln}^{\mathrm{III}}$ complexes. In a series of recent works Trendafilova et al. reported DFT investigations of the IR spectra of $\mathrm{Ln}^{\text {III }}$ complexes with warfarin [211], coumarin-3-carboxylic acid [23], 3,3'(benzylidene)bis(4-hydroxy-coumarin) [22], and pyridinomethylene substituted di(4-hydroxycoumarin) derivatives [212]. In these calculations they used hybrid DFT (B3LYP) in combination with the large-core RECP of Dolg et al. [47]. After introducing a scaling factor of ca. 0.96 the calculated frequencies showed a good agreement with the experimental data, which allowed for a detailed assignment of the experimental spectra. The coordination mode of the ligand could also be inferred by comparing the experimental spectra with those calculated for different model species. B3LYP calculations on the $\mathrm{Ln}^{\mathrm{III}}$ complexes of 3-bromo-4methoxy-2,6-lutidine $N$-oxide were shown to reproduce reasonably well the experimental solid state structures and IR and Raman spectra, although an scaling factor of 0.91 had to be used to fit the calculated and experimental wavenumbers [213]. A similar investigation performed on lanthanide(III) complexes of 5aminoorotic acid allowed to establish a bidentate coordination of the carboxylate group of the ligand by comparing the experimental and calculated IR and Raman spectra [214]. Finally, a DFT investigation including the $4 \mathrm{f}$ electrons in the valence space, in combination with the ZORA approach, was used to investigate the vibrational spectra of lanthanide triflates $\mathrm{Ln}(\mathrm{OTf})_{3}(\mathrm{Ln}=\mathrm{La}, \mathrm{Ce}, \mathrm{Nd}, \mathrm{Eu}, \mathrm{Gd}, \mathrm{Er}, \mathrm{Yb}$ or $\mathrm{Lu})$. These studies concluded that the complexes are six-coordinated with a trigonal prismatic coordination around the lanthanide ion, and that the $4 \mathrm{f}$ orbitals do not participate significantly in bonding [215]. 


\section{Photophysical properties}

Lanthanide(III) complexes may act as light converter molecular devices, as they can absorb UV (or visible) light and emit radiation in the visible or near-infrared spectral regions. The lowest excited states of $\mathrm{Ln}^{\mathrm{III}}$ ions imply the reorganization of electrons within the $4 \mathrm{f}$ shell. However, the $\mathrm{f}$ - $\mathrm{f}$ transitions are parity forbidden (Laporte's rule) and possess very low absorption coefficients (typically lower than $10 \mathrm{dm}^{3} \mathrm{~mol}^{-1} \mathrm{~cm}^{-1}$ ) [216]. Therefore a direct excitation of the $\mathrm{Ln}^{\mathrm{III}}$ ions through their $\mathrm{f}-\mathrm{f}$ transitions represents a very inefficient path for the population of excited states. This limitation is overcome by taking advantage of the so called "antenna effect" [217], which is summarized in the form of a Jablonski diagram in Fig. 10. The ligands play an important double role in luminescent $\mathrm{Ln}^{\mathrm{III}}$ complexes: i) they collect the photons provided by the light source and allow an efficient energy transfer to the emitting levels of the particular lanthanide ion, and ii) they must provide an adequate protection of the $\mathrm{Ln}^{\mathrm{III}}$ from the environment to minimize quenching processes, particularly the vibrational quenching effect of $\mathrm{O}-\mathrm{H}$ oscillators of coordinated water molecules [218]. The energy absorbed by the ligand populates the ligand-centered singlet excited state $\left(\mathrm{S}_{1}\right)$, which in turn populates the ligand-centered excited triplet state via intersystem-crossing (ISC). The emitting level of the lanthanide ion is populated through an energy transfer (ET) from the ligand-centered triplet and/or singlet excited states. It has been shown experimentally that a correlation exists between the energy of the lowest triplet state energy of the ligand $\left(T_{1}\right)$ and the luminescence quantum yield [217]. However, other factors such as the presence of low-lying ligand to metal charge transfer (LMCT) states are known to play an important role in quenching the metal lanthanide centered luminescence, particularly in the case of Eu ${ }^{\text {III }}$ complexes [219]. Furthermore, the energy gap between the ligand centered excited singlet and triplet states was also shown to affect the efficiency of the ISC process, an optimum minimum gap of $5000 \mathrm{~cm}^{-1}$ being required to generate a sizeable ISC [220].

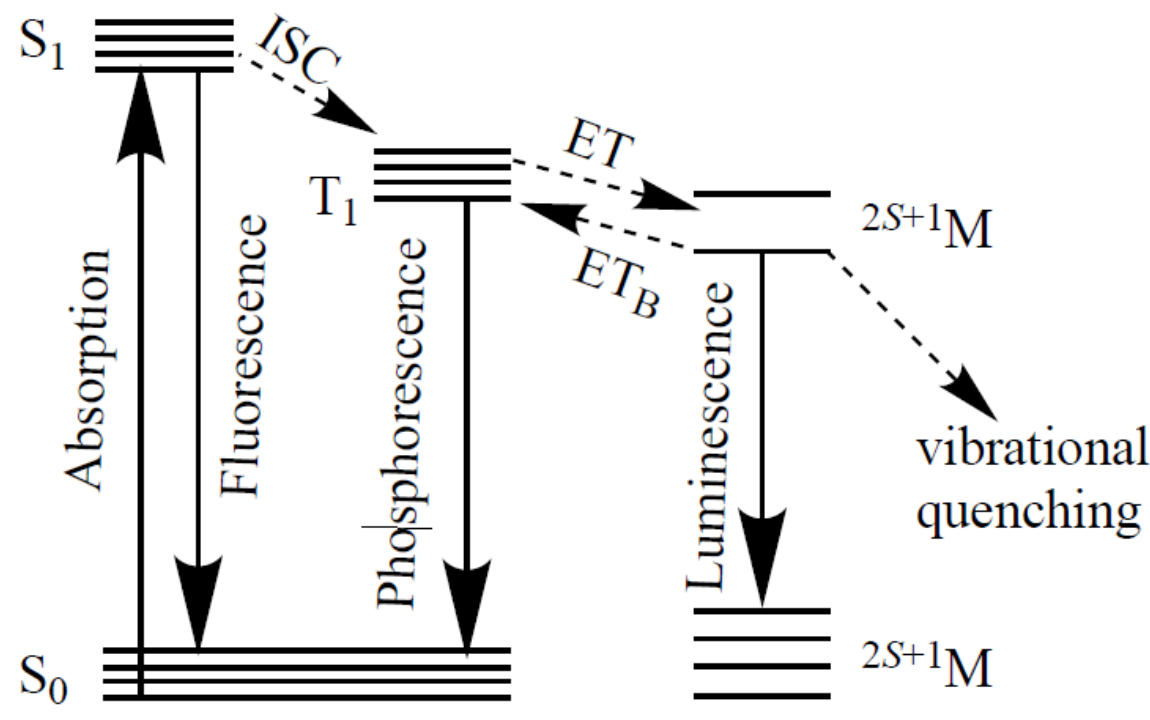

Fig. 10. Photophysical pathways in $\mathrm{Ln}^{\mathrm{III}}$ complexes.

In spite of the great interest and wide range of applications of luminescent lanthanide complexes, theoretical inves tigations are very much behind the experimental knowledge, and only a relatively small number of theoretical studies have been reported in the literature. However, theoretical approaches can be useful to rationalize the different photophysical pathways involved in their optical activity, as well as to provide a general way to screen antenna ligands. Excited state calculations on lanthanide(III) complexes have been 
mostly performed using semi-empirical calculations, in particular combining the sparkle model with the INDO/S-CI approach [221,222]. In recent years time-dependent density functional theory (TDDFT) has emerged as an accurate method for the calculation of excited state properties of molecules [223-225]. Because of the low computational cost, TDDFT is applicable to relatively large systems for which traditional wavefunction-based methods are not feasible. Thus, TDDFT appears to be an excellent approach for investigating the excited states of lanthanide(III) complexes. The main limitation of TDDFT calculations using simple exchange correlation functionals is that they can yield substantial errors when estimating the excitation energy of charge transfer type transitions [226]. However, in other instances the energies of charge-transfer excited singlet and triplet states were found however to be in good agreement with the experiment [227]. Another important drawback of TDDFT is that double- or higher-excitations cannot be modelled by adiabatic TDDFT, while it has been stated that explicit many electron excitations are needed for a proper description of excitations of molecules with open-shell ground states [228]. Therefore, most of the TDDFT studies applied to $\mathrm{Ln}^{\mathrm{III}}$ complexes have been focused in the investigation of ligand-centred excited states, either by using "large-core" RECPs to describe the $\mathrm{Ln}^{\mathrm{III}}$ ions or by performing calculations on simplified models in which $\mathrm{Ln}^{\mathrm{III}}$ ions are not present.

The structure and absorption spectra of several $\mathrm{Ln}^{\mathrm{III}}$-Texaphyrins (Scheme 4) were investigated by Dolg et al. [229] by using B3LYP/TDB3LYP calculations in combination with the pseudopotential method (4f-incore RECP). The calculated structures showed a reasonably good agreement with the experimental X-ray strucures [230]. Furthermore, TDB3LYP calculations predicted two absorption bands in the excitation spectra at 454-462 and 681-686 nm, which fit well with the experimental absorption spectra [231].

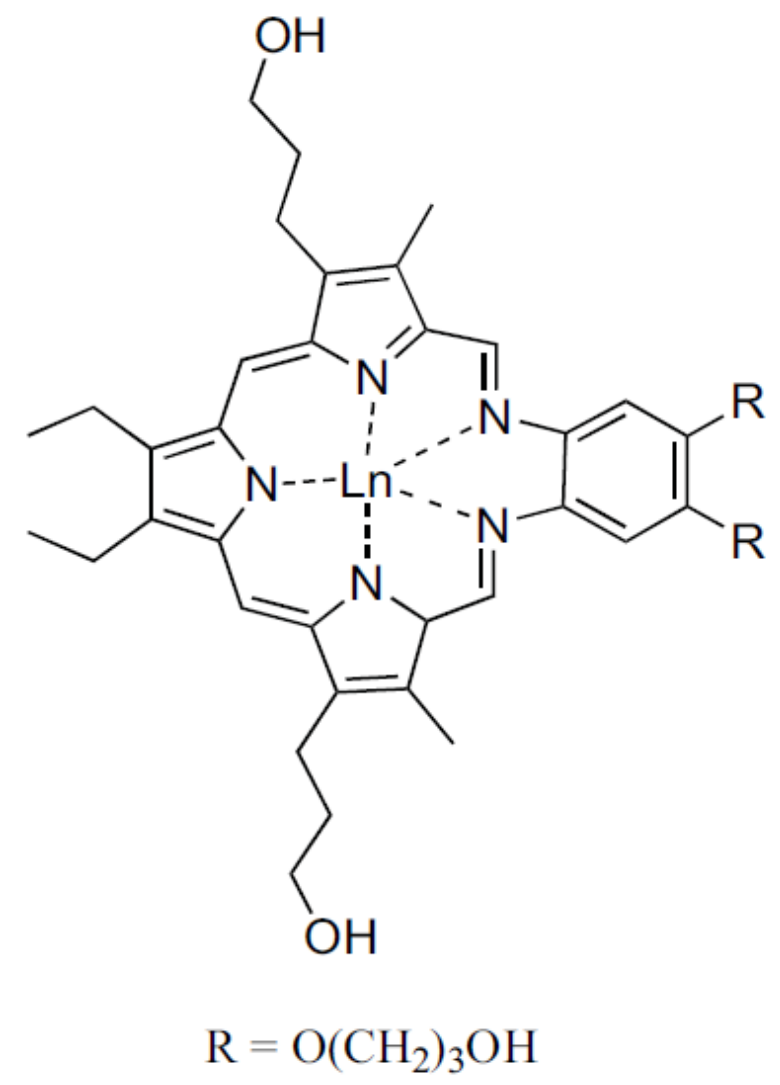

Scheme 4. 
TDDFT calculations were used to investigate the absorption spectra of complexes with formula $\left[\mathrm{LnL}\left(\mathrm{H}_{2} \mathrm{O}\right)_{\mathrm{n}}\right]^{3+}$, where L stands for the tridentate ligands shown in Scheme 5, and $\mathrm{n}$ equals 5 or 6 [232]. In these calculations the authors used a large-core RECP and associated valence basis set for the lanthanides and the standard 6-31G(d) basis set for the remaining atoms. The TDDFT calculations were performed using the LDA or B3LYP functionals on the HF-optimized structures of the ground state. TD-LDA calculations showed various discrepancies between theory and experiment coming from the intensity ratio between excitations. In contrast, TD-B3LYP calculations provided calculated spectra in reasobably good agreement with the experimental ones.<smiles>c1ccc(-c2cccc(-c3ccccn3)n2)nc1</smiles>

Tpy<smiles>c1cnc(-c2ccnc(-c3nccnn3)n2)nn1</smiles>

Btp<smiles>Nc1nc(-c2ccccn2)nc(-c2ccccn2)n1</smiles>

Adptz<smiles>c1ccc(-c2nc(-c3ccccn3)nc(-c3ccccn3)n2)nc1</smiles>

Tptz

Scheme 5.

Piguet et al. [233] investigated the photophysical properties of nine-coordinated $\mathrm{Ln}^{\mathrm{III}}$ podates by using both experimental and theoretical tools. The absolute quantum yield for the $\mathrm{Eu}^{\mathrm{III}}$ analogue measured in water was determined to be quite low $\left(\Phi_{\mathrm{Eu}}{ }^{\text {tot }}=1.8 \times 10^{-3}\right)$, in contrast with that obtained for the luminescence step $\left(\Phi_{\mathrm{Eu}}\right.$ $=0.28$ ). TDDFT calculations performed on simplified models of the ligand indicated that this effect can be attributed to a low energy gap between the excited singlet and triplet states of the ligand, which strongly limits the efficiency of the ${ }^{1} \pi \pi^{*} \rightarrow{ }^{3} \pi \pi$ intersystem crossing (ISC, Fig. 10).

Raymond et al. developped an approach based on DFT/TDDFT calculations (B3LYP/6-311G++(d,p)) to predict absorption and emission properties of $\mathrm{Ln}^{\mathrm{III}}$ complexes with ligands containing the 2hydroxyisophthalamide (IAM), 1-hydroxypyridin-2-one (1,2-HOPO) and 1-methyl-3-hydroxy-pyridin-2-one (Me-3,2-HOPO) chromophores (Scheme 6) [234-239]. This approach involved the replacement of the $\mathrm{Ln}^{\mathrm{III}}$ ion by a $\mathrm{Na}^{+}$cation adopting a bidentate chelating mode for the oxygen atoms in order to mirror the binding 
mode of the lanthanide. While being a crude model, this method has been shown to be quite useful as a tool to understand the electronic structure of the chromophore and to approximate the lowest excited singlet and triplet states of the ligand. Indeed, the energies of the ligand-centred singlet and triplet excited states obtained from these calculations agree (within ca. 5\%) with the experimentally determined absorption maxima and triplet state energies, thereby allowing a quick and accurate assessment of the photophysical properties of potential antenna chromophores prior to ligand synthesis. TDDFT calculations performed on these model systems revealed a $\pi \rightarrow \pi^{*}$ character of the low-lying excited singlet and triplet states. Recently Raymond et al. [240] reported the photophysical properties of $\mathrm{Tb}^{\mathrm{III}}$ complexes with para-substituted 2hydroxyisophthalamide ligands to probe the effect of the substituents on the ligand- and metal-centred luminescence, and establish a method for predicting the effects of chromophore modification on $\mathrm{Tb}^{\mathrm{III}}$ luminescence. The same approach described above involving the replacement of the lanthanide by a $\mathrm{Na}^{+}$ cation provided singlet and triplet state energies in good agreement with the experimental data (Fig. 11). Furthermore, a good correlation was found between the energy of the ligand triplet state and the $\mathrm{Tb}^{\text {III }}$ emission quantum yields determined experimentally.

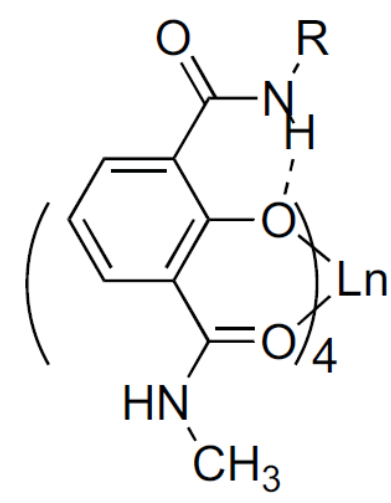

IAM<smiles>[R]NC(=O)c1cccc(=O)n1OCC([R4])C</smiles>

1,2-HOPO<smiles>[R]NC(=O)c1cccc(OCC)c1OCC(C)C</smiles>

Me-3,2-HOPO

\section{Scheme 6.}

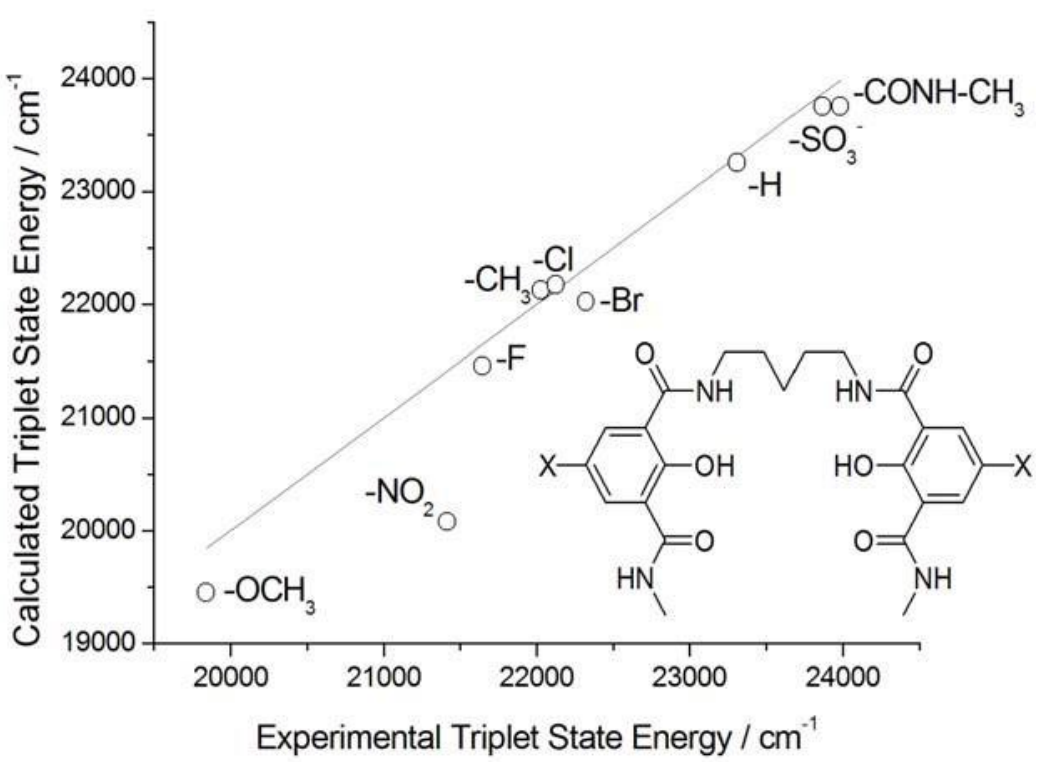

Fig. 11. Correlation between the experimental and TDDFT calculated triplet state energies in Tb ${ }^{\mathrm{III}}$ complexes with parasubstituted 2-hydroxyisophthalamide ligands ( $\mathrm{X}=\mathrm{CH}_{3}, \mathrm{NO}_{2}, \mathrm{~F}, \mathrm{OCH}_{3}, \mathrm{Cl}, \mathrm{Br}, \mathrm{H}, \mathrm{SO}_{3}^{-}$or $\mathrm{CONHCH}_{3}$ ). The solid line represents a perfect match between experimental and calculated values. Data taken from Ref. [240]. 
Picard et al. [241] applied DFT and TDDFT calculations to investigate the relation between the triplet state energy and luminescence properties of hydroxamate complexes with the ligands shown in Scheme 7. These ligands form, upon deprotonation, complexes of general formula $\left[\mathrm{TbL}_{3}\left(\mathrm{H}_{2} \mathrm{O}\right)_{2}\right]$, with $\mathrm{L}=\mathrm{I}$, II, III or IV. The geometrical features and energies of the ligand-centred excited triplet state of the complexes were studied by using the large-core RECP of the Sttutgart group for Tb and the B3LYP functional. The $\triangle$ SCF approach was used to investigate the energy of the triplet state. In this approach, the excitation energy is given as the difference of the ground state energy and the excited state energy determined from two independent calculations, as it is possible to perform geometry optimizations of a given system in its lowest triplet state with the aid of unrestricted calculations. These computations were shown to provide good estimates of the triplet state energy, which was determined experimentally from the emission spectra of the corresponding $\mathrm{Gd}^{\mathrm{III}}$ analogues at $77 \mathrm{~K}$. The $\alpha$ - and $\beta$-Kohn-Sham MOs provided by unrestricted DFT calculations do not allow to describe the lowest-energy triplet state with respect to the ground state in terms of single or several transitions between MOs. Thus, TDDFT calculations were performed in order to get an analysis of the triplet state wavefunctions in terms of electron excitations. Their results showed that the triplet state may be described in terms of the HOMO and LUMO orbitals. In a subsequent paper, these authors showed that the $\triangle \mathrm{SCF}$ approach applied to a crude model such as $\mathrm{NaL}$ (in which the $\mathrm{Ln}^{\mathrm{III}}$ ion is replaced by a $\mathrm{Na}^{+}$cation), reproduce the relative energies of the excited triplet state for the ligand series investigated. However, the energies of the triplet states calculated with the NaL model were found to be stabilized with respect to the experimental value observed for the Tb complex by ca. $2500 \mathrm{~cm}^{-1}$, which was attributed to a decreased electrostatic interaction between the ligand and the metal ion in the NaL model [242].

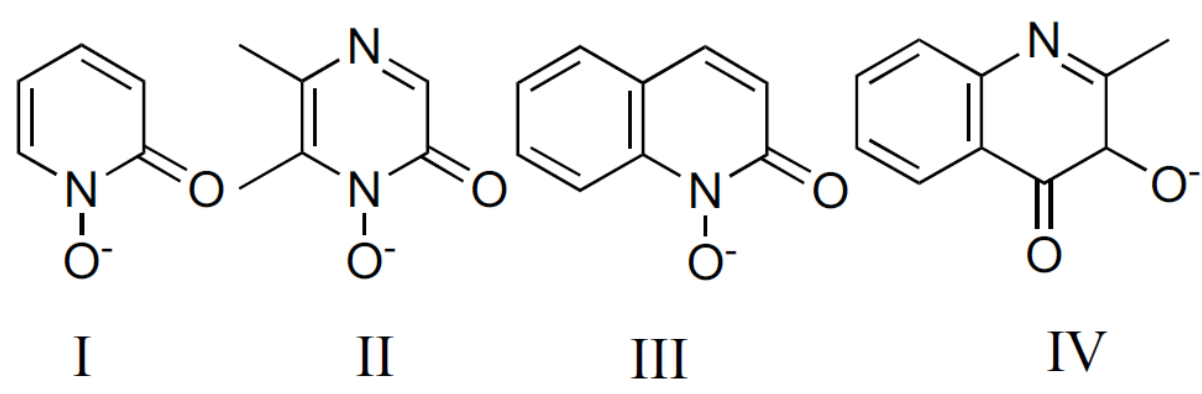

Scheme 7.

Following the work of Picard [241], other authors employed succesfully B3LYP and TD-B3LYP calculations, in combination with large-core RECPs, to investigate different lanthanide complexes. For instance, this approach was used to investigate the absorption spectra of different $\mathrm{Eu}^{\text {III }}$ and $\mathrm{Gd}^{\text {III }}$ trisbipyridine cryptates [243]. TDDFT calculations provided absorption spectra for these complexes in nice agreement with the experiment. Furthermore, $\triangle \mathrm{SCF}$ calculations gave excited triplet state energies in very good agreement with the experimental values obtained from emission spectra, while TDDFT triplet state energies, which correspond to vertical energies, were sistemmatically higher than the $\triangle \mathrm{SCF}$ ones. However, both approaches give a similar evolution of the triplet state energy within this series of related complexes and agree correcly with experimental data. Analogous B3LYP and TD-B3LYP calculations were shown to provide good results for $\mathrm{Eu}^{\mathrm{III}}$ and $\mathrm{Tb}^{\mathrm{III}}$ mixed complexes of $\beta$-diketonates and phosphine oxides [244,245], and $\mathrm{Eu}^{\mathrm{III}}$ and $\mathrm{Tb}^{\mathrm{III}}$ complexes with 2,2'-bipyridine [246]. In the latter case a charge-transfer state induced by $\pi$-stacking interactions could be identified in addition to the classical ligand-to-europium charge transfer state. These two states were shown to fall between the singlet and triplet states of the ligands, thereby facilitating the energy migration from the singlet to the triplet state and eventually to the excited Eu states. A recent investigation on $\mathrm{Tb}^{\mathrm{III}} \beta$-diketonate complexes showed that the energy difference between the excited 
triplet state and the ${ }^{5} \mathrm{D}_{4}$ level of $\mathrm{Tb}^{\mathrm{III}}\left(20400 \mathrm{~cm}^{-1}\right)$ calculated by using TD-B3LYP calculations correlated nicely with the experimental quantum yields.[247] B3LYP and TD-B3LYP calculations in combination with the LANL2DZ basis set was shown to provide an accurate description of the molecular structures, molecular orbitals, atomic charges, UV-vis, IR and Raman spectra of bis(phthalocyaninato) La ${ }^{\mathrm{III}}$ and $\mathrm{Y}^{\mathrm{III}}$ complexes [248].

Hess and co. [186] performed DFT calculations (B3LYP, large-core RECP) on Eu ${ }^{\mathrm{III}}$ complexes with DOTA and DO3A-substituted ligands containing different pendant arms. Subsequently, the physical environment of the metal ion was investigated by calculating charge density maps that were translated into the numerical values of the crystal field parameters that define the crystal field potential influencing the lanthanide ion. These investigations concluded that the antenna attached to the DO3A cage does not perturb the physical environment of the $\mathrm{Eu}^{\mathrm{III}}$ ion when compared to the parent DOTA system. Large-core RECP based B3LYP calculations were also used to investigate the energy transfer process in the $\mathrm{Er}^{\mathrm{III}}$ tris(8-quinolinolate) complex. This study showed that different ligand $\mathrm{C}-\mathrm{H}$ vibrations contribute to the quenching of the $\mathrm{Er}^{\mathrm{III}}$ luminescence, the calculated emission lifetime being in good agreement with the experimental value [249]. Finally, TDDFT calculations including the $4 \mathrm{f}$ electrons in the valence space were successfully used to calculate the absorption spectra $\mathrm{Ln}^{\mathrm{III}}$ mono- and bisporphyrin complexes [250], and $\mathrm{Lu}^{\mathrm{III}}$ bisphthalocyanines [251].

\section{NMR shifts and nuclear spin relaxation parameters}

It has been shown that the theoretical calculation of NMR chemical shifts can be used to aid the experimental assignments as well as for structure validation of both organic molecules [252] and coordination compounds [253-256]. In the particular case of $\mathrm{Ln}^{\mathrm{III}}$ complexes, several DFT investigations [190,257,258] have shown that the ${ }^{13} \mathrm{C}$ NMR chemical shifts of diamagnetic $\mathrm{La}^{\mathrm{III}}$ and $\mathrm{Lu}^{\mathrm{III}}$ complexes can be calculated to a good accuracy by using the Gauge Invariant Atomic Orbital (GIAO) method [259,260]. For the $\mathrm{Lu}^{\mathrm{III}}$ complexes, it has been reported that the calculation of NMR shielding constants using the $46+4 \mathrm{f}^{14}$ large core RECP of Dolg el al. [47] provides inconsistent ${ }^{13} \mathrm{C}$ NMR chemical shifts [190], while the RECP of Stevens et al., [46] which leaves the $4 \mathrm{f}^{14}$ electrons in the valence space, gives results in good agreement with experimental values [258]. B3LYP/ 6-311G(d,p) calculations of the NMR shielding constants of a La ${ }^{\text {III }}$ chelate containing picolinate units provided chemical shift values in good agreement with the experiment, while analogous calculations performed at the HF/6-311G(d,p) level resulted in a poor agreement between the experimental and calculated shifts, which highlights the importance of including electron correlation in these calculations [261].

The calculation of ${ }^{13} \mathrm{C}$ NMR chemical shifts was used to validate the structure in solution of the $\mathrm{La}^{\mathrm{III}}$ and $\mathrm{Lu}^{\mathrm{III}}$ complexes of DO2A2P (Scheme 1). The ${ }^{13} \mathrm{C}$ NMR shifts calculated for the TSAP conformation of the complexes at the B3LYP/6-311G(d,p) level provide a much better agreement with the experimental values than those obtained for the SAP form. This is clearly confirmed by Fig. 12, which shows the differences between experimental and theoretical ${ }^{13} \mathrm{C}$ NMR shift values $(\Delta \delta)$ for the SAP and TSAP isomers of $[\mathrm{Lu}(\mathrm{DO} 2 \mathrm{~A} 2 \mathrm{P})]^{3-}$. There are larger deviations from the experimental values for all carbon nuclei of the SAP form than for the same nuclei of the TSAP one, thereby confirming that these complexes adopt a TSAP conformation in solution. This investigation confirmed that DFT calculations, in combination with the GIAO approach, can be used for structure validation of DOTA-like complexes in solution.

Helm and Yazyev have recently reviewed their own work devoted to the calculation of nuclear spin relaxation parameters in $\mathrm{Gd}^{\mathrm{III}}$ complexes [262], an important issue to understand the physicochemical parameters that determine the efficiency of MRI contrast agents [2]. They investigated the hyperfine interactions of ${ }^{1} \mathrm{H}$ and ${ }^{17} \mathrm{O}$ nuclei of inner-sphere water molecules in $\mathrm{Gd}^{\mathrm{III}}$ complexes $[68,166]$. Hyperfine 
interactions are interactions between the nuclear and electron spins, and are responsible for the shift of the NMR frequency and enhancement of the nuclear spin relaxation in water molecules coordinated to the paramagnetic $\mathrm{Gd}^{\mathrm{III}}$ ion. The approach used to calculate the hyperfine interactions involved either classical or Car-Parrinello molecular dynamics simulations. From the trajectories of these simulations, clusters of molecules were extracted, and then investigated by using DFT calculations with either pure (BPW91) or hybrid (B3PW91) functionals. In these calculations all-electron basis sets were used for Gd in combination with the ZORA or DKH2 approaches to account for relativistic effects. The hyperfine coupling constants between $\mathrm{Gd}^{\mathrm{III}}$ and bound water molecules obtained for $\left[\mathrm{Gd}\left(\mathrm{H}_{2} \mathrm{O}\right)_{8}\right]^{3+}$ and $\left[\mathrm{Gd}(\mathrm{DOTA})\left(\mathrm{H}_{2} \mathrm{O}\right)\right]^{-}$showed that the scalar relaxation mechanism to ${ }^{1} \mathrm{H}$ relaxation can be safely neglected. In the case of ${ }^{17} \mathrm{O}$ nuclei, their calculations provided hyperfine coupling constants in good agreement with the experimental values. A similar methodology was subsequently applied for the investigation of the quadrupolar relaxation mechanism responsible for the longitudinal NMR relaxation of ${ }^{17} \mathrm{O}$ nuclei of water molecules coordinated to $\mathrm{Gd}^{\mathrm{III}}$ [263]. The results obtained led to the conclusion that the quadrupole coupling parameter changes only slightly upon binding of the water molecule to the $\mathrm{Gd}^{\mathrm{III}}$ ion, the value calculated for $\left[\mathrm{Gd}(\mathrm{DOTA})\left(\mathrm{H}_{2} \mathrm{O}\right)\right]^{-}$being very similar to that obtained for neat water.

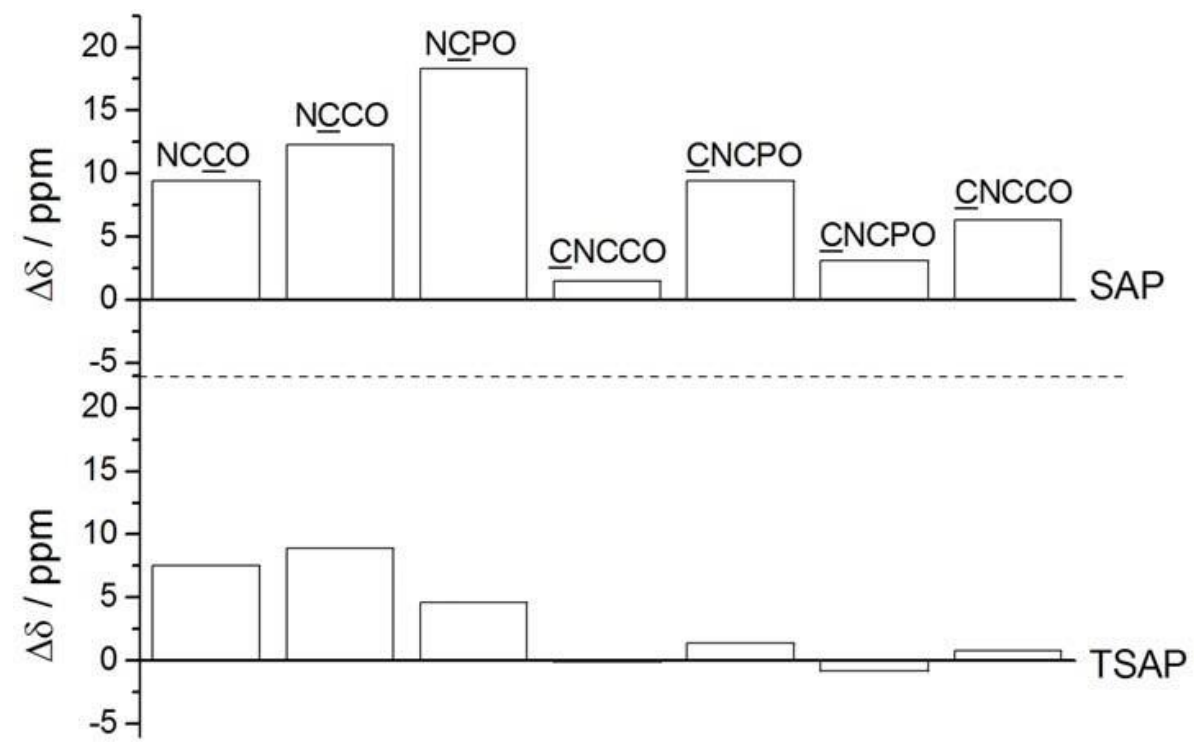

Fig. 12. Differences between experimental and theoretical ${ }^{13} \mathrm{C}$ NMR chemical shifts (B3LYP/6-311G(d,p); small-core RECP[46]) for the SAP and TSAP conformations of [Lu(DO2A2P)] ${ }^{3-}$. Redrawn from Ref. [193].

\section{Magnetic properties}

Theoretical methods based on DFT calculations have been successfully employed to calculate exchange coupling constants in dinuclear and polynuclear transition metal complexes [264]. These studies provided calculated values in very good agreement with the experimental values, particularly when hybrid exchange correlation functionals were used [265,266]. Despite of the extensive experimental data available on $\mathrm{d} / \mathrm{f}$ complexes [267-270], only a few theoretical investigations have been reported to date, probably due to the difficulty to handle spin-orbit effects in relatively large complexes. Most of the experimental and theoretical investigations of the magnetic properties of dinuclear and polynuclear lanthanide complexes were devoted to $\mathrm{Gd}^{\mathrm{III}}$ complexes. This is because $\mathrm{Gd}^{\mathrm{III}}$ presents the largest possible magnetic moment $(S=7 / 2)$, and it lacks of an important orbital contribution that facilitates the analysis of the magnetic properties. Ferbinteanu et al. 
have investigated the magnetic properties of $\mathrm{Gd}^{\mathrm{III}} \mathrm{Cu}^{\mathrm{II}}$ and $\mathrm{Dy}{ }^{\mathrm{III}} \mathrm{Fe}^{\mathrm{III}}$ systems by using CASSCF calculations combined with spin-orbit terms [271,272], However, such calculations can be hardly applied to large polynuclear complexes, which could be however handled with DFT calculations.

In a pioneering work Yan et al. [273] studied the exchange coupling and the spin distributions in three $\mathrm{MGd}^{\mathrm{III}}$ complexes $\left(\mathrm{M}=\mathrm{Cu}^{\mathrm{II}}, \mathrm{Fe}^{\mathrm{III}}\right.$ and $\left.\mathrm{Cr}^{\mathrm{III}}\right)$ using DFT methods and the broken symmetry approach [274], which allows to calculate exchange couplings from the energy difference between the low-spin wavefunction and the state with the highest spin. These calculations predicted the correct sign for the coupling constant $J$ characterizing the ferromagnetic coupling in these systems, but the quantitative agreement between the calculated and experimental values was rather poor. More recently, Ruiz and Cirera [275] reported a DFT study using relativistic approaches to investigate the magnetic properties of heterodinuclear $\mathrm{Gd}^{\mathrm{III}} \mathrm{Cu}^{\mathrm{II}}$ complexes. The authors concluded that the inclusion of scalar relativistic effects, by using either the ZORA or DKH approximations, plays a crucial role to reproduce correctly the sign characterizing the ferromagnetic interaction. Indeed, their B3LYP calculations by using the small core quasi-relativistic pseudopotential proposed by Dolg et al. [48] did not reproduce the correct sign of the interaction. However, Rajaraman et al. [276] employed successfully DFT methods in combination with shape-consistent RECPs of Stevens et al. [46] for $\mathrm{Gd}$ to calculate the exchange coupling constant for the dinuclear $\mathrm{Gd}^{\mathrm{III}} \mathrm{Cu}^{\mathrm{II}}$ complex $\left[\mathrm{L}^{1} \mathrm{CuGd}\left(\mathrm{O}_{2} \mathrm{CCF}_{3}\right)_{3}\left(\mathrm{C}_{2} \mathrm{H}_{5} \mathrm{OH}\right)_{2}\right]$ (where $\mathrm{L}^{1} \quad$ is $\quad N, N^{\prime}$-bis(3-ethoxysalicylidene)-1,2-diamino-2-methylpropanato]. These authors used a number of GGA, meta-GGA and hybrid functionals with varying percentages of HF exchange (Fig. 13). Their results showed that the magnitude of $J$ decreases when the percentage of HF exchange increases independent of the nature of the exchange and correlation functionals employed, both hybrid (e. g. B3LYP) and half-and-half (e. g. BHandH) functionals providing satisfactory results. The $5 \mathrm{~d}$ orbitals of $\mathrm{Gd}^{\mathrm{III}}$ appear to have a predominant role on the coupling, as they gain density via the charge transfer from the $3 \mathrm{~d}$ counterpart and the half filled $4 \mathrm{f}$ orbitals.

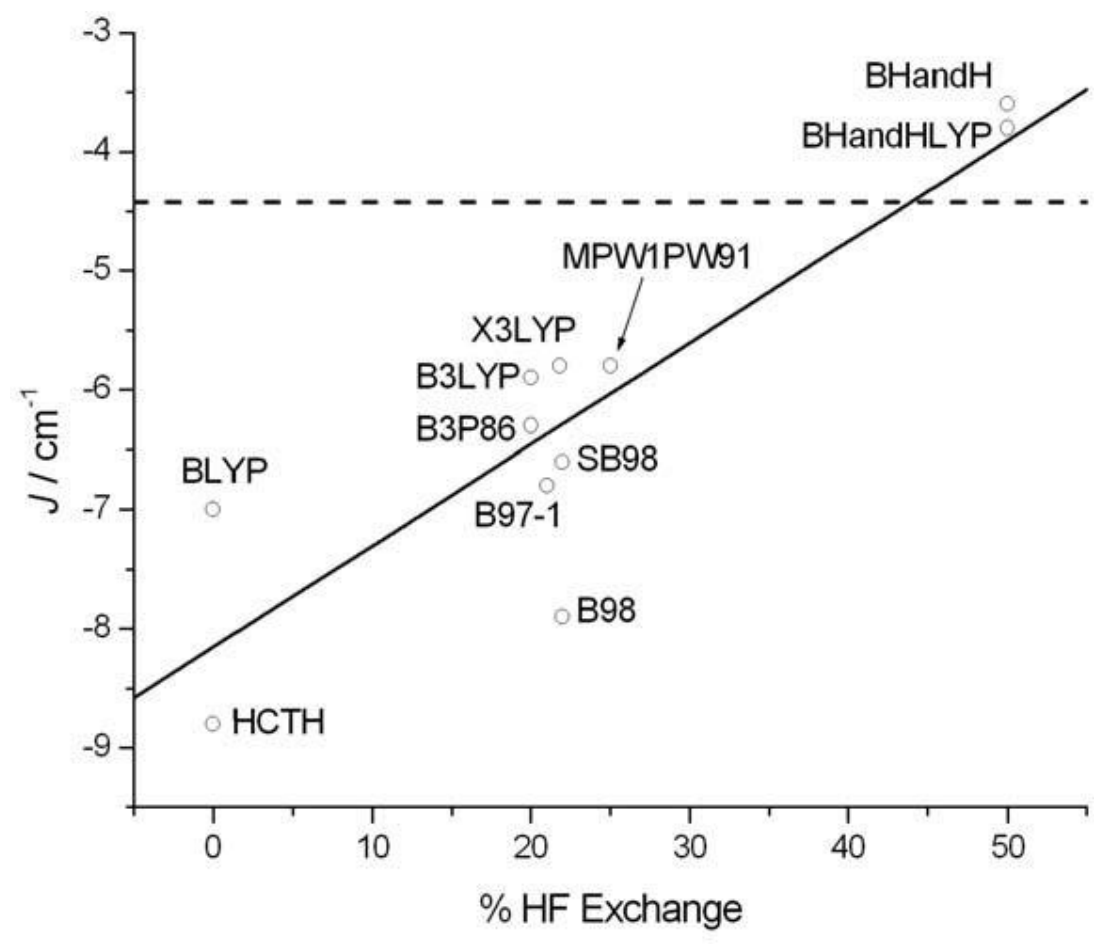

Fig. 13. DFT computed $J$ values obtained with different functionals for $\left[\mathrm{L}^{1} \mathrm{CuGd}\left(\mathrm{O}_{2} \mathrm{CCF}_{3}\right)_{3}\left(\mathrm{C}_{2} \mathrm{H}_{5} \mathrm{OH}\right)_{2}\right]$ as a function of the percentage of $\mathrm{HF}$ exchange. The solid line represents the linear fit of the data, while the dashed line indicates the experimental value $\left(-4.42 \mathrm{~cm}^{-1}, \hat{H}=J \hat{S}_{G d} \cdot \hat{S}_{C u}\right)$. Data taken from Ref. [276]. 
DFT calculations in combination with the RECP approach was used to investigate the relative energy between the different spin states in photomagnetic heterometallic complexes $\left[\mathrm{M}(\mathrm{dmf})_{4}\left(\mathrm{H}_{2} \mathrm{O}\right)_{3}(\mu-\right.$ $\left.\mathrm{CN}) \mathrm{Fe}(\mathrm{CN})_{5}\right] \cdot \mathrm{H}_{2} \mathrm{O}(\mathrm{M}=\mathrm{Nd}, \mathrm{La}, \mathrm{Gd}, \mathrm{Y})$. These calculations suggested that $\mathrm{UV}$ illumination gives a charge transfer from the cyano groups on the iron atom to the lanthanide ion moiety. This is accompanied by a reorganization of the spin state of the $\mathrm{Fe}(\mathrm{CN})_{6}$ unit that accounts for the increased magnetic susceptibility upon illumination with UV light [277]. Pseudopotential calculations in combination with the B3LYP model were also successfully employed to investigate the phosphine-mediated antiferromagnetic coupling in heterobimetallic $\mathrm{Ln}^{\mathrm{III}}-\mathrm{Co}^{\mathrm{II}}$ complexes [278].

\section{Conclusions and outlook}

In this contribution we have shown that DFT calculations represent a powerful tool to investigate the structure, spectroscopic and magnetic properties of lanthanide(III) coordination compounds. DFT methods have matured to a point where the investigation of many chemical properties associated to $\mathrm{Ln}^{\mathrm{III}}$ complexes can be performed on a routine basis. From the data reported in the literature it appears that the $4 \mathrm{f}$ electrons do not participate significantly in bonding, and therefore for many applications do not need to be explicitly included in the valence space. Quasirelativistic f-in-core pseudopotentials can be therefore used for the investigation of the structure, dynamics, vibrational spectra and ligand-centred excited states of relatively large complexes. The use of large-core pseudopotentials significantly reduces the computational effort and eliminate the problems associated to the treatment of open-shell systems. However, the calculation of certain spectroscopic properties such as NMR spectra, magnetic exchange coupling constants and hyperfine interactions requires the use of the more demanding small-core pseudopotentials, which include $4 \mathrm{f}$ electrons in the valence, ot even relativistic all-electron approaches. Furthermore, calculations performed on $\mathrm{Ln}^{\mathrm{III}}$-aqua ions showed that the size of the RECP influences dramatically the calculated free energies of hydration, with f-in-core ECPs performing poorly [111]. This shows that the energetics from large-core calculations of $\mathrm{Ln}^{\mathrm{III}}$ complexes cannot be trusted and should be routinely benchmarked against small-core calculations.

In spite of the progress made during the last decade, the calculation of some properties of $\mathrm{Ln}^{\mathrm{III}}$ complexes with chemical accuracy is still a difficult task for DFT, while some others are out of the reach of the current DFT methods. These properties include the magnetic behavior and exchange coupling constants of $\mathrm{Ln}^{\mathrm{III}}$ compounds other than $\mathrm{Gd}^{\mathrm{III}}$, the calculation of NMR and EPR spectra of paramagnetic $\mathrm{Ln}^{\mathrm{III}}$ complexes, or the calculation of the f-f transitions observed in the absorption and emission spectra of $\mathrm{Ln}^{\mathrm{III}}$ complexes, although in the latter case some progress has been recently done with the so called ligand field density functional theory (LFDFT) approach [91]. Further developments in solvation models will also aid a more adequate description of the structures and properties of these systems in the solution state.

\section{Acknowledgements}

The authors thank Ministerio de Educación y Ciencia (MEC) and Fondo Europeo de Desarrollo Regional (FEDER) (CTQ2009-10721), and Xunta de Galicia (IN845B-2010/063) for financial support. Further, the authors gratefully acknowledge support from the Centro de Supercomputación de Galicia (CESGA). M. R.F. and A. R.-S. thank respectively Ministerio de Educación y Ciencia (FPU program) and Xunta de Galicia (María Barbeito program) for predoctoral fellowships. 


\section{References}

[1] Caravan, P.; Ellinson, J. J.; McMurry, T. J.; Lauffer, R. B. Gadolinium(III) chelates as MRI contrast agents: Structure, dynamics, and applications. Chem. Rev. 1999, 99, 2293-2352.

[2] Merbach, A. E.; Tóth, É. The Chemistry of Contrast Agents in Medical Magnetic Resonance Imaging; Wiley: New York, 2001.

[3] De Leon-Rodriguez, L. M.; Lubag, A. J. M.; Malloy, C. R.; Martinez, G. V.; Gillies, R. J.; Sherry, A. D. Responsive MRI agents for sensing metabolism in vivo. Acc. Chem. Res. 2009, 42, 948-957.

[4] Chan, K. W.-Y.; Wong, W.-T. Small molecular gadolinium(III) complexes as MRI contrast agents for diagnostic imaging. Coord. Chem. Rev. 2007, 251, 2428-2451.

[5] Terreno, E.; Castelli, D. D.; Viale, A.; Aime, S. Challenges for molecular magnetic resonance imaging. Chem. Rev. 2010, 110, 3019-3042.

[6] Liu, S. Bifunctional coupling agents for radiolabeling of biomolecules and target-specific delivery of metallic radionuclides. Adv. Drug Deliv. Rev. 2008, 60, 1347-1370.

[7] Roesch, F. Radiolanthanides in endoradiotheraphy: an overview. Radiochim. Acta 2007, 95, 303311.

[8] Volkert, W. A.; Hoffman, T. J. Therapeutic radiopharmaceuticals. Chem. Rev. 1999, 99, 2269-2292.

[9] Tweedle, M. F. Peptide-targeted diagnostics and radiotherapeutics. Acc. Chem. Res. 2009, 42, 958968.

[10] Parker, D.; Dickins, R. S.; Puschmann, H.; Crossland, C.; Howard, J. A. K. Being excited by lanthanide coordination complexes: aqua species, chirality, excited-state chemistry, and exchange dynamics. Chem. Rev. 2002, 102, 1977-2010.

[11] Bünzli, J.-C. G. Lanthanide luminescence for biomedical analyses and imaging. Chem Rev. 2010, $110,2729-2755$.

[12] Costes, J.-P.; Nicodéme, F. Unequivocal synthetic pathway to heterodinuclear ( $4 \mathrm{f}, 4 \mathrm{f}$ ') complexes: Magnetic Study of relevant $\left(\mathrm{Ln}^{\mathrm{III}}, \mathrm{Gd}^{\mathrm{III}}\right)$ and $\left(\mathrm{Gd}^{\mathrm{III}}, \mathrm{Ln}^{\mathrm{III}}\right)$ complexes. Chem. Eur. J. 2002, 8, 34423447.

[13] Novitchi, G.; Wernsdorfer, W.; Chibotaru, L. F.; Costes, J.-P.; Anson, C. E.; Powell, A. K. Angew. Chem., Int. Ed. 2009, 48, 1614-1619.

[14] Kahn, O. Chemistry and physics of supramolecular magnetic materials. Acc. Chem. Res. 2000, 33, 647-657.

[15] Dam, H. H.; Reinhoudt, D. N.; Verboom, W. Multicoordinate ligands for actinide/lanthanide separations. Coord. Chem. Rev. 2007, 36, 367-377.

[16] Peterman, D. R.; Law, J. D.; Todd, T. A.; Tillotson, R. D. In: Separations for the Nuclear Fuel Cycle in the 21st Century; Lumetta, G. L.; Nash, K. L.; Clark, S. B.; Friese, J. I. Eds.; ACS Symposium Series 933; American Chemical Society: Washinton DC, 2006, pp. 251-259.

[17] Cotton, S. A. Establishing coordination numbers for the lanthanides in simple complexes. $C$. $R$. Chimie 2005, 8, 129-145. 
[18] Maron, L.; Eisenstein, O. DFT modeling of ligands in lanthanide chemistry; Is $\mathrm{Ln}\left[\mathrm{N}\left(\mathrm{SiH}_{3}\right)_{2}\right]_{3}$ a model for $\mathrm{Ln}\left[\mathrm{N}\left(\mathrm{SiMe}_{3}\right)_{2}\right]_{3}$ ? New J. Chem. 2001, 25, 255-258.

[19] Takamatsu, S.; Ishikawa, N. A theoretical study of a drastic structural change of bis(phthalocyanato)lanthanide by ligand oxydation: Towards control of ligand field strength and magnetism of single-lanthanide-ionic single molecule magnet. Polyhedron 2007, 26, 1859-1862.

[20] Ishikawa, N.; Iino, T.; Kaizu, Y.; Study of 1H NMR spectra of dinuclear complexes of heavy lanthanides with phthalocyanines based on separation of the effects of two paramagnetic centers. $J$. Phys. Chem. A 2003, 107, 7879-7884.

[21] Panda, T. K.; Petrovic, D.; Bannenberg, T.; Hrib, C. G.; Jones, P. G.; Tamm, M. Syntheses and structures of lanthanide complexes containing a bis(imidazolin-2-imino)pyridine pincer ligand. Inorg. Chim. Acta 2008, 361, 2236-2242.

[22] Mihaylov, T.; Trendafilova, N.; Georgieva, I. DFT-based molecular modeling and vibrational study of the $\mathrm{La}(\mathrm{III})$ complex of 3,3'-(benzylidene)bis(4-hydroxycoumarin). J. Mol. Model. 2008, 14, 353366.

[23] Mihaylov, T.; Trendafilova, N.; Kostova, I.; Georgieva, I.; Bauer, G. DFT modeling and spectroscopic study of metal-ligand bonding in $\mathrm{La}(\mathrm{III})$ complex of coumarin-3-carboxylic acid. Chem Phys. 2006, 327, 209-219.

[24] Villa, A.; Cosentino, U.; Pitea, D.; Moro, G.; Maiocchi, A. Force field parametrization for gadolinium complexes based on ab initio potential energy surface calculations. J. Phys. Chem. A 2000, 104, 3421-3429.

[25] Henriques, E. S.; Bastos, M.; Geraldes, C. F. G. C.; Ramos, M. J. Computational approaches to the study of some lanthanide(III)-polyazamacrocyclic chelates for magnetic resonance imaging. Int. J. Quantum Chem. 1999, 73, 237-248.

[26] Cosentino, U.; Moro, G.; Pitea, D.; Villa, A.; Fantucci, P. C.; Maiocchi, A.; Uggeri, F. Ab initio investigation of gadolinium complexes with polyamino carboxylate ligands and force fields parametrization of metal-ligands interactions. J. Phys. Chem. A 1998, 102, 4606-4614.

[27] Souza, A. P.; Paz, F. A. A.; Freire, R. O.; Carlos, L. D.; Malta, O. L.; Alver, S. Jr.; de Sá, G. F. Synthesis, crystal structure, and modelling of a new tetramer complex of europium. J. Phys. Chem. B 2007, 111, 9228-9238.

[28] Rodrigues, M. O.; Júnior, N. B. da C.; de Simone, C. A. de; Araújo, A. A. S.; Brito-Silva, A. M.; Paz, F. A. A.; Mesquita, M. E. de; Júnior, S. A.; Freire, R. O. Theoretical and experimental studies of the photoluminescent properties of the coordination polymer $\left[\mathrm{Eu}(\mathrm{DPA})(\mathrm{HDPA})\left(\mathrm{H}_{2} \mathrm{O}\right)_{2}\right] \cdot 4 \mathrm{H}_{2} \mathrm{O}$. J. Phys. Chem. B 2008, 112, 4204-4212.

[29] Maffeo, D.; Lampropoulou, M.; Fardis, M.; Lazarou, Y. G.; Mavridis, I. M.; Mavridou, D. A. I.; Urso, E.; Pratsinis, H.; Kletsas, D.; Yannakopoulou, Novel polycarboxylated EDTA-type cyclodextrins as ligands for lanthanide binding: study of their luminescence, relaxivity properties of Gd(III) complexes, and PM3 theoretical calculations. Org. Biomol. Chem. 2010, 8, 1910-1921.

[30] Freire, R. O.; Rocha, G. B.; Simas, A. M. Sparkle Model for the Calculation of Lanthanide Complexes: AM1 Parameters for Eu(III), Gd(III) and Tb(III). Inorg. Chem. 2005, 44, 3299-3310. 
[31] Freire, R. O.; da Costa, N. B., Jr.; Rocha, G. B.; Simas, A. M. Sparkle/PM3 parameters for the modeling of neodymium(III). Promethium(III), and Samarium(III) complexes. J. Chem. Theory Comput. 2007, 3, 1588-1596.

[32] McNamara, J. P.; Berrigan, S. D.; Hillier, I. H. Semiempirical molecular orbital scheme to study lanthanide(III) complexes: PM3 parameters for europium, gadolinium, and ytterbium. J. Chem. Theory Comput. 2007, 3, 1014-1027.

[33] da Costa, N. B.; Freire, R. O.; dos Santos, M. A. C.; de Mesquita, M. E. Sparkle model and intensity parameters of the $\mathrm{Eu}(3 \text {-amino-2carboxypyridine- } N \text {-oxide })_{3} \cdot 3 \mathrm{H}_{2} \mathrm{O}$ complex. J. Mol. Struct. (Theochem) 2001, 545, 131-135.

[34] Koch, W.; Holthausen, M. C. A Chemist's Guide to Density Functional Theory, 2nd Ed. Wiley-VCH: Weinheim, 2001.

[35] Takeda, K.; Tsuchiya, T.; Nakano, H.; Taketsugu, T.; Hirao, K. Stability of multiply charged anions of lanthanide hexafluorides $\mathrm{LnF}_{6}{ }^{2-}$ and $\mathrm{LnF}_{6}{ }^{3-}\left(\mathrm{Ln}=\mathrm{Ce}\right.$ to Lu) ${ }_{6} \mathrm{~J}_{\text {. Mol. }}$ Struct. (THEOCHEM) 2001, 537, 107-115.

[36] Cao, X.; Dolg, M. Pseudopotential study of lanthanum and lutetium dimers. Theor. Chem. Acc. 2002, 108, 143-149.

[37] Fritsche, L.; Koller, J.; Reinert, Th. Borderline cases in density functional theory. J. Comput. Chem. 2004, 100, 681-694.

[38] Sadhukhan, S.; Muñoz, D.; Adamo, C.; Scuseria, G. E. Predicting proton transfer barriers with density functional methods. Chem. Phys. Lett. 1999, 306, 83-87.

[39] Rotzinger, F. P. Treatment of substitution and rearrangement mechanisms of transition metal complexes with quantum chemical methods. Chem. Rev. 2005, 105, 2003-2037.

[40] Neese, F. Prediction of molecular properties and molecular spectroscopy with density functional theory: From fundamental theory to exchange-coupling. Coord. Chem. Rev. 2009, 253, 526-563.

[41] Dolg, M.; Stoll, H. In: Handbook on the Physics and Chemistry of the Rare Earths; Gschneidner, K. A., Jr.; Eyring, L. Eds.; Elsevier: Amsterdam, 1996, 22, pp. 607-729.

[42] Barysz, M.; Ishikawa, Y. Relativistic Methods for Chemists; Springer: New York, 2010.

[43] Pyykkö, P. Relativistic effects in structural chemistry. Chem. Rev. 1988, 88, 563-594.

[44] Stoll, H.; Metz, B.; Dolg, M. Relativistic energy-consistent pseudopotentials - recent developments. J. Comput. Chem. 2002, 23, 767-778.

[45] Ross, R. B.; Gayen, S.; Ermler, W. C. Ab initio relativistic effective core potentials with spin-orbit operators. V. Ce through Lu. J. Chem. Phys. 1994, 100, 8145-8155.

[46] Cundari, T. R.; Stevens, W. J. Effective core potential methods for the lanthanides. J. Chem. Phys. 1993, $98,5555-5565$.

[47] Dolg, M.; Stoll, H.; Savin, A.; Preuss, H. Energy-adjusted pseudopotentials for the rare earth elements. Theor. Chim. Acta 1989, 75, 173-194.

[48] Dolg, M.; Stoll, H.; Preuss, H. Energy-adjusted ab initio pseudopotentials for the rare earth elements. J. Chem. Phys. 1989, 90, 1730-1734. 
[49] Yang, J.; Dolg. M. Valence basis sets for lanthanide 4f-in-core pseudopotentials adapted for crystal orbital ab initio calculations. Theor. Chem. Acc. 2005, 113, 212-224.

[50] Weigand, A.; Cao, X.; Yang, J.; Dolg, M. Quasirelativistic f-in-core pseudopotentials and corepolarization potentials for trivalent actinides and lanthanides: molecular test for trifluorides. Theor. Chem. Acc. 2010, 126, 117-127.

[51] Huelsen, M.; Weigand, A.; Dolg. M. Quasirelativistic energy-consistent 4f-in-core pseudopotentials for tetravalent lanthanide elements. Theor. Chem. Acc. 2009, 122, 23-29.

[52] Cao, X.; Dolg, M. Segmented contraction shcheme for small-core lanthanide pseudopotential basis sets. J. Mol. Struct. (THEOCHEM) 2002, 581, 139-147.

[53] Cao, X.; Dolg, M. Valence basis sets for relativistic energy-consistent small-core lanthanide pseudopotentials. J. Chem. Phys. 2001, 115, 7348-7355.

[54] Buchachenko, A. A.; Chalasinski, G.; Szczesniak, M. M. Diffuse basis functions for small-core relativistic pseudopotential basis sets and static dipole polarizabilities of selected lanthanides La, Sm, Eu, Tm and Yb. Struct. Chem. 2007, 18, 769-772.

[55] Dolg, M.; Stoll, H.; Preuss, H. A combination of quasirelativistic pseudopotential and ligand field calculations for lanthanide compounds. Theor. Chim. Acta 1993, 85, 441-450.

[56] Rabbe, C.; Mikhalko, V.; Dognon, J. P. Ab initio calculations with effective core potentials on trivalent lanthanide-terpyridine complexes. Theor. Chem. Acc. 2000, 104, 280-283.

[57] Boehme, C.; Wipff, G. Thiophosphoryl complexes of trivalent lanthanide cations: Importance of counterions and stoichiometry for binding energies: A theoretical study. J. Phys. Chem. A 1999, 103, 6023-6029.

[58] Boehme, C.; Wipff, G. Dithiophosphinate complexes of trivalent lanthanide cations: Consequences of counterions and coordination number for binding energies and selectivity. A theoretical study. Inorg. Chem. 1999, 38, 5734-5741.

[59] Boehme, C.; Wipff, G. The energetic and structural effects of steric crowding in phosphate and dithiophosphinate complexes of lanthanide cations $\mathrm{M}^{3+}$ : A computational study. Chem Eur. J. 2001, 7, 1398-1407.

[60] Coupez, B.; Boehme, C.; Wipff, G. Interaction of bifunctional carbonyl and phosphoryl ligands with $\mathrm{M}^{3+}$ lanthanide cations: how strong is the bidentate effect? The role of ligand size and counterions investigated by quantum mechanics. Phys. Chem. Chem. Phys. 2002, 4, 5716-5729.

[61] Baaden, M.; Bugard, M.; Coupez, B.; Boehme, C.; Wipff, G. Lanthanide cation binding to a phosphoryl-calix[4]arene: The importance of solvent and counterions investigated by molecular dynamics and quantum mechanical simulations. Phys. Chem. Chem. Phys. 2002, 4, 5716-5729.

[62] Boehme, C.; Coupez, B.; Wipff, G. Interaction of $\mathrm{M}^{3+}$ lanthanide cations with diamide ligands and their thia analogues: A quantum mechanics study of monodentate vs bidentate binding, counterion effects, and ligand protonation. J. Phys. Chem. A 2002, 106, 6487-6498.

[63] Denecke, M. A.; Rossberg, A.; Panak, P. J.; Weigl, M.; Schimmelpfennig, B.; Geist, A. Characterization and comparison of $\mathrm{Cm}$ (III) and Eu(III) complexed with 2,6-di(5,6-dipropyl-1,2,4triazin-3-yl)pyridine using EXAFS, TRFLS, and quantum-chemical methods. Inorg. Chem. 2005, $44,8418-8425$. 
[64] Dobler, M.; Hirata, M.; Tachimori, S. Quantum chemical study of $\operatorname{Ln}^{\mathrm{III}}$ (pyridine-dicarboxy-amide) complexes. Phys. Chem. Chem. Phys. 2003, 5, 2499-2504.

[65] Shi, T.; Hopkinson, A. C.; Siu, K. W. M. Coordination of triply charged lanthanum in the gas phase: Theory and experiment. Chem Eur. J. 2007, 13, 1142-1151.

[66] Georgieva, I.; Trendafilova, N.; Aquino, A. J. A.; Lischka, H. Theoretical study of metal-ligand interaction in $\mathrm{Sm}(\mathrm{III}), \mathrm{Eu}(\mathrm{III})$, and $\mathrm{Tb}(\mathrm{III})$ complexes of coumarin-3-carboxylic acid in the gas phase and solution. Inorg. Chem. 2007, 46, 10926-10936.

[67] Ouali, N.; Bocquet, B.; Rigault, S.; Morgantini, P.-Y.; Weber, J.; Piguet, C. Analysis of paramagnetic NMR spectra of triple-helical lanthanide complexes with 2,6-dipicolinic acid revisited: A new assignment of structural changes and crystal-field effects 25 years later. Inorg. Chem. 2002, $41,1436-1445$.

[68] Yazyev, O. V.; Helm, L.; Malkin, V. G.; Malkina, O. L. Quantum chemical investigation of hyperfine coupling constants on first coordination sphere water molecule of gadolinium(III) aqua complexes. J. Phys. Chem. A 2005, 109, 10997-11005.

[69] Storchi, L.; Belpassi, L.; Tarantelli, F.; Sgamellotti, A.; Quiney, H. M. An efficient parallel allelectron four-component Dirac-Kohn-Sham program using a distributed matrix approach. J. Chem. Theory Comput. 2010, 6, 384-394.

[70] Hess, B. A. Relativistic electronic-structure calculations employing a 2-component no-pair formalism with external-field projection operators. Phys. Rev. A, 1986, 33 3742-3748.

[71] Jansen, G.; Hess, B. A. Revision of the Douglas-Kroll transformation, Phys. Rev. A 1989, 39, 60166017.

[72] Barysz, M.; Sadlej, A. J. Two-component methods of relativistic quantum chemistry: From the Douglas-Kroll approximation to the exact two-component formalism. J. Mol. Struct. (Theochem) 2001, 573, 181-200.

[73] van Lenthe, E.; Ehlers, A.; Baerends, E.-J. Geometry optimizations in the zero order regular approximation for relativistic effects. J. Chem. Phys. 1999, 110, 8943-8953.

[74] van Lenthe, E.; Baerends, E.-J.; Snijders, J. G. Relativistic regular two-component hamiltonians. J. Chem. Phys. 1993, 99, 4597-4610.

[75] van Lenthe, E.; Baerends, E.-J.; Snijders, J. G. Relativistic total energy using regular approximations. J. Chem. Phys. 1994, 101, 9783-9792.

[76] Van Wüllen, C. Relativistic all-electron density functional calculations. J. Comput. Chem. 1999, 20, $51-62$.

[77] Reiher, M. Douglas-Kroll-Hess theory: a relaticistic electrons-only theory for chemistry. Theor. Chem. Acc. 2006, 116, 241-252.

[78] Hong, G.; Dolg, M.; Li, L. A comparison of scalar-relativistic ZORA and DKH density functional schemes: monohydrides, monoxides and monofluorides of La, Lu, Ac and Lr. Chem. Phys. Lett. 2001, 334, 396-402.

[79] Guillaumont, D. Quantum chemistry study of actinide(III) and lanthanide(III) complexes with tridentate nitrogen ligands. J. Phys. Chem. A 2004, 108, 6893-6900. 
[80] Shestakov, A. F.; Emelyanova, N. S. Application of scalar-relativistic DFT approach for calculation of structural and electronic properties of mercaptobenzothiazolyl lanthanide complexes with luminescent activity. J. Mol. Struct. (THEOCHEM) 2010, 954, 124-129.

[81] te Velde, G.; Bickelhaupt, F. M.; Baerends, E. J.; Guerra, C. F.; Van Gisbergen, S. J. A.; Snijders, J. G.; Ziegler, T. Chemistry with ADF. J. Comput. Chem. 2001, 22, 931-967.

[82] Roos, B. O.; Lindh, R.; Malmqvist, P.-Å.; Veryazov, V.; Widmark, P.-O.; Borin, A. C. New relativistic atomic natural orbital basis sets for lanthanide atoms with applications to the Ce diatom and $\mathrm{LuF}_{3}$. J. Phys. Chem. A 2008, 112, 11431-11435.

[83] Nakajima, T.; Hirao, K. Accurate relativistic Gaussian basis sets determined for the third-order Douglas-Kroll approximation with a finite-nucleus model. J. Chem. Phys. 2002, 116, 8270-8275.

[84] Tsuchiya, T.; Abe, M.; Nakajima, T.; Hirao, K. Accurate relativistic Gaussian basis sets for H through $\mathrm{Lr}$ determined by atomic self-consistent field calculations with the third-order Douglas-Kroll approximation. J. Chem. Phys. 2001, 115, 4463-4472.

[85] Sekiya, M.; Noro, T.; Miyoshi, E.; Osanai, Y.; Koga, T. Relativistic correlating basis sets for lanthanide atoms from Ce to Lu. J. Comput. Chem. 2006, 27, 463-470.

[86] Pantazis, D. A.; Neese, F. All-electron scalar relativistic basis sets for the lanthanides. J. Chem. Theory Comput. 2009, 5, 2229-2238.

[87] Schultz, N. E.; Zhao, Y.; Truhlar, D. G. Density functionals for inorganometallic and organometallic chemistry. J. Phys. Chem. A. 2005, 109, 11127-11143.

[88] Sousa, S. F.; Carvalho, E. S.; Ferreira, D. M.; Tavares, I. S.; Fernandez, P. A.; Ramos, M. J.; Gomes, J. A. N. F. Comparative analysis of the performance of commonly available density functionals in the determination of geometrical parameters for Zinc complexes. J. Comput. Chem. 2009, 30, $2752-$ 2763.

[89] Clark, A. E. Density functional and basis set dependence of hydrated Ln(III) properties. J. Chem. Theory Comput. 2008, 4, 708-718.

[90] Adamo, C.; Maldivi, P. A theoretical study of bonding in lanthanide trihalides by density functional methods. J. Phys. Chem. A 1998, 102, 6812-6820.

[91] Petit, L.; Borel, A.; Daul, C.; Maldivi, P.; Adamo, C. A theoretical characterization of covalency in rare earth complexes through their absorption electronic properties: f-f transitions. Inorg. Chem. 2006, $45,7382-7388$.

[92] Becke, A. D. Density-functional exchange-energy approximation with correct asymptotic-behavior. Phys. Rev. A 1988, 38, 3098-3100.

[93] Lee, C.; Yang, W.; Parr, R. G. Development of the Colle-Salvetti correlation-energy formula into a functional of the electron density. Phys. Rev. B 1988, 37, 785-789.

[94] Perdew, J. P. Density-functional approximation for the correlation energy of the inhomogeneous electron gas. Phys. Rev. B 1986, 33, 8822-8824.

[95] Becke, A. D. Density-functional thermochemistry. III. The role of exact exchange. J. Chem. Phys. 1993, $98,5648-5652$. 
[96] Toraishi, T.; Nagasaki, S.; Tanaka, S. A theoretical study on molecular structure of Eu(III)-salicylate complexes in aqueous system. J. Mol. Struct. (THEOCHEM) 2005, 757, 87-97.

[97] Girichev, G. V.; Giricheva, N. I.; Haaland, A.; Kuzmina, N. P.; Samdal, S.; Strenalyuk, T. N.; Tverdova, N. V.; Zaitseva, I. G. Molecular structures of tris(dipivaloylmethanato) complexes of the lanthanide metals, $\operatorname{Ln}(\mathrm{dpm}) 3$, studied by gas electron diffraction and density functional calculations: A comparison of the Ln-O bond distances and enthalphies in $\mathrm{Ln}(\mathrm{dpm})_{3}$ complexes and the cubic sequioxides, $\mathrm{Ln}_{2} \mathrm{O}_{3}$. Inorg. Chem. 2006, 45, 5179-5186.

[98] Puntus, L. N.; Lyssenko, K. A.; Pekareva, I. S.; Antipin, M. Y. Characterisation of geometrc isomers of europium chlorides with 2,2'-bipyridine based on X-ray diffraction, luminescence and quantum chemical data. Mol. Phys. 2010, 108, 557-572.

[99] Núñez, C.; Mato-Iglesias, M.; Bastida, R.; Macías, A.; Pérez-Lourido, P.; Platas-Iglesias, C.; Valencia, L. Solid-state and solution structure of lanthanide(III) complexes with a flexible Py- $\mathrm{N}_{6}$ macrocyclic ligand. Eur. J. Inorg. Chem. 2009, 1086-1095.

[100] Charbonniére, L. J.; Schurhammer, R.; Mameri, S.; Wipff, G.; Ziessel, R. F. Photophysical and structural impact of phosphorylated anions associated to lanthanide complexes in water. Inorg. Chem. 2005, 44, 7151-7160.

[101] Heiberg, H.; Gropen, O.; Laerdahl, J. K.; Swang, O.; Wahlgren, U. The performance of density functional theory for $\mathrm{LnF}(\mathrm{Ln}=\mathrm{Nd}, \mathrm{Eu}, \mathrm{Gd}, \mathrm{Yb})$ and $\mathrm{YbH}$. Theor. Chem. Acc. 2003, 110, 118-125.

[102] Kuta, J.; Clark, A. E. Trends in aqueous hydration across the $4 \mathrm{f}$ period assessed by reliable computational methods. Inorg. Chem. 2010, 49, 7808-7817.

[103] Erras-Hanauer, H.; Clark, T.; van Eldik, R. Molecular orbital and DFT studies on water exchange mechanisms of metal ions. Coord. Chem. Rev. 2003, 238-239, 233-253.

[104] Mato-Iglesias, C.; Balogh, E.; Platas-Iglesias, C.; tóth, É.; de Blas, A.; Rodríguez-Blas, T. Pyridineand phosphonate-containing ligands for stable lanthanide complexation. An experimental and theoretical study to assess the solution structure. Dalton Trans. 2006, 5404-5415.

[105] Hardcastle, K. I.; Botta, M.; Fasano, M.; Digilio, G. Experimental evidence for a second coordination sphere water molecule in the hydration of YbDTPA - Insights for a re-assessment of the relaxivity data of GaDTPA. Eur. J. Inorg. Chem. 2000, 971-977.

[106] Balogh, E.; Mato-Iglesias, M.; Platas-Iglesias, C.; Tóth, É.; Djanashvili, K.; Peters, J. A.; de Blas, A.; Rodríguez-Blas, T. Pyridine- and phosphonate-containing ligands for stable Ln complexation. Extremely fast water exchange on the $\mathrm{Gd}^{\mathrm{III}}$ chelates. Inorg. Chem.2006, 45, 8719-8728.

[107] Tomasi, J.; Mennucci, B.; Cammi, R. Quantum mechanical continuum solvation models. Chem. Rev. 2005, 105, 2999-3093.

[108] Klamt, A.; Schüürmann, G. COSMO: A new approach to dielectric screening in solvents with explicit expressions for the screening energy and its gradient. J. Chem. Soc., Perkin trans. 2, 1993, 799-805.

[109] Eckert, F.; Klamt, A. Fast solvent screening via quantum chemistry: COSMO-RS approach. AIChE J. 2002, 48, 369-385.

[110] Gutowski, K. E.; Dixon, D. A. Predicting the energy of the water exchange reaction and free energy of solvation for the Uranyl ion in aqueous solution. J. Phys. Chem. A 2006, 110, 8840-8856. 
[111] Dinescu, A.; Clark, A. E. Thermodynamic and structural features of aqueous Ce(III). J. Phys. Chem. A 2008, 112, 11198-11206.

[112] Li, H.; Jensen, J. H. Improving the efficiency and convergence of geometry optimization with the polarizable continuum model: New energy gradients and molecular surface tessellation. J. Comput. Chem. 2004, 25, 1449-1462.

[113] Pearson, R. G. J. Am. Chem. Soc. 1963, 85, 3533-3539.

[114] Frey, S. T.; Horrocks, W. DeW., Jr. On correlating the frequency of the ${ }^{7} \mathrm{~F}_{0} \rightarrow{ }^{5} \mathrm{D}_{0}$ transition in $\mathrm{Eu}^{3+}$ complexes with the sum of nephelauxetic paramenters for all the coordinating atoms. Inorg. Chim. Acta 1995, 229, 383-390.

[115] Carlos, L. D.; Malta, O. L.; Albuquerque, R. Q. A covalent fraction model for lanthanide compounds. Chem. Phys. Lett. 2005, 415, 238-242.

[116] Peters, J. A.; Huskens, J.; Raber, D. J. Lanthanide induced shifts and relaxation rate enhancements. Prog. NMR Spectrosc. 1996, 28, 283-350.

[117] Dickins, R. S.; Parker, D.; Bruce, J. I.; Tozer, D. J. Correlation of optical and NMR spectral information with coordination variation for axially symmetric macrocyclic $\mathrm{Eu}(\mathrm{III})$ and $\mathrm{Yb}(\mathrm{III})$ complexes: axial donor polarisability determines ligand field and cation donor preference. Dalton Trans. 2003, 1264-1271.

[118] Di Bari, L.; Pintacuda, G.; Salvadori, P.; Dickins, R. S.; Parker, D. Effect of axial ligation on the magnetic and electronic properties of lanthanide complexes of octadentate ligands. J. Am. Chem. Soc. 2000, 122, 9257-9264.

[119] Tancrez, N.; Feuvrie, C.; Ledoux, I.; Zyss, J.; Toupet, L.; Le Bozec, H.; Maury, O. Lanthanide complexes for second order non-linear optics: Evidence for the direct contribution of $\mathrm{f}$ electrons to the quadratic hyperpolarizability. J. Am. Chem. Soc. 2005, 127, 13474-13475.

[120] Adamo, C.; Maldivi, P. Ionic versus covalent character in lanthanide complexes. A hybrid density functional study. Chem. Phys. Lett. 1997, 268, 61-68.

[121] Reed, A. E.; Weinstock, R. B.; Weinhold, F. Natural-population analysis, J. Chem. Phys. 1985, 83, 735-746.

[122] Maron, L.; Eisestein, O. Do f electrons play a role in the lanthanide-ligand bonds? A DFT study of $\mathrm{Ln}\left(\mathrm{NR}_{2}\right)_{3} ; \mathrm{R}=\mathrm{H}, \mathrm{SiH}_{3}$. J. Phys. Chem. A 2000, 104, 7140-7143.

[123] Eisestein, O.; Maron, L. DFT studies of some structures and reactions of lanthanide complexes. $J$. Organomet. Chem. A 2002, 647, 190-197.

[124] Perrin, L.; Maron, L.; Eisenstein, O. Some structural and electronic properties of $\mathrm{MX}_{3}(\mathrm{M}=\mathrm{Ln}, \mathrm{Sc}$, $\mathrm{Y}, \mathrm{Ti}^{+}, \mathrm{Zr}^{+}, \mathrm{Hf}^{+} ; \mathrm{X}=\mathrm{H}, \mathrm{Me}, \mathrm{Hal}, \mathrm{NH}_{2}$ ) from DFT calculations. Faraday Discuss. 2003, 124, 25-39.

[125] Hong, G.; Schautz, F.; Dolg, M. Ab inition study of metal-ring bonding in the bis $\left(\eta^{6}\right.$ benzene)lanthanide and -actinide complexes $\mathrm{M}\left(\mathrm{C}_{6} \mathrm{H}_{6}\right)_{2}(\mathrm{M}=\mathrm{La}, \mathrm{Ce}, \mathrm{Nd}, \mathrm{Gd}, \mathrm{Tb}, \mathrm{Lu}, \mathrm{Th}, \mathrm{U}) . J . A m$. Chem. Soc. 1999, 121, 1502-1512.

[126] Maldivi, P.; Petit, L.; Adamo, C.; Vetere, V. Theoretical description of metal-ligand bonding within f-element complexes. A succesful and necessary interplay between theory and experiment. $C$. $R$. Chimie 2007, 10, 888-896. 
[127] Groen, C. P.; Varga, Z.; Kolonits, M.; Peterson, K. A.; Hargittai, M. Does the 4f electron configuration affect molecular geometries? A joint computational, vibrational spectroscopic, and electron diffraction study of dysprosium tribromide. Inorg. Chem. 2009, 48, 4143-4153.

[128] Minasian, S. G.; Krinsky, J. L.; Rinehart, J. D.; Copping, R.; Tyliszczak, T.; Janousch, M.; Shuh, D. $\mathrm{K}$; Arnold, J. A comparison of $4 \mathrm{f} v s$ f metal-metal bonds in $\left(\mathrm{CpSiMe}_{3}\right)_{3} \mathrm{M}-\mathrm{ECp}^{*}(\mathrm{M}=\mathrm{Nd}, \mathrm{U}$; $\mathrm{E}=$ $\mathrm{Al}, \mathrm{Ga} ; \mathrm{Cp}^{*}=\mathrm{C}_{5} \mathrm{Me}_{5}$ ): Synthesis, thermodynamics, magnetism, and electronic structure. J. Am. Chem. Soc. 2009, 131, 13767-13783.

[129] Arliguie, T.; Belkhiri, L.; Bouaoud, S.-E.; Thuéry, P.; Villiers, C.; Boucekkine, A.; Ephritikhine, M. Lanthanide(III) and actinide(III) $\left[\mathrm{M}\left(\mathrm{BH}_{4}\right)_{2}(\mathrm{THF})_{5}\right]\left[\mathrm{BPh}_{4}\right]$ and $\left[\mathrm{M}\left(\mathrm{BH}_{4}\right)_{2}(18\right.$-crown-6)][BPh 4$](\mathrm{M}=$ $\mathrm{Nd}, \mathrm{Ce}, \mathrm{U})$ : Synthesis, crystal structure, and density functional theory investigation of the covalent bonding contribution to metalborohydride bonding. Inorg. Chem. 2009, 48, 221-230.

[130] Petit, L.; Borel, A.; Daul, C.; Maldivi, P.; Adamo, C. A theoretical characterization of covalency in rare earth complexes through their absorption electronic properties: f-f transitions. Inorg. Chem. 2006, $45,7382-7388$.

[131] Roger, M.; Barros, N.; Arliguie, T.; Thuery, P.; Maron, L.; Ephritikhine. U(SMes* $)_{\mathrm{n}}(\mathrm{n}=3,4)$ and $\mathrm{Ln}\left(\mathrm{SMes}^{*}\right)_{3}$ (Ln La, Ce, Pr, Nd): Lanthanide(III)/Actinide(III) differentiation in agostic interactions and an unprecedented $\eta^{3}$ ligantion mode of the arylthiolate ligand from X-ray diffraction and DFT analysis. J. Am. Chem. Soc. 2006, 128, 8790-8802.

[132] Gaunt, A. J.; Reilly, S. D.; Enriquez, A. E.; Scott, B. L.; Ibers, J. A.; Sekar, P.; Ingram, K. I. M.; Kaltsoyannis, N.; Neu, M. P. Experimental and theoretical comparison of actinide and lanthanide bonding in $\mathrm{M}\left[\mathrm{N}\left(\mathrm{EPR}_{2}\right)_{2}\right]_{3}$ complexes $(\mathrm{M}=\mathrm{U}, \mathrm{Pu}, \mathrm{La}, \mathrm{Ce} ; \mathrm{E}=\mathrm{S}, \mathrm{Se}, \mathrm{Te} ; \mathrm{R}=\mathrm{Ph}, i \mathrm{Pr}, \mathrm{H})$. Inorg. Chem. 2008, 47, 29-41.

[133] Vetere, V.; Maldivi, P.; Adamo, C. Comparative studies of quasirelativistic density functional methods for the description of lanthanide and actinide complexes. J. Comput. Chem. 2003, 24, 850858.

[134] Ingram, K. I. M.; Tassell, M. J.; Gaunt, A. J.; Kaltsoyannis, N. Covalency in the f element-chalcogen bond. Computational studies of $\left.\mathrm{M}\left[\mathrm{N}(\mathrm{EPR})_{2}\right)_{2}\right]_{3}(\mathrm{M}=\mathrm{La}, \mathrm{Ce}, \mathrm{Pr}, \mathrm{Pm}, \mathrm{Eu}, \mathrm{U}, \mathrm{Np}, \mathrm{Pu}, \mathrm{Am}, \mathrm{Cm} ; \mathrm{E}=\mathrm{O}$, $\mathrm{S}, \mathrm{Se}, \mathrm{Te} ; \mathrm{R}=\mathrm{H}$, $\left.{ }^{\mathrm{P}} \mathrm{P}, \mathrm{Ph}\right)$. Inorg. Chem. 2008, 47, 7824-7833.

[135] Miguirditchian, M.; Guillaneux, D.; Guillamont, D.; Moisy, P.; Madic, C.; Jensen, M. P.; Nash, K. L. Thermodynamic study of the complexation of trivalent actinide and lanthanide cations by ADPTZ, a tridentate N-donor ligand. Inorg. Chem. 2005, 44, 1404-1412.

[136] Meskaldji, S.; Belkhiri, L.; Arliguie, T.; Fourmigué, M.; Ephritikhine, M.; Boucekkine, A. Density functional theory investigations of the homoleptic tris(dithiolene) complexes $\left[\mathrm{M}(\mathrm{dddt})_{3}\right]^{-q}(q=3,2$; $\mathrm{M}=\mathrm{Nd}^{3+}$ and $\mathrm{U}^{3+/ 4+}$ ) related to lanthanide(III)/Actinide(III) differenciation. Inorg. Chem. 2010, 49, 3192-3200.

[137] Vallet, V.; Fischer, A.; Szabó, Z.; Grenthe, I. The structure and bonding of Y, Eu, U, Am and Cm complexes as studied by quantum chemical methods and X-ray crystallography. Dalton Trans. 2010, 7666-7672.

[138] Krogh-Jespersen, K.; Romanelli, M. D.; Melman, J. H.; Emge, T. J.; Brennan, J. G. Covalent bonding and the trans influence in lanthanide compounds. Inorg. Chem. 2010, 49, 552-560. 
[139] Clavaguéra, C.; Dognon, J.-P.; Pyykkö, P. Calculated lanthanide contractions for molecular trihalides and fully hydrated ions: The contributions from relativity and 4 f-shell hybridization. Chem. Phys. Lett. 2006, 429, 8-12.

[140] Tatewaki, H.; Matsuoka, O. All-electron Dirac-Fock-Roothaan calculations on the electronic structure of GdF molecule. J. Chem Phys. 1997, 106, 4558-4565.

[141] Dolg, M.; Liu, W.; Kalvoda, S. Performance of relativistic density functional and ab initio pseudopotential approaches for systems with high-spin multiplicities: Gadolinium diatomics GdX (X = H, N, O, F, P, S, Cl, Gd). Int. J. Quant. Chem. 2000, 76, 359-370.

[142] Schinzel, S.; Bindt, M.; Visseaux, M.; Chermette, H. Structural and electronic analysis of lanthanide complexes: Reactivity may not necessarily be independent of the identity of the lanthanide atom-A DFT study. J. Phys. Chem. A 2006, 110, 11324-11331.

[143] Furet, E.; Costuas, K.; Rabiller, P.; Maury, O. On the sensitivity of f electrons to their environment. J. Am. Chem. Soc. 2008, 130, 2180-2183.

[144] Chatterjee, A.; Maslen, E. N.; Watson, K. J. Electron densities in crystals of nonaaqualanthanoid(III) tris(trifluoromethanesulfonates). Acta Cryst. 1988, B44, 386-395.

[145] Cossy, C.; Helm, L.; Powell, D. H.; Merbach, A. E. A change in coordination number from nine to eight along the lanthanide(III) aqua ion series in solution: a neutron diffraction study. New J. Chem. 1995, 19, 27-35.

[146] Cossy, C.; Barner, A. C.; Enderby, J. E.; Merbach, A. E. The hydration of $\mathrm{Dy}^{3+}$ and $\mathrm{Yb}^{3+}$ in aqueous solution: A neutron scattering first order difference study. J. Chem Phys. 1989, 90, 3254-3260.

[147] Djanashvili, K.; Platas-Iglesias, C.; Peters, J. A. The structure of the lanthanide aquo ions in solution as studied by ${ }^{17} \mathrm{O}$ NMR spectroscopy and DFT calculations. Dalton Trans. 2008, 602-607.

[148] Persson, I.; D'Angelo, P.; De Panfilis, S.; Sandström, M.; Eriksson, L. Hydration of lanthanoid(III) ions in aqueous solution and crystalline hydrates studied by EXAFS spectroscopy and crystallography: The myth of the "gadolinium break". Chem. Eur. J. 2008, 14, 3056-3066.

[149] Kowall, T.; Foglia, F.; Helm, L.; Merbach, A. E. Molecular dynamics simulation study of lanthanide ions in aqueous solution including water polarization. Change in coordination number from 9 to 8 along the series. J. Am. Chem. Soc. 1995, 117, 3790-3799.

[150] Kowall, T.; Foglia, F.; Helm, L.; Merbach, A. E. Mechanisms of water exchange between lanthanide(III) aqua ions $\left[\mathrm{Ln}\left(\mathrm{H}_{2} \mathrm{O}\right)_{\mathrm{n}}\right]^{3+}$ and bulk water: A molecular dynamics simulation approach including high-pressure effects. Chem. Eur. J. 1996, 2, 285-294.

[151] Villa, A.; Hess, B.; Saint-Martin, H. Dynamics and structure of Ln(III)-aqua ions: A comparative molecular dynamics study using ab initio based flexible and polarizable model potentials. J. Phys. Chem. B 2009, 113, 7270-7281.

[152] Duvail, M.; Spezia, R.; Vitorge, P. A dynamic model to explain hydration behaviour along the lanthanide series. ChemPhysChem 2008, 9, 693-696.

[153] Kowall, T.; Foglia, F.; Helm, L.; Merbach, A. E. Molecular dynamics simulation study of lanthanide ions $\mathrm{Ln}^{3+}$ in aqueous solution. Analysis of the structure of the first hydration shell and the origin of symmetry fluctuations. J. Phys. Chem. 1995, 99, 13078-13087. 
[154] Fujiwara, T.; Mori, H.; Mochizuki, Y.; Tatewaki, H.; Miyoshi, E. Theoretical study of hydration models of trivalent rare-earth ions using model core potentials. J. Mol. Struct. (THEOCHEM) 2010, 949, 28-35.

[155] Cosentino, U.; Villa, A.; Pitea, D.; Moro, G.; Barone, V. Extension of computational chemistry to the study of lanthanide(III) ions in aqueous solution: Implementation and validation of a continuum solvent approach. J. Phys. Chem. B 2000, 104, 8001-8007.

[156] Consentino, U.; Moro, G.; Pitea, D.; Calabi, L.; Maiocchi, A. Ab initio effective core potential calculations on lanthanide complexes: basis sets and electron correlation effects in the study of [Gd$\left.\left(\mathrm{H}_{2} \mathrm{O}\right)_{9}\right]^{3+}$. J. Mol. Struct. (THEOCHEM) 1997, 392, 75-85.

[157] Buzko, V.; Sukhno, I.; Buzko, M. Ab initio and DFT study of $\mathrm{Lu}^{3+}$ hydration. J. Mol. Struct. (THEOCHEM) 2009, 894, 75-79.

[158] Buzko, V.; Sukhno, I.; Buzko, M. Ab initio and DFT study of La ${ }^{3+}$ hydration. Int. J. Quant. Chem. 2007, 107, 2353-2360.

[159] van Sijl, J.; Allan, N. L.; Davies, G. R.; van Westrenen, W. Molecular modelling of rare earth element complexation in subduction zone fluids. Geochim. Cosmochim Acta 2009, 73, 3934-3947.

[160] Ciupka, J.; Cao-Dolg, X.; Wiebke, J.; Dolg, M. Computational study of lanthanide(III) hydration. Phys. Chem. Chem. Phys. 2010, 12, 13215-13223.

[161] Kvamme, B.; Wander, M. C. F.; Clark, A. E. The role of basis set superposition error in water addition reactions to $\mathrm{Ln}(\mathrm{III})$ cations. Int. J. Quant. Chem. 2009, 109, 2474-2481.

[162] Seitz, M.; Oliver, A. G.; Raymond, K. N. The lanthanide contraction revisited. J. Am. Chem. Soc. 2007, 46, 351-353.

[163] Barone, V.; Cossi, M.; Tomasi, J. A new definition of cavities for the computation of solvation free energies by the polarizable continuum model. J. Chem. Phys. 1997, 107, 3210-3221.

[164] Car, R.; Parrinello, M. Unified approach for molecular dynamics and density-functional theory. Phys. Rev. Lett. 1985, 55, 2471-2474.

[165] Yazyev, O. V.; Helm, L. ${ }^{170}$ nuclear quadrupole coupling constants of water bound to a metal ion: A gadolinium(III) case study. J. Chem. Phys. 2006, 125, 054503.

[166] Yazyev, O. V.; Helm, L. Gadolinium (III) ion in liquid water: Structure, dynamics, and magnetic interactions from first principles. J. Chem. Phys. 2007, 127, 084506.

[167] Hermann, P.; Kotek, J.; Kubicek, V.; Lukes, I. Gadolinium(III) complexes as MRI contrast agents: ligand design and properties of the complexes, Dalton Trans. 2008, 3027-3047.

[168] Corey, E. J.; Bailar, J. C., Jr. The stereochemistry of complex inorganic compounds. XXII. Stereospecific effects in complex ions. J. Am. Chem. Soc. 1959, 81, 2620-2629.

[169] Beattie, J. K. Conformational analysis of tris(ethylenediamine) complexes. Acc. Chem. Res. 1971, 4, 253-259.

[170] Aime, S.; Botta, M.; Fasano, M.; Marques, M. P. M.; Geraldes, C. F. G. C.; Pubanz, D.; Merbach, A. E. Conformational and coordination equilibria on DOTA complexes of lanthanide metal ions in aqueous solution studies by ${ }^{1} \mathrm{H}-\mathrm{NMR}$ spectroscopy. Inorg. Chem. 1997, 36, 2059-2068. 
[171] Hoeft, S.; Roth, K. Struktur und Dynamik von Lanthanoid-Tetraazacyclododecantetraacetat-(DOTA)Komplexen in Lösung. Chem. Ber. 1993, 126, 869-873.

[172] Aime, S.; Botta, M.; Ermondi, G. NMR study of solution structures and dynamics of lanthanide(III) complexes of DOTA. Inorg. Chem. 1992, 31, 4291-4299.

[173] Jacques, V.; Desreux, J. F. Quantitative two-dimensional EXSY spectroscopy and dynamic behavior of paramagnetic lanthanide macrocyclic chelate: YbDOTA (DOTA $=1,4,7,10-$ tetraazacyclododecane-N,N',N",N"'-tetraacetic acid. Inorg. Chem. 1994, 33, 4048-4053.

[174] Aime, S.; Barge, A.; Botta, M.; Fasano, M.; Ayala, J. D.; Bombieri, G. Crystal structure and solution dynamics of the lutetium(III) chelate of DOTA. Inorg. Chim. Acta 1996, 246, 423-429.

[175] Woods, M.; Aime, S.; Botta, M.; Howard, J. A. K.; Moloney, J. M.; Navet, M.; Parker, D.; Port, M.; Rousseaux, O. Correlation of water exchange rate with isomeric composition in diastereoisomeric gadolinium complexes of tetra(carboxyethyl)dota and related macrocyclic ligands. J. Am. Chem. Soc. 2000, 122, 9781-9792.

[176] Dunand, F. A.; Aime, S.; Merbach, A. E. First ${ }^{17}$ O NMR observation of coordinated water on both isomers of $\left[\mathrm{Eu}(\mathrm{DOTAM})\left(\mathrm{H}_{2} \mathrm{O}\right)\right]^{3+}$ : A direct access to water exchange and its role in the isomerization. J. Am. Chem. Soc. 2000, 122, 1506-1512.

[177] Zhang, S.; Kovacs, Z.; Burgess, S.; Aime, S.; Terreno, E.; Sherry, A.D. \{DOTAbis(amide) \}lanthanide complexes: NMR evidence for differences in water-molecule exchange rates for coordination isomers. Chem. Eur. J. 2001, 7, 288-296.

[178] Woods, M.; Kovacs, Z.; Zhang, S.; Sherry, A. D. Towards the rational design of magnetic resonance imaging contrast agents: Isolation of the two coordination isomers of lanthanide DOTA-type complexes. Angew. Chem. Int. Ed. 2003, 42, 5889-5892.

[179] Henriques, E. S.; Geraldes, C. F. G. C.; Ramos, M. J. Modelling studies in aqueous solution of lanthanide(III) chelates designed for nuclear magnetic resonance biomedical applications. Mol. Phys. 2003, 101, 2319-2333.

[180] Ranganathan, R. S.; Raju, N.; Fan, H.; Zhang, X.; Tweedle, M. F.; Desreux, J. F.; Jacques, V. Polymethylated DOTA ligands. 2. Synthesis of rigidified lanthanide chelates and studies on the effect of alkyl substitution on conformational mobility and relaxivity. Inorg. Chem. 2002, 41, 68566866.

[181] Chang, C. A.; Liu, C. Y.-L.; Chen, C.-Y.; Chou, X.-M. Ligand preorganization in metal ion complexation: Molecular mechanics/dynamics, kinetics, and laser-excited luminescence studies of trivalent lanthanide complex formation with macrocyclic ligands TETA and DOTA. Inorg. Chem. 2001, 40, 3448-3455.

[182] Fossheim, R.; Dugstad, H.; Dahl, S. G. Molecular modelling of tetrahydroxymethyl-substituted DOTA derivatives and their Gd(III) ion complexes. Eur. J. Med. Chem. 1995, 30, 539-546.

[183] Fossheim, R.; Dahl, S. G. Molecular structure and dynamics of aminopolycarboxylates and their lanthanide ion complexes. Acta Chem. Scand. 1990, 44, 698-706.

[184] Pérez-Mayoral, E.; Soriano, E.; Cerdán, S.; Ballesteros, P. Experimental and theoretical study of lanthanide complexes based on linear and macrocyclic polyaminopolycarboxylic acids containing pyrazolylethyl arms. Molecules 2006, 11, 345-356. 
[185] Moreau, J.; Guillon, E.; Aplincourt, P.; Pierrard, J.-C.; Rimbault, J.; Port, M.; Aplincourt, M. Thermodynamic and structural properties of $\mathrm{Eu}^{3+}, \mathrm{Gd}^{3+}$ and $\mathrm{Tb}^{3+}$ complexes with 1,4,7,10-tetra(2glutaryl)-1,4,7,10-tetraazacyclododecane in solution: EXAFS, luminescence, potentiometric studies, and quantum calculations. Eur. J. Inorg. Chem. 2003, 3007-3020.

[186] Hess, B. A., Jr.; Kedziorski, A.; Smentek, L.; Bornhop, D. J. Role of the antenna in tissue selective probes built of lanthanide-organic chelates. J. Phys. Chem. A 2008, 112, 2397-2407.

[187] Smentek, L.; Hess, B. A., Jr.; Cross, J. P.; Manning, H. C.; Bornhop, D. J. Density-functional theory structures of 1,4,7,10-tetraazacyclododecane-1,4,7,10-tetraacetic acid complexes for ions across the lanthanide series. J. Chem. Phys. 2005, 123, 244302.

[188] Yerly, F.; Borel, A.; Helm, L.; Merbach, A. E. MD simulations of acyclic and macrocyclic Gd ${ }^{3+}$ based MRI contrast agents: Influence of the internal mobility on water proton relaxivity. Chem. Eur. J. 2003, 9, 5468-5480.

[189] Borel, A.; Helm, L.; Merbach, A. E. Molecular dynamics simulations of MRI-relevant Gd ${ }^{\text {III }}$ chelates: Direct access to outer-sphere relaxivity. Chem. Eur. J. 2001, 7, 600-610.

[190] Cosentino, U.; Villa, A.; Pitea, D.; Moro, G.; Barone, V.; Maiocchi, A. Conformational characterization of lanthanide(III)-DOTA complexes by ab initio investigation in vacuo and in aqueous solution. J. Am. Chem. Soc. 2002, 124, 4901-4909.

[191] Cosentino, U.; Pitea, D.; Moro, G.; Barone, V.; Villa, A.; Muller, R. N.; Botteman, F. Theoretical investigation into the influence of conformational equilibria on the water exchange process in magnetic resonance imaging contrast agents. Theor. Chem. Acc. 2004, 111, 204-209.

[192] Cosentino, U.; Pitea, D.; Moro, G.; Saracino, G. A. A.; Villa, A. Conformational behaviour determines the low relaxivity state of a conditional MRI contrast agent. Phys. Chem. Chem. Phys. 2009, 11, 3943-3950.

[193] Purgel, M.; Baranyai, Z.; de Blas, A.; Rodríguez-Blas, T.; Banyai, I.; Platas-Iglesias, C.; Toth, I. An NMR and DFT investigation on the conformational properties of lanthanide(III) 1,4,7,10tetraazacyclododecane-1,4,7,10-tetraacetate analogues containing methylenephosphonate pendant arms. Inorg. Chem. 2010, 49, 4370-4382.

[194] Regueiro-Figueroa, M.; Esteban-Gómez, D.; de Blas, A.; Rodríguez-Blas, T.; Platas-Iglesias, C. Structure and dynamics of lanthanide(III) complexes with an $\mathrm{N}$-alkylated do3a ligand $\left(\mathrm{H}_{3} \mathrm{do} 3 \mathrm{a}=\right.$ 1,4,7,10-tetraazacyclododecane-1,4,7-triacetic acid): A combined experimental and DFT study. Eur. J. Inorg. Chem. 2010, 3586-3595.

[195] A description of the standard basis sets and levels of theory can be found in: Foresman, J. B.; Frisch, A. E. Exploring Chemistry with Electronic Structure Methods, 2nd ed., Gaussian Inc., Pittsburgh, PA, 1996.

[196] Notni, J.; Pohle, K.; Peters, J. A.; Gorls, H.; Platas-Iglesias, C. Structural study of Ga(III), In(III), and $\mathrm{Fe}(\mathrm{III})$ complexes of triazamacrocycle based ligands with $\mathrm{N}_{3} \mathrm{~S}_{3}$ donor set. Inorg. Chem. 2009, $48,3257-3267$.

[197] Pollet, R.; Marx, D. Ab initio simulation of a gadolinium-based magnetic resonance imaging contrast agent in aqueous solution. J. Chem. Phys. 2007, 126, 181102. 
[198] Kotek, J.; Hermann, P.; Vojtísek, P.; Lukes, I.; Peters, J. A.; Vander Elst, L.; Muller, R. N. Lanthanide(III) complexes of a mono(methylphosphonate) analogue of $\mathrm{H}_{4} \mathrm{dota}$ : The influence of protonation of the phosphonate moiety on the TSAP/SAP isomer ratio and the water exchange rate. Chem. Eur. J. 2005, 11, 2373-2384.

[199] Kálmán, F. K.; Baranyai, Z.; Tóth, I.; Bányai, I.; Király, R.; Brücher, E.; Aime, S.; Sun, X.; Sherry, A. D.; Kovacs, Z. Synthesis, potentiometric, kinetic, and NMR studies of 1,4,7,10tetraazacyclododecane-1,7-bis(acetic acid)-4,10-bis(methylenephosphonic acid) (DO2A2P) and its complexes with $\mathrm{Ca}(\mathrm{II}), \mathrm{Cu}(\mathrm{II}), \mathrm{Zn}(\mathrm{II})$ and lanthanide(III) ions. Inorg. Chem. 2008, 47, 3851-3862.

[200] Avecilla, F.; Peters, J. A.; Geraldes, C. F. G. C. X-ray structure of a sodium salt of [Gd(DOTP) $]^{5-}$ Implications for its second-sphere relaxivity and the ${ }^{23} \mathrm{Na}$ NMR hyperfine effects of $[\mathrm{Tm}(\mathrm{DOTP})]^{5-}$. Eur. J. Inorg. Chem. 2003, 4179-4186.

[201] Di Vaira, M.; Stoppioni, P. Theoretical investigation on the geometries of DOTA and DOTA-like complexes and on the transition states of their conformational equilibria. New J. Chem. 2002, 26, 136-144.

[202] Natrajan, L. S.; Khoabane, N. M.; Dadds, B. L.; Muryn, C. A.; Pritchard, R. G.; Heath, S. L.; Kenwright, A. M.; Krupov, I.; Faulkner, S. Probing the structure, conformation, and stereochemical exchange in a family of lanthandie complexes derived from tetrapyridyl-appended cyclen. Inorg. Chem. 2010, 49, 7700-7709.

[203] Mato-Iglesias, M.; Roca-Sabio, A.; Pálinkás, Z.; Esteban-Gómez, D.; Platas-Iglesias, C.; Tóth, É.; de Blas, A.; Rodríguez-Blas, T. Lanthanide complexes based on a 1,7-diaza-12-crown-4 platform containing picolinate pendants: A new structural entry for the design of magnetic resonance imaging contrast agents. Inorg. Chem. 2008, 47, 7840-7851.

[204] Pálinkás, Z.; Roca-Sabio, A.; Mato-Iglesias, M.; Esteban-Gómez, D.; Platas-Iglesias, C.; de Blas, A.; Rodríguez-Blas, T.; Tóth, É. Stability, water exchange, and anion binding studies on lanthanide(III) complexes with a macrocyclic ligand based on 1,7-diaza-12-crown-4: Extremely fast water exchange on the $\mathrm{Gd}^{3+}$ chelate. Inorg. Chem. 2009, 48, 8878-8889.

[205] Roca-Sabio, A.; Mato-Iglesias, M.; Esteban-Gómez, D.; de Blas, A.; Rodríguez-Blas, T.; PlatasIglesias, C. The effect of ring size variation on the structure and stability of lanthanide(III) complexes with crown esthers containing picolinate pendants. Dalton Trans. 2011, 40, 384-392.

[206] Roca-Sabio, A.; Mato-Iglesias, M.; Esteban-Gómez, D.; Tóth, É.; de Blas, A.; Platas-Iglesias, C.; Rodríguez-Blas, T. Macrocyclic receptor exhibiting unprecedented selectivity for light lanthanides. J. Am. Chem. Soc. 2009, 131, 3331-3341.

[207] Fernández-Fernández, M. del C.; Bastida, R.; Macías, A.; Pérez-Lourido, P.; Platas-Iglesias, C.; Valencia, L. Lanthanide(III) complexes with a tetrapyridine pendant-armed macrocyclic ligand: ${ }^{1} \mathrm{H}$ NMR structural determination in solution, x-ray diffraction, and density-functional theory calculations. Inorg. Chem. 2006, 45, 4484-4496.

[208] Smentek, L.; Hess, B. A., Jr. Conformational analysis of Eu(III)-(ethylenedinitrilo)tetrakis (methylphosphonates) (EDTMP). Collect. Czech. Chem. Commun. 2008, 73, 1437-1456.

[209] Núñez, C.; Bastida, R.; Macías, A.; Mato-Iglesias, M.; Platas-Iglesias, C.; Valencia, L. A hexaaza macrocyclic ligand containing acetohydrazide pendants for $\mathrm{Ln}$ (III) complexation in aqueous solution. Solid-state and solution structure and DFT calculations. Dalton Trans. 2008, 3841-3850. 
[210] Mondry, A.; Janicki, R. From structural properties of the EuIII complex with ethylenediaminetetra(methylenephosphonic acid) ( $\mathrm{H}_{8}$ EDTMO) towards biomedical applications. Dalton Trans. 2006, 4702-4710.

[211] Mihaylov, Tz.; Trendafilova, N.; Georgieva, I.; Kostova, I. Coordination properties of warfarin towards Pr(III) predicted form DFT and FT-IR studies. Chem. Phys. 2010, 374, 37-45.

[212] Georgieva, I.; Kostova, I.; Trendafilova, N.; Rastogi, V. K.; Bauer, G.; Kiefer, W. Raman, FT-IR and DFT studies of ortho-, meta- and para-pyridinomethylene substituted di(4-hydroxycoumarin) and their Ce(III), La(III) and Nd(III) complexes. J. Raman Spectrosc. 2006, 37, 742-754.

[213] Godlewska, P.; Ban-Oganowska, H.; Macalik, L.; Hanuza, J.; Oganowski, W.; Roszak, S.; Lipkowski, P. Normal coordinate analysis and DFT calculations of the vibrational spectra for lanthanide(III) complexes with 3-bromo-4-methoxy-2,6-lutidine N-oxide: $\mathrm{LnCl}_{3}\left(3 \mathrm{Br}_{4} \mathrm{CH}_{3} \mathrm{OC}_{7} \mathrm{H}_{7} \mathrm{NO}\right)_{3}(\mathrm{Ln}=\mathrm{Pr}, \mathrm{Nd}, \mathrm{Sm}, \mathrm{Eu}, \mathrm{Gd}, \mathrm{Dy})$. J. Mol. Struct. 2006, 782, 1-15.

[214] Kostova, I.; Peica, N.; Kiefer, W. Theoretical and spectroscopic studies of 5-aminoorotic acid and its new lanthanide(III) complexes. J. Raman Spectrosc. 2007, 38, 205-216.

[215] Hannachi, D.; Ouddai, N.; Chermette, H. A quantum chemistry investigation on the structure of lanthanide triflates $\mathrm{Ln}(\mathrm{OTf})_{3}$ where $\mathrm{Ln}=\mathrm{La}, \mathrm{Ce}, \mathrm{Nd}, \mathrm{Eu}, \mathrm{Gd}, \mathrm{Er}, \mathrm{Yb}$ and Lu. Dalton Trans. 2010, 39, 3673-3680.

[216] Bünzli, J.-C. G. In: Lanthanide Prober in Life, Chemical and Earth Sciences; Bünzli, J.-C. G.; Choppin, G. R. Eds.; Elsevier Science B. V: Amsterdam, 1989, pp. 219-293.

[217] Latva, M.; Takalo, H.; Mukkala, V.-M.; Matachescu, C.; Rodriguez-Ubis, J. C.; Kankare, J. Correlation between the lowest triplet energy level of the ligand and lanthanide(III) luminescence quantum yield. J. Lumin. 1997, 75, 149-169.

[218] Beeby, A.; Clarkson, I.M.; Dickins, R.S.; Faulkner, S.; Parker, D.; Royle, L.; de Sousa, A.S.; Williams, J.A.G.; Woods, M. Non-radiative deactivation of the excited states of europium, terbium and ytterbium complexes by proximate energy-matched $\mathrm{OH}, \mathrm{NH}$ and $\mathrm{CH}$ oscillators: an improved luminescence method for establishing solution hydration states. J. Chem. Soc., Perkin Trans. 2, 1999, 493-503.

[219] Gawryszewska, P.; Malta, O. L.; Longo, R. L.; Goncalves e Silva, F.R.; Alves, S.; Mierzwicki, K.; Latajka, Z.; Pietraszkiewicz, M.; Legendziewicz, J. Experimental and theoretical study of the photophysics and structures of europium cryptates incorporating 3,3'-bi-isoquinoline-2,2'-dioxide. ChemPhysChem 2004, 5, 1577-1584.

[220] Stemers, F. J.; Verboom, W.; Reinhoudt, D. N.; Vandertol, E. B.; Verhoeven, J. W. New sensitizermodified calix[4]arenes enabling near-UV excitation of complexed luminescent lanthanide ions. $J$. Am. Chem. Soc. 1995, 117, 9408-9414.

[221] de Sá, G.F.; Malta, O. L.; de Mello Donegá, C.; Simas, A. M.; Longo, R. L.; Santa-Cruz, P. A.; da Silva Jr., E. F. Spectroscopic properties and design of highly luminescent lanthanide coordination complexes. Coord. Chem. Rev. 2000, 196, 165-195.

[222] Faustino, W. M.; Malta, O. L.; Teotonio, E. E. S.; Brito, H. F.; Simas, A. M.; de Sá, G. F. Photoluminescence of europium(III) dithiocarbamate complexes: Electronic structure, charge transfer and energy transfer. J. Phys. Chem. A 2006, 110, 2510-2516. 
[223] Stratmann, R. E.; Scuseria, G. E.; Frisch, M. J. An efficient implementation of time-dependent density-functional theory for the calculation of excitation energies of large molecules. J. Chem. Phys. 1998, 109, 8218-8224.

[224] Bauernschmitt, R.; Ahlrichs, R. Treatment of electronic excitations within the adiabatic approximation of time dependent density functional theory. Chem. Phys. Lett. 1996, 256, 454-464;

[225] Casida, M. E. ; Jamorski, C. ; Casida, K. C. ; Salahub, D. R. Molecular excitation energies to highlying bound states from time-dependent density-functional response theory: Characterization and correction of the time-dependent local density approximation ionization threshold. J. Chem. Phys. 1998, 108, 4439-4449.

[226] Dreuw, A.; Head-Gordon, M. Failure of time-dependent density functional theory for long-range charge transfer excited states: The zincbacteriochlorin-bactereochlorin and bactereochlorophyllspheroidene complexes. J. Am. Chem. Soc. 2004, 126, 4007-4016.

[227] Kadjane, P.; Platas-Iglesias, C.; Ziessel, R.; Charbonnière, L. J. Luminescence properties of heterodinuclear Pt-Eu complexes from unusual nonadentate ligands. Dalton Trans. 2009, 5688-5700.

[228] Cox, H.; Stace, A. J. Recent advances in the visible and UV spectroscopy of metal dication complexes. Int. J. Phys. Chem. 2010, 29, 555-588.

[229] Cao, X.; Dolg, M. Density functional studies on lanthanide(III) texaphyrins ( $\mathrm{Ln}-\mathrm{Tex}^{2+}, \mathrm{Ln}=\mathrm{La}, \mathrm{Gd}$, Lu): structure, stability and electronic excitation spectrum. Mol. Phys. 2003, 101, 2427-2435.

[230] Sessler, J. L.; Mody, T. D.; Hemmi, G. M.; Vicent, L. Synthesis and structural characterization of lanthanide(III) texaphyrins. Inorg. Chem. 1993, 32, 3175-3187.

[231] Young, S. W.; Woodburn, K. W.; Wright, M.; Mody, T. D.; Fan, Q.; Sessler, J. L. Lutetium texaphyrin (PCl-0123): A near-infrared, water-soluble photosensitizer. Photochem. Photobiol. 1996, 63, 892-897.

[232] Gutierrez, F.; Rabbe, C.; Poteau, R.; Daudey, J. P. Theoretical study of Ln(III) complexes with polyaza-aromatic ligands: Geometries of $\left[\mathrm{LnL}\left(\mathrm{H}_{2} \mathrm{O}\right)_{\mathrm{n}}\right]^{3+}$ complexes and successes and failures of TD-DFT. J. Phys. Chem. A 2005, 109, 4325-4330.

[233] Senegas, J.-M.; Bernardinelli, G.; Imbert, D.; Bünzli, J.-C. G.; Morgantini, P.-Y.; Weber, J.; Piguet, C. Connecting terminal carboxylate groups in nine-coordinate lanthanide podates: Consequences of the thermodynamic, structural, electronic and photophysical properties. Inorg. Chem. 2003, 42, 4680-4695.

[234] Moore, E. G.; Xu, J.; Dodani, S. C.; Jocher, C. J.; D'Aléo, A.; Seitz, M.; Raymond, K. N. 1-Methyl3hydroxy-pyridin-2-one complexes of near infra-red emitting lanthanides: Efficient sensitization of $\mathrm{Yb}(\mathrm{III})$ and $\mathrm{Nd}(\mathrm{III})$ in aqueous solution. Inorg. Chem. 2010, 49, 4156-4166.

[235] D'Aléo, A.;Xu, J.; Moore, E. G.; Jocher, C. J.; Raymond, K. N. Aryl-bridged 1-hydroxypyridin-2one: Sensitizer ligands for Eu(III). Inorg. Chem. 2008, 47, 6109-6111.

[236] D'Aléo, A.; Moore, E. G.; Szigethy, G.; Xu, J.; Raymond, K. N. Aryl-bridged 1-hydroxypyridin-2one: Effect of the bridge on the Eu(III) sensitization process. Inorg. Chem. 2009, 48, 9316-9324.

[237] D'Aléo, A.; Moore, E. G.; Szigethy, G.; Xu, J.; Raymond, K. N. Aryl-bridged 1-hydroxypyridin-2one: Sensitizer ligands for Eu(III). Inorg. Chem. 2008, 47, 6109-6111. 
[238] Moore, E. G.; Samuel, A. P. S.; Raymond, K. N. From Antenna to assay: lessons learned in lanthanide luminescence. Acc. Chem. Res. 2009, 42, 542-552.

[239] Moore, E. G.; Xu, J.; Jocher, C. J.; Castro-Rodríguez, I.; Raymond, K. N. Highly luminescent lanthanide complexes of 1-hydroxy-2-pyridones. Inorg. Chem. 2008, 47, 3105-3118.

[240] Samuel, A. P. S.; Xu, J.; Raymond, K. N. Predicting efficient antenna ligands for Tb(III) emission. Inorg. Chem. 2009, 48, 687-698.

[241] Gutierrez, F.; Tedeschi, C.; Maron, L.; Daudey, J.-P.; Poteau, R.; Azema, J.; Tisnès, P.; Picard, C. Quantum chemistry-based interpretations on the lowest triplet state of luminescent lanthanide complexes. Part 1. Relation between the triplet state energy of hydroxamate complexes and their luminescence properties. Dalton Trans. 2004, 1334-1347.

[242] Gutierrez, F.; Tedeschi, C.; Maron, L.; Daudey, J.-P.; Azema, J.; Tisnès, P.; Picard, C.; Poteau, R. Quantum chemistry-based interpretations on the lowest triplet state of luminescent lanthanide complexes. Part 2. Influence of the electrostatic interactions on the triplet state energy of terbium complexes. J. Mol. Struct. (THEOCHEM) 2005, 756, 151-162.

[243] Guillaumont, D.; Bazin, H.; Benech, J.-M.; Boyer, M.; Mathis, G. Luminescent Eu(III) and Gd(III) trisbipyridine cryptates: Experimental and theoretical study of the substituent effects. ChemPhysChem 2007, 8, 480-488.

[244] Aiga, F.; Iwanaga, H.; Amano, A. Density functional theory investigation of novel Eu(III) complexes with asymmetric bis(phosphine) oxides. J. Phys. Chem. A 2007, 111, 12141-12145.

[245] Iwanaga, H.; Aiga, F. Novel Tb(III) complexes with two different structures of phosphine oxides and their properties. J. Lumin. 2010, 130, 812-816.

[246] Puntus, L. N.; Lyssenko, K. A.; Pekareva, I. S.; Bünzli, J.-C. G. Intermolecular interactions as actors in energy-transfer processes in lanthanide complexes with 2,2'-bipyridine. J. Phys. Chem. B 2009, $113,9265-9277$.

[247] De Silva, C. R.; Li, J.; Zheng, Z.; Corrales, L. R. Correlation of calculated excited-state energies and experimental quantum yields of luminescent $\mathrm{Tb}(\mathrm{III}) \beta$-diketonates. J. Phys. Chem. A 2008, 112, 4527-4530.

[248] Zhang, Y.; Cai, X.; Zhou, Y.; Zhang, X.; Xu, H.; Liu, Z.; Li, X.; Jiang, J. Structures and spectroscopic properties of bis(phthalocyaninato) yttrium and lanthanum complexes: Theoretical study based on density functional theory calculations. J. Phys. Chem. A 2007, 111, 392-400.

[249] Ning, L.; Italo, M.; Brivio, G. P. Infrared luminescence quenching in erbium(III) tris(8quinolinolate); an ab initio approach. J. Mater. Chem. 2007, 17, 4464-4470.

[250] Liao, M.-S.; Watts, J. D.; Huang, M.-J. DFT/TDDFT study of lanthanide ${ }^{\mathrm{III}}$ mono- and bisporphyrin complexes. J. Phys. Chem. A 2006, 110, 13089-13098.

[251] Kahlal, S.; Mentec, A.; Pondaven, A.; L'Her, M.; Saillard, J.-Y. Substituent effect in unsymmetrical lutetium bisphthalocyanines: A DFT analysis. New J. Chem. 2009, 33, 574-582.

[252] Barone, G.; Gomez-Paloma, L.; Duca, D.; Silvestri, A.; Riccio, R.; Bifulco, G. Structure validation of natural products by quantum-mechanical GIAO calculations of ${ }^{13} \mathrm{C}$ NMR chemical shifts. Chem. Eur. J. 2002, 8, 3233-3239. 
[253] Platas-Iglesias, C.; Esteban, D.; Ojea, V.; Avecilla, F.; de Blas, A.; Rodríguez-Blas, T. Templating Schiff-base lateral macrobicycles: An experimental and theoretical study of the intermediates. Inorg. Chem. 2003, 42, 4299-4307.

[254] Vaiana, L.; Regueiro-Figueroa, M.; Mato-Iglesias, M.; Platas-Iglesias, C.; Esteban-Gómez, D.; de Blas, A.; Rodríguez-Blas, T. Seven-coordination versus six-coordination in divalent first-row transition-metal complexes derived from 1,10-diaza-15-crown-5. Inorg. Chem. 2007, 46, 8271-8282.

[255] Panda, M.; Phuan, P.-W.; Kozlowski, M. C. Utility of calculated ${ }^{13} \mathrm{C}$ NMR chemical shifts in differenciating conformational isomers: a study of metal-complexed and uncomplexed bispidines. Chem. Commun. 2002, 1552-1553.

[256] Autschbach, J. Density functional theory applied to calculating optical and spectroscopic properties of metal complexes: NMR and optical activity. Coord. Chem. Rev. 2007, 251, 1796-1821.

[257] González-Lorenzo, M.; Platas-Iglesias, C.; Avecilla, F.; Faulkner, S.; Pope, S. J. A.; de Blas, A.; Rodríguez-Blas, T. Structural and photophysical properties of lanthanide(III) complexes with a novel octadentate iminophenolate bibracchial lariat ether. Inorg. Chem. 2005, 44, 4254-4262.

[258] Mato-Iglesias, M.; Rodríguez-Blas, T.; Platas-Iglesias, C.; Starck, M.; Kadjane, P.; Ziessel, R.; Charbonnière, L. Solution structure and dynamics, stability, and NIR emission properties of lanthanide complexes with a carboxylated bispyrazolylpyridyl ligand. Inorg. Chem. 2009, 48, 1507 1518.

[259] Dichfield, R. Mol. Phys. A gauge-invariant LCAO method for N.M.R. chemical shifts. 1974, 27, 789-807.

[260] Wolinski, K.; Hilton, J. F.; Pulay, P. Efficient Implementation of the Gauge-Independent Atomic Orbital Method for NMR Chemical Shift Calculations. J. Am. Chem. Soc. 1990, 112, 8251-8260.

[261] Platas-Iglesias, C.; Mato-Iglesias, M.; Djanashvili, K.; Muller, R. N.; Vander Elst, L.; Peters, J. A.; de Blas, A.; Rodríguez-Blas, T. Lanthanide chelates containing pyridine units with potential application as contrast agents in magnetic resonance imaging. Chem. Eur. J. 2004, 10, 3579-3590.

[262] Yazyev, O. V.; Helm, L. Nuclear spin relaxation parameters of MRi contrast agents - Insight from quantum mechanical calculations. Eur. J. Inorg. Chem. 2008, 201-211.

[263] Yazyev, O.; Helm, L. 170 nuclear quadrupole coupling constants of water bound to a metal ion: a gadolinium(III) case study. J. Chem. Phys. 2006, 125, 054503.

[264] Ciofini, I.; Daul, C. A. DFT calculations of molecular magnetic properties of coordination compounds. Coord. Chem. Rev. 2003, 238-239, 187-209.

[265] Ruiz, E.; Rodriguez-Fortea, A.; Cano, J.; Alvarez, S.; Alemany, P. About the calculation of exchange coupling constants in polynuclear transition metal complexes. J. Comput. Chem. 2003, 24 , 982-989.

[266] Ruiz, E.; Cano, J.; Alvarez, S. Density functional study of exchange coupling constants in singlemolecule magnets: The $\mathrm{Fe}_{8}$ complex. Chem. Eur. J. 2005, 11, 4767-4771.

[267] Avecilla, F.; Platas-Iglesias, C.; Rodriguez-Cortiñas, R.; Guillemot, G.; Bünzli, J.-C. G.; Brondino, C.; Geraldes, C. F. G. C.; de Blas, A.; Rodriguez-Blas, T. Structural characterisation, EPR and magnetic properties of f-f and f-d lanthanide(III) phenolic cryptates. J. Chem. Soc., Dalton Trans. 2002, 4658-4665. 
[268] Kahn, O. Chemistry and physics of supramolecular magnetic materials. Acc. Chem. Res. 2000, 33, 647-657.

[269] Andruh, M.; Costes, J.-P.; Diaz, C.; Gao, S. 3d-4f combined chemistry: Synthetic strategies and magnetic properties. Inorg. Chem. 2009, 48, 3342-3359.

[270] Costes, J.-P.; Vendier, L. Cu-Ln complexes with a single $\mu$-oximato bridge. C. R. Chimie 2010, 13, 661-667.

[271] Paulovoc, J.; Cimpoesu, F.; Ferbinteanu, M.; Hirao, K. Mechanism of ferromagnetic coupling in copper(II)-gadolinium(III) complexes. J. Am. Chem. Soc. 2004, 126, 3321-3331.

[272] Ferbinteanu, M.; Kajiwara, T.; Choi, K.-Y.; Nojiri, H.; Nakamoto, A.; Kojima, N.; Cimpoesu, F.; Fujimura, Y.; Takaishi, S.; Yamashita, M. A binuclear Fe(III)Dy(III) single molecule magnet. Quantum effects and models. J. Am. Chem. Soc. 2006, 128, 9008-9009.

[273] Yan, F.; Chen, Z. Magnetic coupling constants and spin density maps for heterobinuclear complexes $\mathrm{GdCu}(\mathrm{OTf})_{3}(\text { bdmap })_{2} \quad\left(\mathrm{H}_{2} \mathrm{O}\right) \cdot \mathrm{THF}, \quad\left[\mathrm{Gd}\left(\mathrm{C}_{4} \mathrm{H}_{7} \mathrm{ON}\right)_{4}\left(\mathrm{H}_{2} \mathrm{O}\right)_{3}\right]\left[\mathrm{Fe}(\mathrm{CN})_{6}\right] \cdot 2 \mathrm{H}_{2} \mathrm{O}, \quad$ and $\left[\mathrm{Gd}\left(\mathrm{C}_{4} \mathrm{H}_{7} \mathrm{ON}\right)_{4}\left(\mathrm{H}_{2} \mathrm{O}\right)_{3}\right]\left[\mathrm{Cr}(\mathrm{CN})_{6}\right] \cdot 2 \mathrm{H}_{2} \mathrm{O}$ : A density functional study. J. Phys. Chem. A 2000, 104, 6295-6300.

[274] Noodleman, L. Valence bond description of antiferromagnetic coupling in transition metal dimers. $J$. Chem. Phys. 1981, 74, 5737-5743.

[275] Cirera, J.; Ruiz, E. Exchange coupling in $\mathrm{Cu}^{\mathrm{II}} \mathrm{Gd}^{\mathrm{III}}$ dinuclear complexes: A theoretical perspective. $C$. R. Chimie 2008, 11, 1227-1234.

[276] Rajaraman, G.; Totti, F.; Bencini, A.; Caneschi, A.; Sessoli, R.; Gatteschi, D. Density functional studies on the exchange interaction of a dinuclear $\mathrm{Gd}(\mathrm{III})-\mathrm{Cu}(\mathrm{II})$ complex: method assessment, magnetic coupling mechanism and magneto-structural correlations. Dalton Trans. 2009, 3153-3161.

[277] Svendsen, H.; Overgaard, J.; Chevallier, M. A.; Collet, E.; Chen, Y.-S.; Jensen, F.; Iversen, B. B. Photomagnetic switching of heterometallic complexes $\left[\mathrm{M}(\mathrm{dmf})_{4}\left(\mathrm{H}_{2} \mathrm{O}\right)_{3}(\mu-\mathrm{CN}) \mathrm{Fe}(\mathrm{CN})_{5}\right] \cdot \mathrm{H}_{2} \mathrm{O}(\mathrm{M}=$ $\mathrm{Nd}, \mathrm{La}, \mathrm{Gd}, \mathrm{Y})$ analyzed by single-crystal x-ray diffraction and ab initio theory. Chem. Eur. J. 2010, $16,7215-7223$.

[278] Raturi, R.; Lefebvre, J.; Leznoff, D. B.; McGarvey, B. R.; Johnson, S. A. A phosphine-mediated through-space exchange coupling pathway for unpaired electrons in a heterobimetallic lanthanidetransition metal complex. Chem Eur. J. 2008, 14, 721-730. 